Environmental Assessment for the

\title{
Construction and Operation of the \\ Howard T. Ricketts Laboratory
}

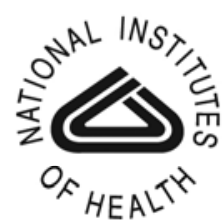

National Institutes of Health

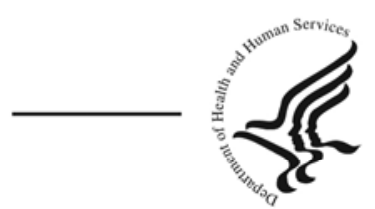

U.S. Department of Health and Human Services

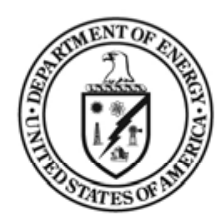

U.S. Department of Energy 

Environmental Assessment for the

\section{Construction and Operation of the \\ Howard T. Ricketts Laboratory}

U.S. Department of Health and Human Services

National Institutes of Health

9000 Rockville Pike

Bethesda, MD 20892

U.S. Department of Energy

9800 South Cass Avenue

Argonne, IL 60439 



\section{EXECUTIVE SUMMARY}

The National Institutes of Health (NIH) has proposed to partially fund the construction of the Howard T. Ricketts (HTR) regional biocontainment laboratory (RBL) by the University of Chicago at the U.S. Department of Energy's (DOE's) Argonne National Laboratory in Argonne, Illinois. The HTR Laboratory (HTRL) would be constructed, owned, and operated by the University of Chicago on land leased to it by DOE. The preferred project site is located north of Eastwood Drive and west of Outer Circle Road and is near the biological sciences building. This environmental assessment addresses the potential environmental effects resulting from construction and operation of the proposed facility.

The proposed project involves the construction of a research facility with a footprint up to approximately $44,000 \mathrm{ft}^{2}\left(4,088 \mathrm{~m}^{2}\right)$. The proposed building would house research laboratories, including Biosafety Level 2 and 3 biocontainment space, animal research facilities, administrative offices, and building support areas. The NIH has identified a need for new facilities to support research on potential bioterrorism agents and emerging and re-emerging infectious diseases, to protect the nation from such threats to public health. This research requires specialized laboratory facilities that are designed, managed, and operated to protect laboratory workers and the surrounding community from accidental exposure to agents. The proposed HTRL would provide needed biocontainment space to researchers and promote the advancement of knowledge in the disciplines of biodefense and emerging and re-emerging infectious diseases.

Several alternatives were considered for the location of the proposed facility, as well as a no action alternative. The preferred alternative includes the construction of a research facility, up to $44,000 \mathrm{ft}^{2}\left(4,088 \mathrm{~m}^{2}\right)$, at Argonne National Laboratory, a secure government location.

Potential impacts to natural and cultural resources have been evaluated in this document. The proposed activities would result in the conversion of approximately 4 acres ( 2 ha) of old field and open woodland for the proposed facility and landscaped areas. Impacts of the proposed project on the following resources would be minor or negligible: human health, socioeconomics, air quality, noise levels, water quality, waste management, land use, the visual environment, cultural resources, soils, terrestrial biota, wetlands or aquatic biota, threatened and endangered species, transportation, utilities and services, and environmental justice.

This environmental assessment has been completed to satisfy the requirements of the National Environmental Policy Act of 1969 and has been prepared in accordance with NIH guidelines and in coordination with federal, state, and local agency requirements. On the basis of the results of this assessment, impacts to environmental resources from the proposed project would be minor or negligible, provided that the project is implemented in accordance with the impact avoidance and mitigation measures described herein. 


\section{CONTENTS}

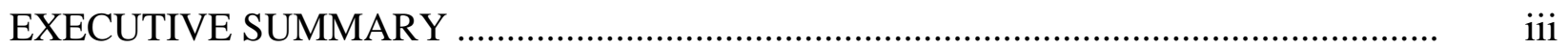

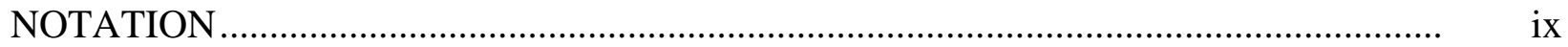

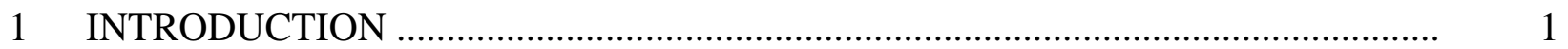

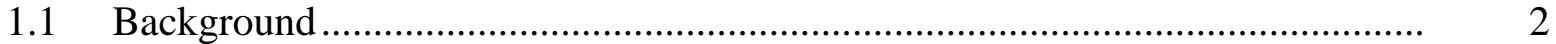

1.2 Location and Physical Setting......................................................................

1.3 Scope of This Environmental Assessment............................................................. 3

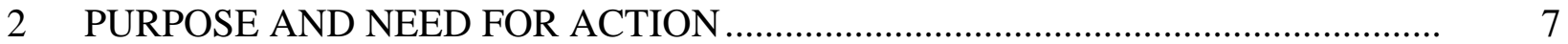

$2.1 \quad$ National Institutes of Health ..................................................................................

2.1.1 Purpose ........................................................................................

2.1.2 Need..................................................................................

2.2 U.S. Department of Energy ............................................................................. 8

2.3 Public Involvement ................................................................................ 10

3 PROPOSED ACTION AND ALTERNATIVES …………………………….............. 11

$3.1 \quad$ Proposed Action................................................................................................. 11

3.1.1 General Description of a Biocontainment Facility .................................. 11

3.1.2 HTRL Site Layout ............................................................................ 12

3.1.3 Description of the HTRL Facility ......................................................... 12

3.1.4 HTRL Construction....................................................................... 21

3.1.5 HTRL Operations ............................................................................... 21

3.2 No Action....................................................................................................... 36

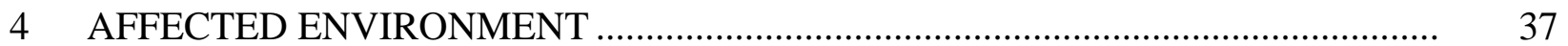

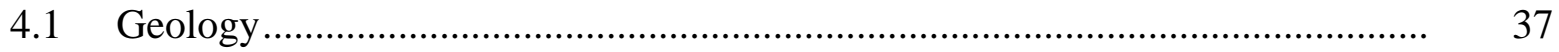

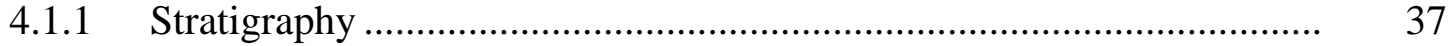

4.1.2 Seismic Activity .................................................................................. 37

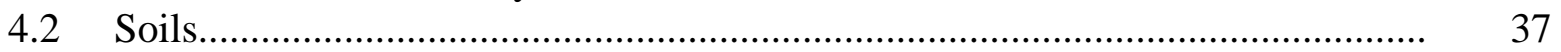

$4.3 \quad$ Water Resources .................................................................................... 38

4.3.1 Surface Water ................................................................................. 38

4.3.2 Groundwater .............................................................................. 39

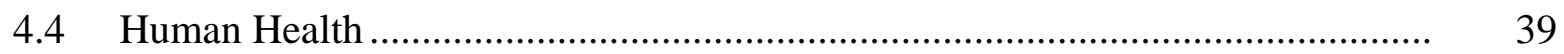

4.4.1 Medical Facilities ......................................................................... 39

4.4.2 Health and Safety ......................................................................... 40

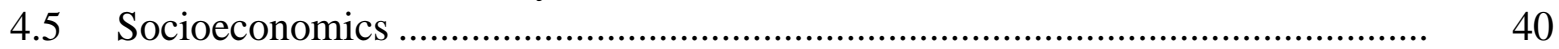

4.5.1 Employment ................................................................................. 41

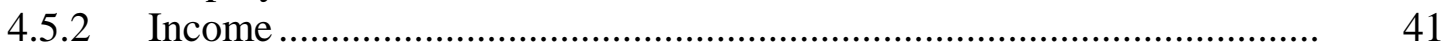




\section{CONTENTS (Cont.)}

4.6 Climate and Meteorology ……………………............................................... 42

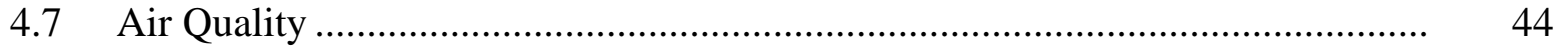

4.7.1 Existing Emissions .......................................................................... 44

4.7.2 Ambient Air Quality......................................................................... 45

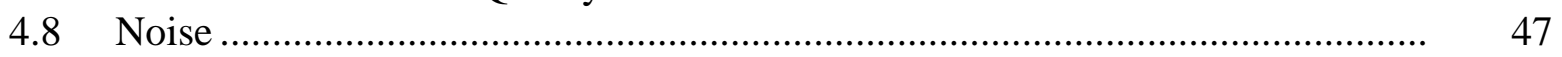

4.9 Waste Management.............................................................................................. 49

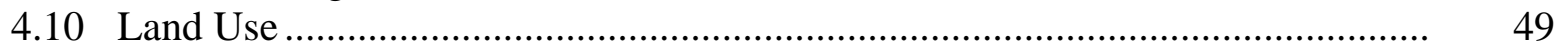

4.11 Visual Environment ................................................................................ 49

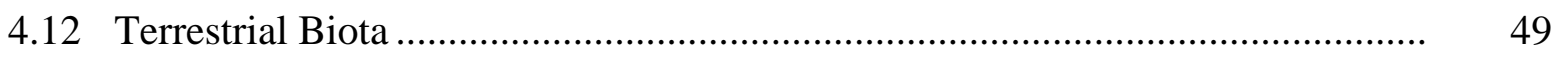

4.13 Wetlands, Floodplains, and Aquatic Biota ……………………........................ 51

4.14 Threatened and Endangered Species ................................................................... 52

4.15 Cultural Resources .................................................................................... 53

4.15.1 Prehistoric Context ........................................................................... 53

4.15.2 Ethnohistoric Context........................................................................ 54

4.15.3 Historic Context ................................................................................ 54

4.15.4 Argonne National Laboratory ............................................................ 54

4.16 Transportation................................................................................................. 55

4.17 Utilities and Services ...................................................................................... 56

4.18 Environmental Justice ...................................................................................... 56

$5 \quad$ ENVIRONMENTAL CONSEQUENCES …………................................................ 61

5.1 Construction and Routine Operations .............................................................. 61

5.1.1 Human Health..................................................................................... 61

5.1.2 Socioeconomics ................................................................................. 64

5.1.3 Air Quality, Climate, and Meteorology ..................................................... 66

5.1.4 Noise ............................................................................................ 68

5.1.5 Water Quality .................................................................................... 69

5.1.6 Solid Waste Management....................................................................... $\quad 70$

5.1.7 Land Use.......................................................................................

5.1.8 Visual Environment......................................................................... 71

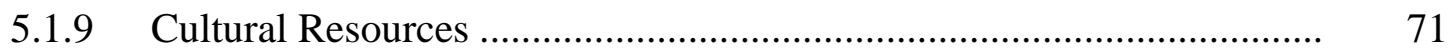

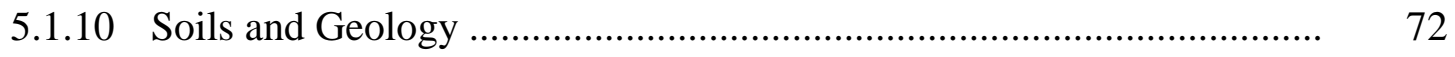

5.1.11 Terrestrial Biota.................................................................................

5.1.12 Wetlands and Aquatic Biota..................................................................... 73

5.1.13 Threatened and Endangered Species .......................................................

5.1.14 Transportation ...............................................................................

5.1.15 Utilities and Services....................................................................... 76

5.1.16 Environmental Justice ........................................................................ 76

5.2 Accidents/Abnormal Events ............................................................................... 76

5.2.1 Impacts to Facility Workers................................................................... 76

5.2.2 Impacts to Noninvolved Workers and the Public ...................................... 77 


\section{CONTENTS (Cont.)}

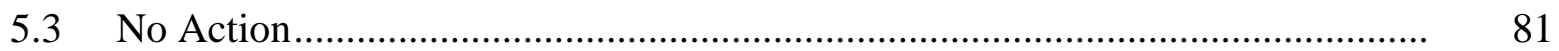

5.4 Cumulative Impacts ................................................................................... 81

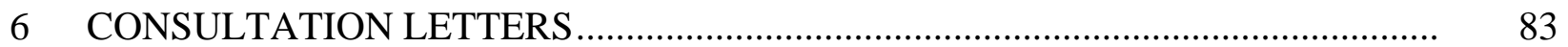

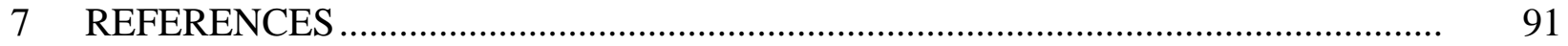

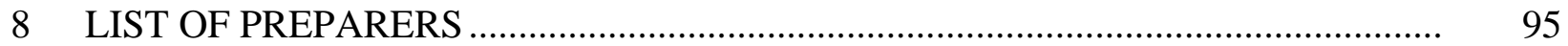

APPENDIX A: Guidelines for Biosafety Level 1 through BSL-3 …………………......... A-1

APPENDIX B: Centers for Disease Control and Prevention

Category A, B, and C Priority Pathogens ……………………………….... B-1

APPENDIX C: Atmospheric Release of Biological Agents ……………………………...... C C-1

\section{FIGURES}

1.1 Location of Argonne National Laboratory ………........................................................... 4

1.2 Location of the Howard T. Ricketts Laboratory at Argonne ........................................ 5

$3.1 \quad$ HTRL Site Layout ................................................................................................ 13

3.2 Artist's Rendering of the HTRL .................................................................................. 14

4.1 Wind Rose at the 10-m Level for the Argonne Meteorological Station from 1994 through 2003............................................................................................ 43

4.2 Minority Composition of Populations within 5 and $50 \mathrm{mi}$ of Argonne, Based on 2000 U.S. Census Data ............................................................................

4.3 Low-Income Composition of Populations within 5 and $50 \mathrm{mi}$ of Argonne, Based on 2000 U.S. Census Data 


\section{TABLES}

$1.1 \quad$ HTRL Site Information ..............................................................................

2.1 Biosafety Levels, Practices, Safety Equipment, and Facilities ................................ 9

4.1 Hospitals, Doctors, and Emergency Services in the Vicinity of Argonne ................ 39

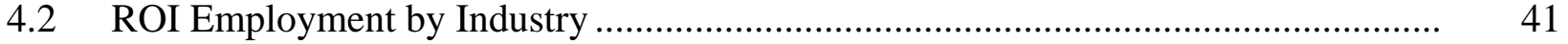

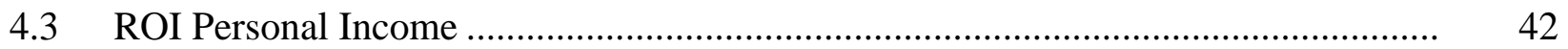

4.4 Emissions of Criteria Pollutants and Volatile Organic Compounds

from DuPage County and Argonne Sources in 2002 ............................................ 45

4.5 National Ambient Air Quality Standards, Illinois State Ambient

Air Quality Standards, Maximum Allowable Increments for Prevention of Significant Deterioration, and Highest Background Levels

Representative of Argonne National Laboratory .................................................

4.6 State of Illinois Sound Emission Standards ...................................................... 48

4.7 Summary of the Distribution of Minority and Low-Income

Populations Surrounding Argonne, 2000 ........................................................... 57

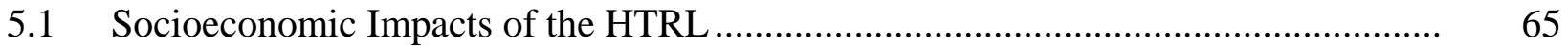

B-1 NIAID Category A, B, and C Priority Pathogens ............................................ B-2 


\section{NOTATION}

The following is a list of acronyms and abbreviations, chemical names, and units of measure used in this document. Some acronyms used only in tables may be defined only in those tables.

\section{ACRONYMS, ABBREVIATIONS, AND CHEMICAL NAMES}

\begin{tabular}{|c|c|}
\hline ABSL & animal biosafety level \\
\hline AHR & animal holding room \\
\hline AQCR & air quality control region \\
\hline ARC & Animal Resource Center \\
\hline ARO & Alternate Responsible Official \\
\hline BLS & U.S. Bureau of Labor Statistics \\
\hline BMBL & Biosafety in Microbiological and Biomedical Laboratories \\
\hline BMP & best management practice \\
\hline $\mathrm{BOD}_{5}$ & 5-day biological oxygen demand \\
\hline BSC & biological safety cabinet \\
\hline BSD & Biological Sciences Division \\
\hline BSL & biosafety level \\
\hline BSO & Biological Safety Officer \\
\hline CAA & Clean Air Act \\
\hline CBDP & Chemical and Biological Defense Program \\
\hline CCTV & closed-circuit television \\
\hline CDC & Centers for Disease Control and Prevention \\
\hline CEQ & Council on Environmental Quality \\
\hline CFR & Code of Federal Regulations \\
\hline $\mathrm{CO}$ & carbon monoxide \\
\hline DA & Department of the Army \\
\hline DNL & day-night level \\
\hline DOC & U.S. Department of Commerce \\
\hline DOE & U.S. Department of Energy \\
\hline DOL & U.S. Department of Labor \\
\hline EA & environmental assessment \\
\hline E.O. & Executive Order \\
\hline EPA & U.S. Environmental Protection Agency \\
\hline EIS & environmental impact statement \\
\hline FEMA & Federal Emergency Management Agency \\
\hline FTE & full-time equivalent \\
\hline
\end{tabular}


GLRCE Great Lakes Regional Center for Excellence

HAP hazardous air pollutant

HEPA high-efficiency particulate air

HID $_{50}$ human infective dose for $50 \%$ of exposed humans

HTRL Howard T. Ricketts Laboratory

I-55 Interstate 55

IBC Institutional Biosafety Committee

IEPA Illinois Environmental Protection Agency

LAI laboratory-acquired illness

LLW low-level radioactive waste

MCE maximum credible event

MEP mechanical, electrical, and piping/plumbing

NAAQS National Ambient Air Quality Standards

NBL national biocontainment laboratory

NEPA National Environmental Policy Act

NFPA National Fire Protection Association

$\mathrm{NH}_{3} \quad$ ammonia

NIAID National Institute of Allergy and Infectious Diseases

NIH National Institutes of Health

$\mathrm{NO}_{2} \quad$ nitrogen dioxide

NOAA National Oceanic and Atmospheric Administration

$\mathrm{NO}_{\mathrm{X}} \quad$ nitrogen oxides

NPDES National Pollution Discharge Elimination System

NRHP National Register of Historic Places

NSC National Safety Council

$\mathrm{O}_{3} \quad$ ozone

OSEAR Office of Safety, Environmental Affairs, and Radiation Safety

OSHA Occupational Safety and Health Administration

$\mathrm{Pb} \quad$ lead

PEIS programmatic environmental impact statement

PI Principal Investigator

PIMW potentially infectious medical waste

PM particulate matter

$\mathrm{PM}_{2.5} \quad$ particulate matter with an aerodynamic diameter of $2.5 \mu \mathrm{m}$ or less

$\mathrm{PM}_{10} \quad$ particulate matter with an aerodynamic diameter of $10 \mu \mathrm{m}$ or less

PPE personal protective equipment

PSD prevention of significant deterioration 


\begin{tabular}{|c|c|}
\hline QA & quality assurance \\
\hline QC & quality control \\
\hline RBL & regional biocontainment laboratory \\
\hline RCE & $\begin{array}{l}\text { Regional Center for Excellence for Biodefense and Emerging Infectious Disease } \\
\text { Research }\end{array}$ \\
\hline RCRA & Resource Conservation and Recovery Act \\
\hline RO & Responsible Official \\
\hline ROI & region of influence \\
\hline RP-2 & research laboratory personnel, BSL-2 level \\
\hline SAAQS & State Ambient Air Quality Standards \\
\hline SHPO & State Historic Preservation Office \\
\hline $\mathrm{SO}_{2}$ & sulfur dioxide \\
\hline SWMU & solid waste management unit \\
\hline SWPPP & storm water pollution prevention plan \\
\hline TDS & total dissolved solids \\
\hline TSS & total suspended solids \\
\hline UCOM & University of Chicago Occupational Medicine Clinic \\
\hline USAMRMC & U.S. Army Medical Research and Materiel Command \\
\hline USC & United States Code \\
\hline USDA & U.S. Department of Agriculture \\
\hline VOC & volatile organic compound \\
\hline
\end{tabular}

\section{UNITS OF MEASURE}

\begin{tabular}{|c|c|c|c|}
\hline${ }^{\circ} \mathrm{C}$ & degree(s) Celsius & $\mathrm{Hz}$ & hertz \\
\hline & & in. & inch(es) \\
\hline d & day(s) & & \\
\hline $\mathrm{dB}$ & decibel(s) & $\mathrm{km}$ & kilometer(s) \\
\hline $\mathrm{dB}(\mathrm{A})$ & A-weighted decibel(s) & $\mathrm{kV}$ & kilovolt(s) \\
\hline & & kVA & kilovolt-ampere(s) \\
\hline F & degree(s) Fahrenheit & & \\
\hline $\mathrm{ft}$ & foot (feet) & $\mathrm{L}$ & liter(s) \\
\hline $\mathrm{ft}^{2}$ & square foot (feet) & & \\
\hline $\mathrm{ft}^{3}$ & cubic foot (feet) & $\mathrm{m}$ & meter(s) \\
\hline & & $\mathrm{m}^{2}$ & square meter(s) \\
\hline al & gallon(s) & $\mathrm{m}^{3}$ & cubic meter(s) \\
\hline & & $\mathrm{mg}$ & milligram(s) \\
\hline & hour(s) & $\mathrm{mi}$ & mile(s) \\
\hline ha & hectare(s) & $\mathrm{mL}$ & milliliter(s) \\
\hline
\end{tabular}




$\begin{array}{llll}\text { min } & \text { minute(s) } & \mathrm{V} & \text { volt(s) } \\ \text { mph } & \text { mile(s) per hour } & \mathrm{yd}^{3} & \text { cubic yard(s) } \\ \text { ppm } & \text { part(s) per million } & \mathrm{yr} & \text { year(s) } \\ \mathrm{s} & \text { second(s) } & \mu g & \text { microgram(s) } \\ \mathrm{t} & \text { metric ton(s) } & & \end{array}$




\section{ENVIRONMENTAL ASSESSMENT FOR THE CONSTRUCTION AND OPERATION OF THE HOWARD T. RICKETTS LABORATORY}

\section{INTRODUCTION}

The National Institutes of Health (NIH) has proposed to partially fund the construction of the Howard T. Ricketts (HTR) regional biocontainment laboratory (RBL) by the University of Chicago (University) at the U.S. Department of Energy's (DOE's) Argonne National Laboratory (Argonne) in Argonne, Illinois. The overall objective of the RBL construction program is to fund the design, construction, renovation, commissioning, installation, and certification of fixed equipment in RBL state-of-the-art biosafety level 3 (BSL-3) biocontainment laboratories and any required associated BSL-2 laboratories, animal facilities, and research support space. RBLs must preferentially support the research being funded by the NIH's National Institute of Allergy and Infectious Diseases (NIAID) Regional Centers for Excellence for Biodefense and Emerging Infectious Disease Research (RCEs) and must also support other research on biodefense and emerging infectious diseases being funded by NIAID. RBLs will be part of the NIAID RCE Biodefense Network and will serve as regional resources for research institutions in the area. In addition, RBLs will be available and prepared to assist national, state, and local public health efforts in the event of a bioterrorism emergency.

The HTR Laboratory (HTRL) would be constructed, owned, and operated by the University on land it leases from DOE within the boundaries of Argonne. Argonne is operated by the University of Chicago for DOE under Contract W-31-109-Eng-38. The University's operation of the HTRL would be distinct from the University's operation of Argonne under contract to DOE. No DOE funds would be used to construct or operate the HTRL.

When the significance of the environmental impacts that could result from a proposed federal action is uncertain, the National Environmental Policy Act (NEPA) requires that an environmental assessment be conducted (United States Code, Title 42, Sections 4321-4347 [42 USC §§ 4321-4347]). Since both the NIH's partial funding of the proposed construction of the HTRL and DOE's execution of a lease for the construction and operation of the proposed HTRL would be federal actions, the NIH and DOE have determined that these actions require review pursuant to NEPA. This environmental assessment (EA) has been prepared according to the requirements of NEPA, NEPA implementing regulations, and procedures promulgated by the President's Council on Environmental Quality (CEQ) (Code of Federal Regulations, Title 40, Parts 1500-1508 [40 CFR Parts 1500-1508]), by DOE (10 CFR Part 1021), and by the NIH (U.S. Department of Health and Human Services General Administration Manual, Part 30).

EAs are public documents that have three defined functions:

- Provide sufficient evidence and analysis showing that either an environmental impact statement (EIS) needs to be prepared or that the proposed action will have no significant impact on the environment; 
- Help an agency comply with NEPA when no EIS is necessary (i.e., help identify better alternatives and mitigation measures); and

- Facilitate preparation of an EIS when one is necessary.

This EA discusses the need for the proposed action, alternatives to the proposed action, and the potential environmental impacts of both the proposed action and the alternatives. Section 6 provides copies of letters of consultation.

\subsection{BACKGROUND}

On October 15, 2002, NIAID, one of the national research institutes that make up the $\mathrm{NIH}$, announced its intent to fund construction of two national biocontainment laboratories (NBLs) and nine RBLs. In February 2003, the University submitted a proposal to the NIH to construct the HTRL on the grounds of Argonne. The University has entered into a lease with DOE for a 4-acre (2-ha) parcel of land at Argonne upon which the HTRL would be constructed and operated. The term of the lease is 25 years following completion of construction. In September 2003, the NIH announced that it would award a grant to the University to construct the HTRL at Argonne.

In August 2002, NIAID had solicited applications from research institutions across the United States to develop RCEs for the scientific study of diseases that pose a threat to U.S. national security as well as world health. The University joined a consortium of other research institutions to prepare a proposal to submit to the NIH for a Midwest RCE, now called the Great Lakes RCE (GLRCE). The RCE and NBL/RBL programs are interrelated federal biodefense initiatives; the RCEs conduct research on various diseases, and the NBLs and RBLs would provide specialized facilities in which to conduct parts of this research.

Research on emerging and re-emerging infectious diseases and potential bioterrorism agents requires specialized laboratory facilities in addition to the facilities available at the campuses of the RCE members. The RBLs and the more highly specialized NBLs would provide such facilities. In addition, the RBLs would be major resources for academic institutions. Experts working at the RBLs, in this case the HTRL, would use their expertise to facilitate training; to act as resources; and to assist researchers, physicians, and first responders to better understand agents and the impacts of agents on their areas of focus (e.g., medical care and emergency response).

Throughout the nation, there are hundreds of biocontainment facilities in various sizes, at various levels, and for various purposes. For example, hospitals often have special laboratories specifically designed to contain infectious materials. These facilities, many in urban areas, have a superb record of safe operations, with regard to both their workers and their neighbors. However, most of these facilities are not qualified to support the research outlined by the NIH. There is a shortage of appropriate facilities that are able to meet the accelerating concerns about emerging and re-emerging diseases and agents of bioterrorism. 
Key elements that make RBLs distinct are their active recruitment of expert researchers around the region, superior technological resources, operating efficiency, commitment to train researchers and personnel responsible for public safety, and commitment to promptly respond to national or regional needs. The likelihood of discovering diagnostic tools, vaccines, and therapeutics would be greatly improved as a result of the interdisciplinary exchanges that would occur in such facilities.

\subsection{LOCATION AND PHYSICAL SETTING}

The HTRL would be located in DuPage County, Illinois, on a site that is approximately 4 acres (2 ha) in size within Argonne National Laboratory. Argonne is located $27 \mathrm{mi}$ (43 km) southwest of Chicago (Figure 1.1). It is a federal facility that is dedicated to energy research and development. It is administered by DOE's Office of Science and operated by the University of Chicago.

The HTRL would be located southeast of Building 202 (biological sciences) and east of Building 201 (DOE and Argonne administration) in the northern portion of Argonne (Figure 1.2). This area is readily accessible by an interstate highway (Interstate 55 [I-55]) and local roads (Cass Avenue and Lemont Road) as well as Argonne roads. Access to the Argonne site is controlled by the Argonne Security Department. The HTRL site contains a mixture of grassy meadow and second-growth woodland. The area is adjacent to a parking lot used by Building 202 and 201 workers. The site is further described in Table 1.1 and Section 4, Affected Environment.

\subsection{SCOPE OF THIS ENVIRONMENTAL ASSESSMENT}

This EA is limited to the characterization and analysis of the probable and possible environmental impacts associated with building and operating the proposed facility. While plans call for the structure to be up to $27,541 \mathrm{ft}^{2}\left(2,559 \mathrm{~m}^{2}\right)$ net, occupying a footprint of up to $44,000 \mathrm{ft}^{2}\left(4,088 \mathrm{~m}^{2}\right)$, it may actually be smaller. It would provide space for up to 50 permanent employees and visiting scientists. The facility would contain laboratories, offices, and animal quarters (vivarium) for small rodents. A loading area and emergency generators would be located at the rear of the building. Access by employees and scientists would be on the west, at the front

of the building; deliveries and services would occur on the east, at the back of the building. 


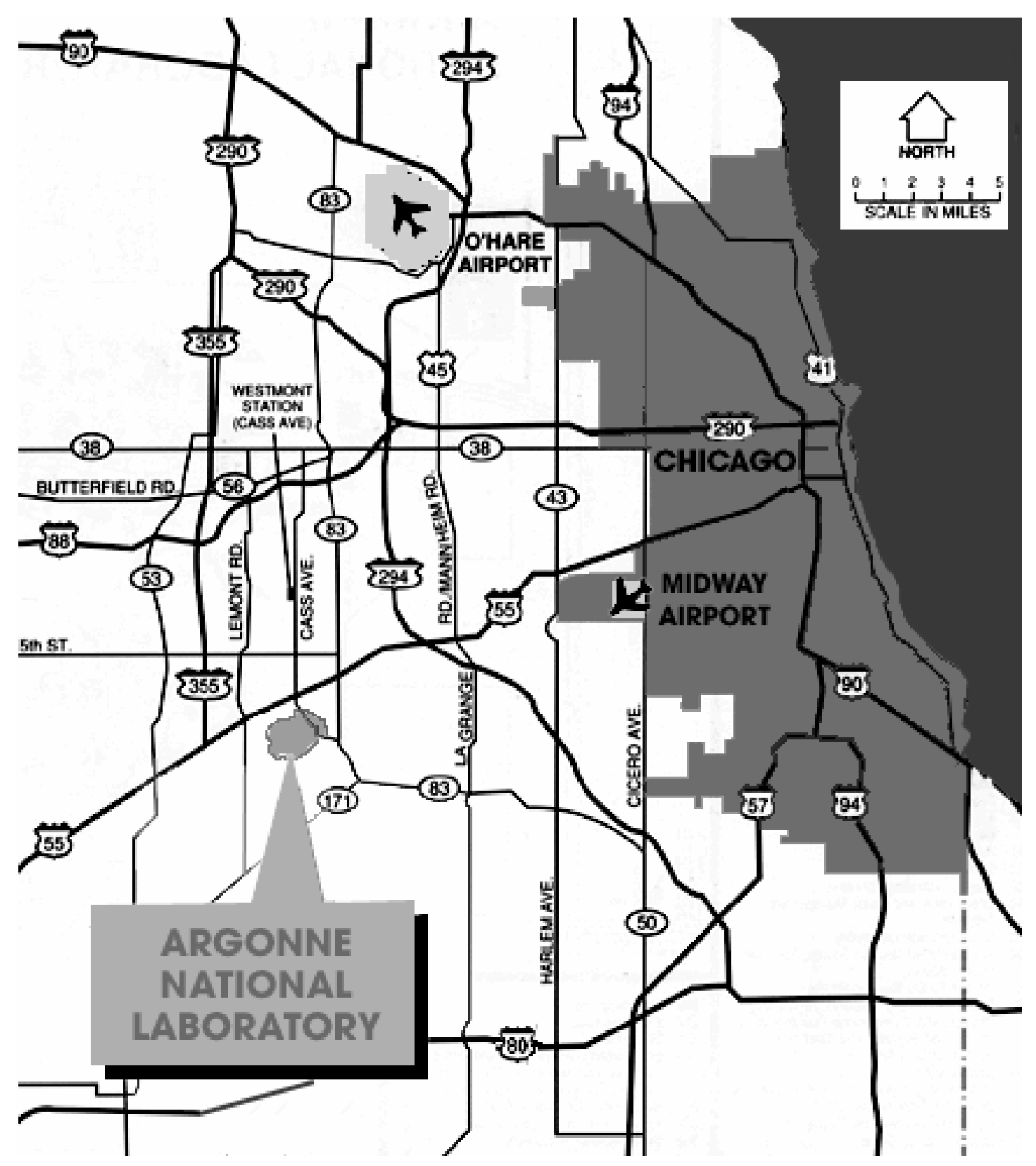

FIGURE 1.1 Location of Argonne National Laboratory 


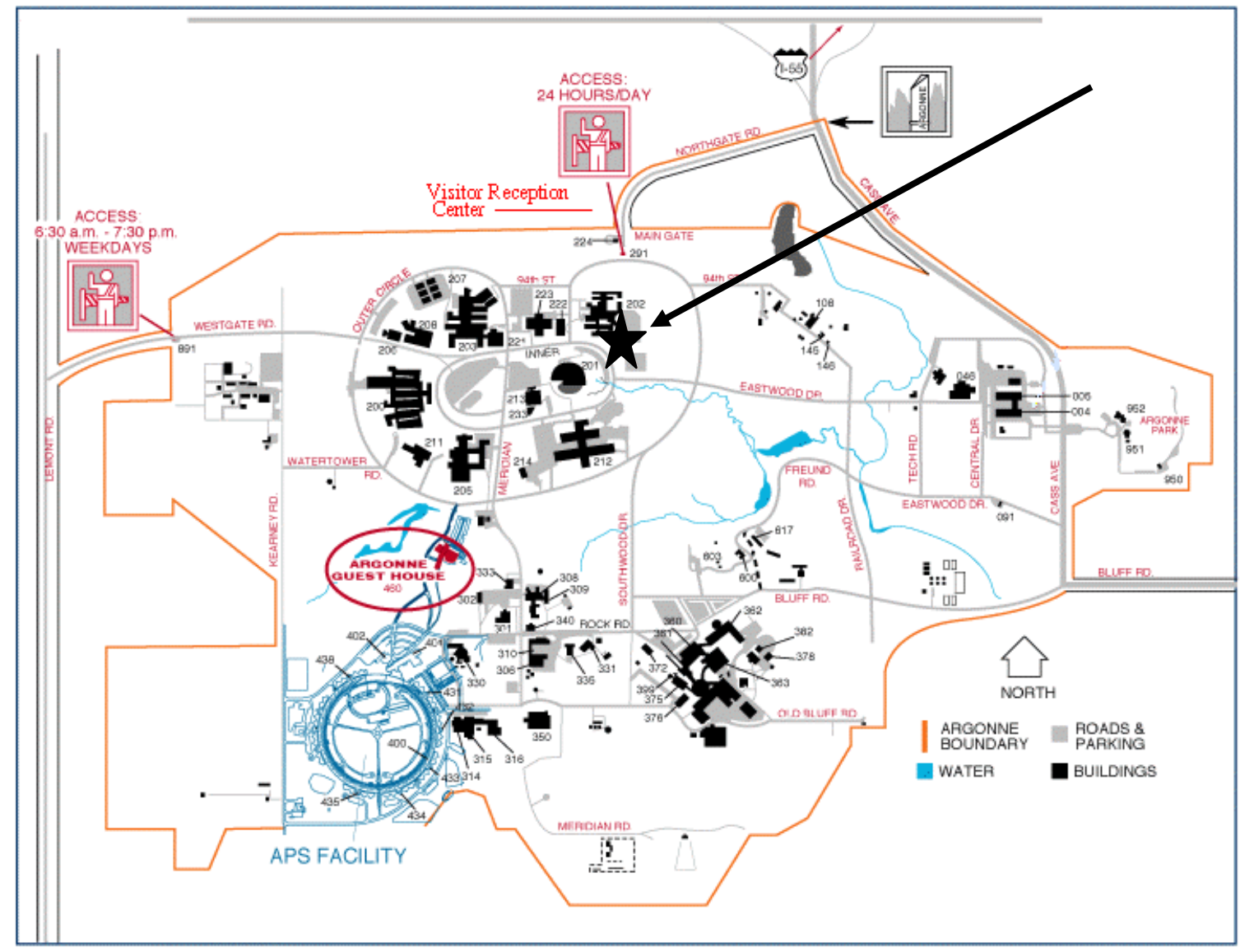

FIGURE 1.2 Location of the Howard T. Ricketts Laboratory at Argonne (arrow and star)

TABLE 1.1 HTRL Site Information

\begin{tabular}{ll}
\hline & $41^{\circ} 42^{\prime} 53^{\prime \prime}$ \\
Latitude & $87^{\circ} 58^{\prime} 38^{\prime \prime}$ \\
Longitude & $700-718 \mathrm{ft}(213-219 \mathrm{~m})$ \\
Elevation & Flat \\
General topography & DuPage \\
County & 9700 South Cass Avenue \\
Address & Argonne, Illinois 60439 \\
& Chicago, Illinois \\
Nearest major city & I-55 \\
Nearest interstate & Midway, O’Hare \\
Airports & \\
\hline
\end{tabular}




\section{PURPOSE AND NEED FOR ACTION}

\subsection{NATIONAL INSTITUTES OF HEALTH}

\subsubsection{Purpose}

The NIH's goals include promoting biodefense research in order to help protect our nation against bioterrorism and to control and respond to emerging or re-emerging infectious diseases. To meet this goal, the NIH places a high priority on research designed to prevent, diagnose, and treat diseases caused by organisms that could be used as bioterrorism agents and diseases that are emerging or re-emerging threats to public health. Since a major challenge to meeting this need is the serious shortage of high-level biocontainment laboratories, NIAID developed a comprehensive approach to help provide the needed facilities. It includes the awarding of both grants and contracts. The construction of the HTRL, funded in part by the NIH, would advance this goal.

\subsubsection{Need}

In the past century, medical research has led to improved health and increased life expectancy, largely because of the success achieved in preventing and treating infectious diseases. This success has been a product of the use of antibiotics and vaccines, improved hygiene, and increased public awareness. However, as bacteria and viruses evolve, are transported to new environments, or develop resistance to drugs and vaccines, new natural threats to health continually emerge. To control epidemics and protect the public health, medical researchers must quickly identify naturally occurring microbes and then develop diagnostic tests, treatments, and vaccines for them. To prepare for bioterrorism (i.e., the deliberate release of a microbe into a community in which it is not a current health concern), identical scientific skills and strategies are needed.

For more than 50 years, NIAID has led the nation's medical research community in its efforts to understand, treat, and prevent the myriad of infectious diseases that threaten hundreds of millions of people worldwide. Because NIAID has had broad experience, expertise, and success in developing medical tools to fight infectious diseases, it now also plays a leading role in the nation's fight against bioterrorism. A NIAID "blue-ribbon panel” determined that there is a critical need to make research resources more widely available to support the implementation of NIAID's biodefense research agenda. NIAID is expanding its research programs to accelerate the development of new and improved diagnostics, treatments, and vaccines to protect civilians from deadly infectious diseases, whether they emerge naturally or are deliberately released in a bioterrorist attack.

This research must be conducted in special biosafety laboratories and in accordance with the many laws, regulations, policies, and well-established guidelines of the NIH, the Centers for Disease Control and Prevention (CDC), the Occupational Safety and Health Administration 
(OSHA), and the U.S. Department of Agriculture (USDA) (where applicable) that govern not only the research on these microbes but also the design, management, and operation of these laboratories. All the provisions aim to protect not only the laboratory workers but also the surrounding community from accidental exposure to agents. Throughout the United States, there are many institutions and companies that have both infectious disease research programs and the laboratory suites required to perform this research. However, most of these laboratories are either small, dedicated to particular uses, or in need of modernization. In addition, some hospitals have small laboratory or clinical areas that can operate at this level, including space for isolating patients suspected or known to have certain highly contagious diseases. Despite these resources, recent bioterrorism events have made it very clear that from a strategic national perspective, there is a serious shortage of adequate laboratory space. This problem has been well documented by the Institute of Medicine and has been repeatedly identified in NIAID's strategic planning process. Thus, NIAID's agenda for biodefense research and for research on emerging infectious diseases includes plans to construct and renovate BSL-3 and BSL-4 laboratories around the country. (Biosafety levels are further defined in Table 2.1.) To be most effective, these laboratories must be located where established teams of researchers already work side by side on related scientific problems.

The work to be conducted in these NIAID-funded laboratories would:

- Include research on the biology of the disease-causing agents;

- Incorporate laboratory and animal model studies to test the usefulness of new drugs and vaccines and diagnostic tests to detect, treat, and prevent illness among civilians;

- Involve adherence to all relevant security and safety standards required by law; and

- NOT include research on bioweapons. (This is not permissible under international law.)

\subsection{U.S. DEPARTMENT OF ENERGY}

DOE's purpose in leasing the 4-acre (2 ha) parcel of Argonne to the University of Chicago would be to further the goals of another federal agency (NIH) by providing space at a secure government location for implementing an aspect of its biodefense program. 


\section{TABLE 2.1 Biosafety Levels, Practices, Safety Equipment, and Facilities}

\begin{tabular}{|c|c|c|c|c|}
\hline $\begin{array}{l}\text { Biosafety } \\
\text { Level }\end{array}$ & Agents & Practices & $\begin{array}{l}\text { Safety Equipment } \\
\text { (Primary Barriers) }\end{array}$ & $\begin{array}{c}\text { Facilities } \\
\text { (Secondary Barriers) }\end{array}$ \\
\hline 1 & $\begin{array}{l}\text { Not known to consistently } \\
\text { cause disease in healthy adults }\end{array}$ & $\begin{array}{l}\text { Standard microbiological } \\
\text { practices }\end{array}$ & None required & Open bench-top sink required \\
\hline 2 & $\begin{array}{l}\text { Associated with human } \\
\text { disease, hazard = percutaneous } \\
\text { injury, ingestion, mucous } \\
\text { membrane exposure }\end{array}$ & $\begin{array}{l}\text { BSL-1 practices plus: } \\
\text { • Limited access } \\
\text { - Biohazard warning signs } \\
\text { - “Sharps” precautions } \\
\text { - Biosafety manual defining any } \\
\text { needed waste decontamination } \\
\text { or medical surveillance policies }\end{array}$ & $\begin{array}{l}\text { Primary barriers = Class I or II } \\
\text { biological safety cabinets (BSCs) } \\
\text { or other physical containment } \\
\text { devices used for all manipulations } \\
\text { of agents that cause splashes or } \\
\text { aerosols of infectious materials; } \\
\text { personal protective equipment } \\
\text { (PPE): laboratory coats, gloves, } \\
\text { face protection as needed }\end{array}$ & $\begin{array}{l}\text { BSL-1 plus: } \\
\text { - Autoclave available }\end{array}$ \\
\hline 3 & $\begin{array}{l}\text { Indigenous or exotic agents } \\
\text { with potential for aerosol } \\
\text { transmission; disease may } \\
\text { have serious or lethal } \\
\text { consequences }\end{array}$ & $\begin{array}{l}\text { BSL-2 practices plus: } \\
\text { - Controlled access } \\
\text { - Decontamination of all waste } \\
\text { - Decontamination of lab } \\
\text { clothing before laundering } \\
\text { - Baseline serum }\end{array}$ & $\begin{array}{l}\text { Primary barriers = Class I or II } \\
\text { BSCs or other physical } \\
\text { containment devices used for all } \\
\text { open manipulations of agents; } \\
\text { PPE; protective lab clothing; } \\
\text { gloves; respiratory protection as } \\
\text { needed }\end{array}$ & $\begin{array}{l}\text { BSL-2 plus: } \\
\text { - Physical separation from access } \\
\text { corridors } \\
\text { - Self-closing, double-door access } \\
\text { - Exhaust air not recirculated } \\
\text { - Negative airflow into laboratory }\end{array}$ \\
\hline 4 & $\begin{array}{l}\text { Dangerous/exotic agents } \\
\text { which pose high risk of life- } \\
\text { threatening disease, aerosol- } \\
\text { transmitted lab infections; or } \\
\text { related agents with unknown } \\
\text { risk of transmission }\end{array}$ & $\begin{array}{l}\text { BSL-3 practices plus: } \\
\text { - Clothing change before } \\
\text { entering } \\
\text { - Shower on exit } \\
\text { - All material decontaminated on } \\
\text { exit from facility }\end{array}$ & $\begin{array}{l}\text { Primary barriers = All procedures } \\
\text { conducted in Class III BSCs or } \\
\text { Class I or II BSCs in combination } \\
\text { with full-body, air-supplied, } \\
\text { positive-pressure personnel suit }\end{array}$ & $\begin{array}{l}\text { BSL-3 plus: } \\
\text { - Separate building or isolated zone } \\
\text { - Dedicated supply, exhaust, vacuum, } \\
\text { and decontamination systems } \\
\text { - Other requirements as outlined by } \\
\text { CDC and NIH (1999) }\end{array}$ \\
\hline
\end{tabular}

Source: CDC and NIH (1999). 


\subsection{PUBLIC INVOLVEMENT}

The University conducted public involvement as part of the preparation of the proposal to the NIH for construction of the HTRL. These activities included announcements in local news media of the pending proposal to the NIH, a presentation about the proposal to the Argonne/DOE Community Leaders Round Table, a presentation and comment meeting for the general public, and a Web site available for public review. The Web site allowed individuals to e-mail questions to the University. These activities were performed outside of the NEPA process. The University will continue to perform public involvement activities as needed during construction and operation of the HTRL. The EA will be sent to the Illinois Point of Contact for distribution to potentially interested state organizations, and, upon request, to members of the public. 


\section{PROPOSED ACTION AND ALTERNATIVES}

\subsection{PROPOSED ACTION}

Under the proposed action, the NIH would partially fund the construction by the University of Chicago of an RBL to be used for NIH-funded research. The University has proposed that this funding be used to construct the HTRL on a site at Argonne that the University has leased from DOE. The HTRL would be operated by the University for 25 years. Research at the HTRL would be conducted by members of the GLRCE, including the University.

The University would construct and operate the HTRL and be responsible for ensuring that HTRL activities adhered with all applicable regulations of the NIH, CDC, OSHA, and USDA (where applicable). DOE as landlord would provide the HTRL with certain resources and infrastructure through its Argonne site utility systems. These would include electricity, water, steam, condensate, wastewater treatment and disposal, communication tie-ins, and some emergency and security services. These HTRL/Argonne interfaces are covered in the following descriptions.

\subsubsection{General Description of a Biocontainment Facility}

The HTRL would be a state-of-the-art biocontainment facility. It would house office space, BSL-2 laboratories, BSL-3 laboratories, and an associated vivarium for working with small rodents. BSL-3 facilities are designed to meet CDC and NIH specifications described in Biosafety in Microbiological and Biomedical Laboratories (BMBL) (CDC and NIH 1999). These detailed guidelines, summarized in Table 2.1 and presented in detail in Appendix A, were developed on the basis of early laboratory experience that showed that microbiology laboratory workers without protection may acquire infections from the microorganisms being studied. The BMBL was developed to provide guidelines for protecting the microbiology laboratory workers. The protection is provided by a means of engineering controls, management policies, and work practices and procedures.

BSL-1 guidelines are used in laboratories where the microorganisms under study are not known to cause disease in humans. BSL-2 guidelines are used where the microorganisms under study pose a moderate risk to laboratory workers and the environment. Examples of such organisms include the measles virus and certain forms of Salmonella. For these organisms, immunizations or antibiotic treatments are available. BSL-3 guidelines are used when the microorganisms under study could cause serious or potentially lethal diseases through inhalation, such as Mycobacterium tuberculosis. Treatment is available for these microorganisms. The CDC has developed a list of priority microorganisms that could potentially be studied in BSL-2 and BSL-3 laboratories, such as those in the HTRL (see Appendix B). 


\subsubsection{HTRL Site Layout}

The HTRL site is about 4 acres (2 ha) in size. As shown in Figure 1.2, the site is located in the 200 Area of Argonne, on land owned by DOE and leased to the University. This location provides not only a secure environment but also a comprehensive infrastructure capable of supporting the facility. The HTRL site would contain the building itself, walkways from existing parking areas located west of the building, and an access road and loading area at the east end of the building (Figure 3.1). The requirement for redundant utility systems would be accommodated by buried and/or surface utility lines from existing Argonne utility lines to the east and south of the facility.

\subsubsection{Description of the HTRL Facility}

The NIH requires that institutions proposing RBLs maximize safety and apply the most stringent interpretation of the federal guidelines for design and operation of BSL-3 facilities to meet the safety needs of the occupants and the community. In addition, the NIH requires that operational effectiveness, reliability, and flexibility for adapting to future needs be maximized. The designs also have to incorporate features to facilitate the interaction and collaboration of the scientists who are using the facility.

\section{HTRL Building}

To develop the design for the HTRL, the University employed the expertise of Flad \& Associates, an architectural firm with extensive experience in designing biosafety facilities. The HTRL (Figure 3.2) would have a footprint of up to 44,000 $\mathrm{ft}^{2}\left(4,088 \mathrm{~m}^{2}\right)$ and would encompass up to $54,100 \mathrm{ft}^{2}\left(5,026 \mathrm{~m}^{2}\right)$ gross (up to $27,541 \mathrm{ft}^{2}$ net ([2,559 $\left.\mathrm{m}^{2}\right]$ ) of space. The project's total cost would be about $\$ 32$ million. In order to have BSL-2 and BSL-3 facilities for visiting scientists from GLRCE research institutions, the HTRL would include office and work space to allow for a total of up to about 50 permanent staff members and visiting scientists. The laboratory would have a specialized facility (called a vivarium) to care for small rodents. The focus of the research conducted at the HTRL would be governed by the University by an oversight committee whose members would select the most meritorious research in the regions to be conducted. The HTRL Director would be a member of the oversight committee. The operation of the HTRL would be the responsibility of the management of the HTRL, in accordance with all standard operating procedures developed by the University. The HTRL would adopt stringent precautions to protect its employees and neighbors.

The building is nominally designed to house up to five principal investigators and all necessary scientific, administrative, technical, safety, and maintenance support personnel. The building's exterior would be designed to be harmonious with the existing brick buildings that would surround it. There are no structures on the proposed construction site.

The building would have a walkable interstitial area above the first-floor laboratories and vivarium. All air handlers and fans would be located in an enclosed penthouse above the 


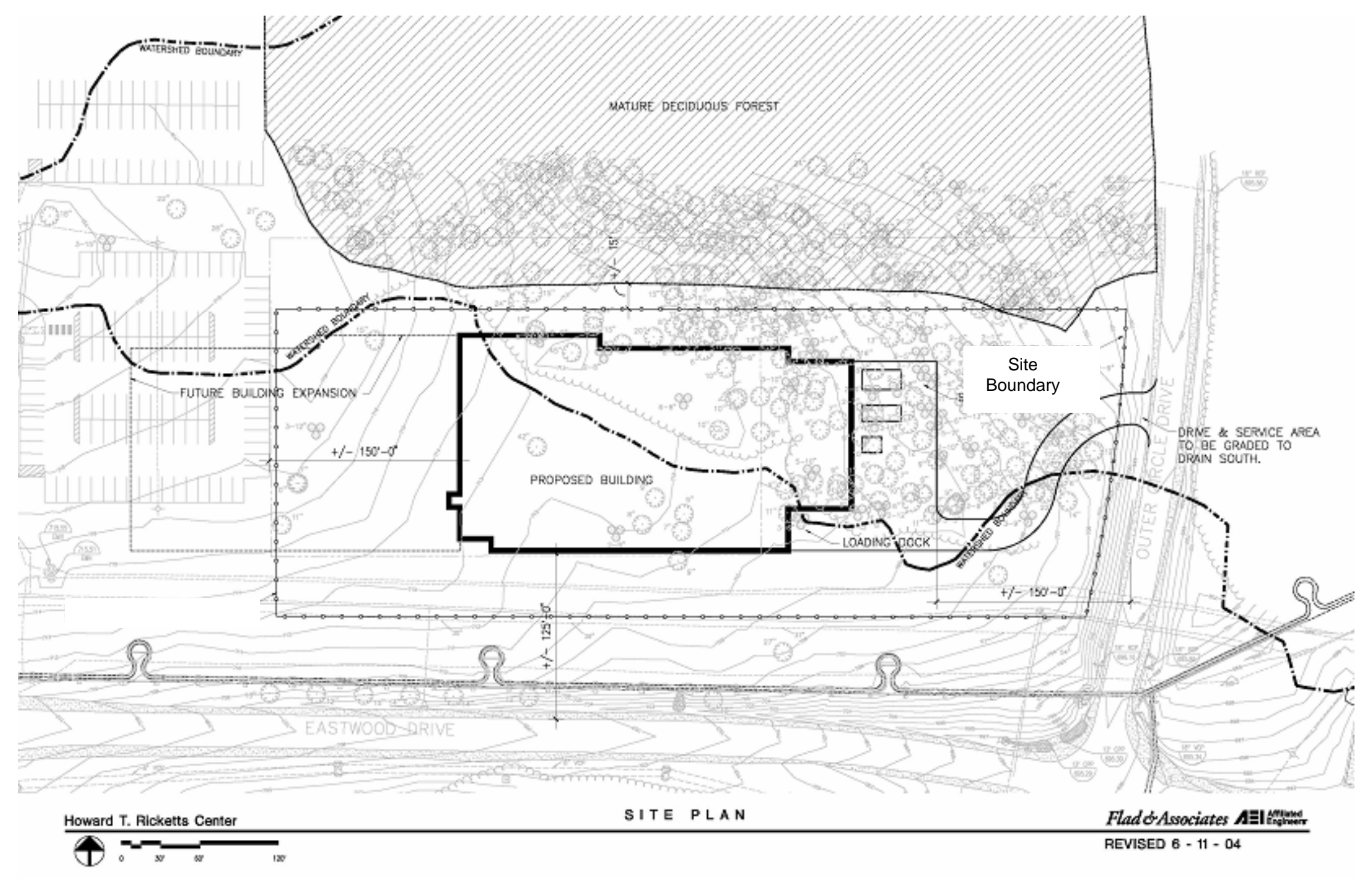

\section{FIGURE 3.1 HTRL Site Layout}




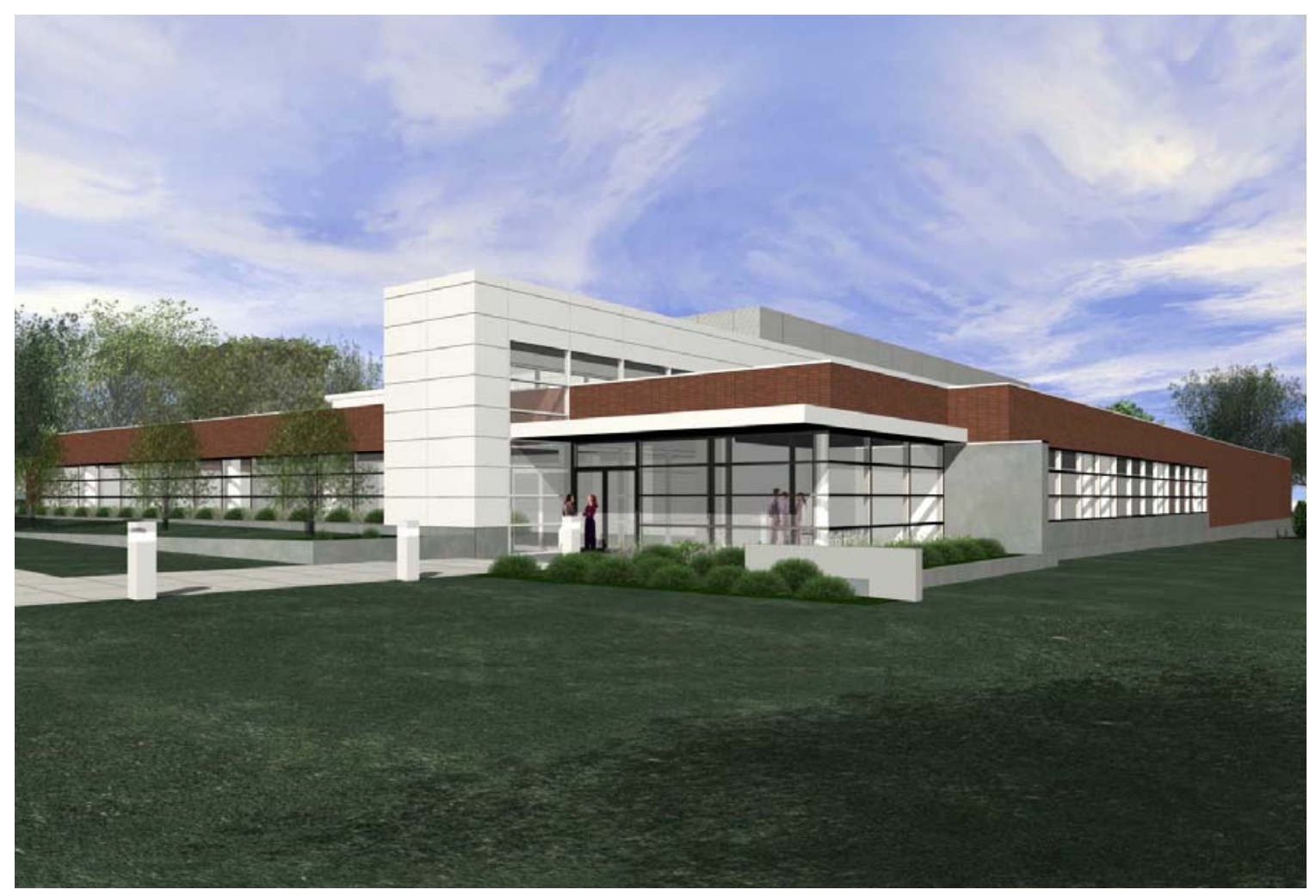

FIGURE 3.2 Artist's Rendering of the HTRL

interstitial area. This design would give maintenance personnel access to essentially all electrical distribution and mechanical equipment without requiring them to enter the biocontainment areas.

The building would meet International Building Code and National Fire Protection Association (NFPA) codes and applicable site standards. The building would also meet applicable local and state codes, all current NIH design and certification standards, all CDC and $\mathrm{NIH}$ biosafety requirements (including BSL-3 requirements and guidelines in the BMBL), and applicable federal regulations governing the use of pathogenic agent (agent). The building would be commissioned in accordance with the NIH Model Commissioning Guide (NIH 2004a). Portions of the HTRL would be hardened with reinforced grout-filled concrete to minimize damage that could result from external influences (e.g., tornadoes).

\section{Laboratories and Support Areas}

The functional areas in the building would include the following:

- $\quad$ One BSL-2 microbiology laboratory and integral support areas;

- Up to four BSL-3 microbiology laboratories and integral support areas (in two two-laboratory suites); 
- Core support facilities and laboratories;

- A vivarium with one animal biosafety level 2 (ABSL-2) suite with four animal holding rooms (AHRs); and

- One ABSL-3 suite with six AHRs.

The single BSL-2 microbiology laboratory would have an open design with up to 36 individual workstations and include the following support areas: an equipment room, 2 tissue culture rooms, 2 incubator rooms, and 2 gas cylinder closets (co-located with BSL-3 laboratories). The tissue culture and incubator rooms (each replicated at opposite ends of the BSL-2 microbiology laboratory) would contain biological safety cabinets (BSCs), incubators, shakers, and centrifuges. There would be an equipment room for noisy equipment and fume hoods. The BSL-2 laboratory would also have a partial interstitial space to allow access to mechanical, electrical, and piping controls above the laboratory and integral support areas.

The four architecturally and mechanically identical BSL-3 microbiology laboratory areas would be located next to the BSL-2 facilities. Each BSL-3 laboratory would have separate entry and exit air locks for biocontainment. Each two-laboratory BSL-3 suite would share a decontamination area, autoclave, and pass-through. A card reader or some other security device, such as a PIN pad or biometric reader, would individually control access to each of the four laboratory areas. The BSL-3 laboratories would have an interstitial space to allow access to mechanical, electrical, and piping controls above the laboratory suites.

A single laboratory support area would be next to both the BSL-2 and BSL-3 laboratory suites. This area would include a stock room, space for storing laboratory chemicals and solvents, a darkroom for photographic processing, an imaging room for microscopy, a radioisotope laboratory and hood for radio-tracer studies, a freezer farm, and glass washing equipment.

The vivarium would include an ABSL-2 suite with four AHRs and an ABSL-3 suite with six AHRs. The HTRL vivarium would be designed to accommodate up to 30,000 rodents at any given time. The ABSL-3 suite would have a dual-corridor design (one clean and one dirty) and occupy one-half of the total space for the vivarium. The other half of the vivarium space would be occupied by the ABSL-2 suite, which would have a single-corridor design. Both the ABSL-2 and ABSL-3 areas would share support services, including cage washing equipment, space for storing food and bedding, a necropsy and digester area, and staff support spaces. The design would minimize intrusion into the vivarium, because offices, support functions, and mechanical service equipment would be outside the biocontainment area. A walkable interstitial space located directly above the vivarium would provide access to mechanical valves, dampers, air filters, and electrical panels. Airlocks with interlocking doors would be located at all ABSL-3 corridors to reduce the risk of contamination. Entry and exit to the vivarium would be gained via one of three "shower-out" locker rooms.

The BSL-2 and BSL-3 laboratory and vivarium space would be separated from the building/facility areas and the office/conference areas to ensure a clear demarcation between 
biocontainment spaces and conventional spaces. Entry to the BSL-3 laboratories and ABSL-3 areas would be controlled with card readers. All mechanical controls and filters for utilities that would serve the laboratories would be accessed from outside the laboratory spaces, primarily from the interstitial space.

\section{Mechanical, Electrical, and Piping/Plumbing (MEP) Systems}

MEP systems would be designed in accordance with NIH design policies and guidelines (NIH 2003), BMBL recommendations, and applicable codes and standards. The MEP systems would be designed to achieve a reliable, flexible, and environmentally acceptable facility. Appropriate design concepts, such as high-efficiency particulate air (HEPA) filtration of exhaust air and plumbing vents, would be incorporated to enhance biocontainment safety for occupants as well as the surrounding community. A conventional HEPA filter consists of a continuous sheet of a special paper-like, glass-fiber filter medium that is pleated into a "V" configuration with separators between the pleats. This forms the filter element, which is then bonded into a rigid frame. HEPA filters remove small particles that are "respirable," meaning they are of a size to reach the smallest passages in the lungs, and are at least $99.7 \%$ efficient for particles 0.3 microns in size. HEPA filters must be periodically inspected.

Mechanical systems would use steam as the primary heating source and chilled water as the primary cooling source. Ventilation systems serving laboratory and vivarium areas would be one-pass, 100\%-outdoor-air systems. Exhaust air would be HEPA filtered and discharged at a height high enough above the roof level and at an outlet velocity fast enough to facilitate mixing with outside air, and the system would be located appropriately to avoid re-entrainment of exhaust air into the ventilation system intakes. Most critical ventilation and utility systems would be arranged for redundancy to maintain continuous operation.

Electrical service to the building would be obtained via one independent line in a duct bank with multiple conduits for future replacement. Emergency power service for the new building would be available from a diesel-driven generator with enough fuel storage for 48 hours of operation (with prompt availability of replacement fuel via a University of Chicago contract). The fuel quality would be monitored in accordance with a standardized Argonne preventive maintenance procedure. Fuel would be replaced if it no longer met the acceptance criteria. Lights in cage washing areas, AHRs, glass washing areas, and BSL-3 areas would be enclosed and gasketed in a manner so that they could be hosed down. Lights within the animal facility holding rooms would be dimmable and provided with programmable automatic lighting control systems. A fire alarm system would be installed, along with provisions for security, access control, and closed-circuit television (CCTV). The manual pull stations, fire alarm/sensor system, and sprinkler flow indicators would be continuously monitored by the on-site Argonne Fire Department.

Air Handling System. The BSL-2 laboratory and offices, and the BSL-3 laboratory and vivarium would each be served by one air handling unit. One air handler would be backup for either the BSL-3 laboratory or vivarium. It is estimated that total system airflow requirements 
would be $21,600 \mathrm{ft} 3 / \mathrm{min}\left(612 \mathrm{~m}^{3} / \mathrm{min}\right)$. Supply air terminals with hot water reheat coils would be provided to maintain the airflow and temperature at each space. The ABSL-2 and ABSL-3 vivarium spaces would be served by two air handling units, with each unit sized for $100 \%$ of the total system capacity requirements. It is estimated that total system airflow requirements would be $46,500 \mathrm{ft}^{3} / \mathrm{min}\left(1,317 \mathrm{~m}^{3} / \mathrm{min}\right)$. Constant volume supply air terminals with hot water reheat coils would be provided to maintain the airflow and temperature at each space. The supply air handling units would include $95 \%$ filtration of the air to the laboratory and vivarium.

Exhaust air from the individual BSL-3 laboratory spaces and ABSL-3 vivarium spaces would be filtered via independent HEPA filters at each space. All ductwork from the biocontainment spaces to the HEPA filters would be made of welded stainless steel. All HEPA filter housings would include in-place dioctylphthalate (DOP) test sections (for testing in accordance with American Society of Mechanical Engineers [ASME] standard AG-1) and inlet and outlet isolation dampers. Duct branches to all BSL-3 spaces (laboratory and vivarium) would be equipped with bubble-tight dampers to allow gaseous decontamination. Bubble-tight isolation dampers would be built to withstand a minimum pressure of $10 \mathrm{in}$. $(25 \mathrm{~cm})$ water column.

The radioisotope laboratory fume hood would be served by a separate exhaust system with two exhaust fans, with each fan sized individually for the total required airflow. The radioisotope exhaust system would use welded stainless-steel ductwork and be equipped with a filter housing consisting of prefilters, HEPA filters, and carbon filters.

Electrical Power Service. It is estimated that the normal electrical load for the building would be about $960 \mathrm{kVA}$, which would include $20 \%$ spare capacity for future use. The new building would be constructed in the central 200 Area of the Argonne site, where several other research buildings and facilities that depend on a highly reliable source of electrical power are located. Electrical power for the 200 Area is fed by two 13.2-kV loops. The new building would be able to be connected to either loop via an automatic or a manual transfer switch at a double-ended unit substation. The 13.2-kV loops are fed from Argonne substation 544, which has two sources originating out of Argonne substation 543. Substation 543 is served by two 138-kV transmission lines, one originating at the Will County Generating Station in Romeoville and the other at ComEd's McCook substation (a very large substation with numerous 138-kV lines and a tie-in to ComEd's 345-kV system).

The HTRL service would be connected to a primary selective double-ended unit substation at Argonne. If a primary feeder or transformer failed or was taken out of service for maintenance, the breaker to the dead primary source would be opened, and the tie breaker would be closed. In this configuration, full power would be restored to both ends of the substation via the secondary power source.

Because of the critical nature of the HTRL, a high level of system reliability would be required, and an emergency/standby power source would be provided. Because of the ventilation loads that would be imposed by the BSL-2 and BSL-3 laboratories, it is expected that the emergency/standby load would be a significant percentage of normal load requirements. It is estimated that the emergency electrical load would be approximately $850 \mathrm{kVA}$, which would 
include $25 \%$ spare capacity for future use. The emergency/standby power source for the building would be derived from a single $480 \mathrm{~V} / 277 \mathrm{~V}$ diesel-powered engine-generator set located outdoors in a weatherproof, sound-attenuated enclosure, and it would feed a new switchboard located inside the building in a dedicated emergency electrical equipment room. Fuel storage would be provided for a generator run time of 48 hours at full load and integrated into the base of the generator.

Fire Alarm System. The fire alarm system for the facility would utilize Argonne's standard system. It would be composed of smoke detectors, heat detectors, duct heat detectors, manual pull stations, and audio/visual signaling devices. Smoke detection devices would be installed within laboratory spaces and other areas per Argonne standards. In addition, a very early smoke detection apparatus (VESDA) system would be installed within BSL-3 laboratory suites and the AHRs for early warning detection.

The pull stations, smoke detector signals, duct heat detectors, and sprinkler flow indicators would be continuously monitored at the Argonne Fire Department. The sprinkler control valves would be chained and locked open. Response time for arrival of Fire Department apparatus and personnel at the new building would be less than 2 minutes. Members of the Argonne Fire Department are specially trained in hazardous materials response and biosafety. The facility would also have its own hazardous materials and biosafety response team. The Fire Department maintains a custom-built personnel decontamination trailer and is a member of a multidepartmental mutual aid organization.

Networking and Telecommunications Services. Networking and telecommunications services equipment, infrastructure, and a wiring system (consisting of conduits, cable trays, raceways, cable, and other equipment) would be obtained from Building 221. The system would extend underground (approximately 1,000 ft) [305 m] to the new building.

Security System. Security access control and CCTV would be provided at both the building perimeter and within the facility. A system would be provided for monitoring scientific equipment, including low-temperature freezers, environmental chambers, and autoclaves. An intercom system would be provided for communication with personnel in the BSL-3 laboratory and ABSL-3 vivarium. A sound system would be provided and interfaced with the sitewide public address system to allow emergency paging within the building. The Argonne emergency management process would provide public address announcements to give early warnings of impending storms, thus allowing hazardous materials to be secured in an orderly manner.

The Argonne Office of Safeguards and Security maintains a uniformed protective force and has a central physical security office for continuous monitoring of access controls. Access controls for some Argonne facilities require end-of-day communications between facility users and the security office. 
Specific security measures for the building would be developed with the assistance of the Argonne Office of Safeguards and Security. Security would be addressed by the development of a Safeguards and Security Plan for the facility.

Water and Wastewater Systems. The building water systems would operate on available water pressure from the Argonne domestic water system and Argonne laboratory water system. Wastewater would be discharged for treatment to the two Argonne sewer systems.

Potable Water System. The Argonne domestic water system would provide potable water to the HTRL via a single incoming water line. A backflow prevention valve would be included on the supply line, thus eliminating a path for water to flow back through the system supply. Normal pressure of water flow causes a check valve in the device to open, while loss of pressure causes the check valve to close preventing water from flowing back into the supply line. The source of potable water at Argonne is Lake Michigan. It is delivered by a regional water system. Groundwater is no longer a water source at Argonne. The HTRL domestic water system would discharge to the Argonne domestic wastewater system.

Laboratory Water System. The HTRL would have laboratory water delivered from the central Argonne water loop. Although the source of laboratory water would be the same as the source of potable water (i.e., Lake Michigan), the output from the HTRL laboratory water would be discharged to the Argonne laboratory wastewater system. Each BSL-3 program space would be isolated from other BSL-3 program spaces by means of reduced-pressure principal backflow preventers located in the interstitial space above the room served. Separate semi-instantaneous water heaters would provide $82^{\circ} \mathrm{C}\left(180^{\circ} \mathrm{F}\right)$ water to serve the vivarium cage washing equipment. Two units sized for $100 \%$ of the load at $40 \mathrm{gal} / \mathrm{min}(151 \mathrm{~L} / \mathrm{min})$ each are anticipated. The hot water would be circulated to maintain the temperature.

Animal Drinking Water. An automatic watering system would provide chlorinated water to a bottle filler in the cage washing facility. An automated supply of animal drinking water to each animal room is not anticipated. The animal watering system would be isolated from the domestic water system by a reduced-pressure backflow preventer.

Laboratory Wastewater System. A dedicated HTRL laboratory wastewater system would be provided to serve the BSL-2 laboratory equipment, fume hoods, cup sinks, and vivarium. Effluent waste would discharge to the Argonne laboratory wastewater treatment system via the Argonne laboratory sewer system. Drainage systems would be gravity type, arranged to minimize the potential for stoppages, backflow, or cross contamination. Each drainage system would be vented to the atmosphere. The cooling tower blowdown and overflow effluents would also be directed to the Argonne laboratory sewer system and Argonne laboratory wastewater treatment plant. 
Effluent wastes from each BSL-3 program space would be segregated from other BSL-3 program spaces with local running traps. Fixture traps within BSL-3 laboratories would discharge to a deep seal trap. A manhole access would allow for testing. Duplex pumps would discharge the wastewater to the Argonne laboratory sewer system at a metered rate. Each BSL-3 drain would be vented to the atmosphere through a HEPA vent filter.

Sanitary Wastewater System. A separate conventional sanitary wastewater and vent system would serve domestic plumbing fixtures. Plumbing fixtures would drain by gravity through building drains to the Argonne sanitary sewer system, which feeds the Argonne sanitary wastewater treatment system. High organic content wastewater from vivarium areas would also discharge to the Argonne sanitary wastewater treatment system. This would include tissue digester discharges. Animal waste and bedding from the cages would be collected, autoclaved, and disposed of as general trash, and therefore would not be discharged to the Argonne wastewater treatment system. Wastewater from the cage washing process would also discharge to the Argonne sanitary wastewater treatment system.

Storm Water System. A dedicated storm drainage system would be provided to discharge rainwater. A site-specific storm water management plan covering both construction and postconstruction operation would be developed as part of detailed engineering design. Storm water from the HTRL site would be discharged either via surface flow to existing drainage channels or by piped discharge to local water courses. Ultimately, storm water runoff flow from those portions of the HTRL site would be directed to the discharge point at the southeast corner of Outer Circle Drive and Eastwood Extension, into Freund Brook, a tributary of Sawmill Creek.

High-Purity Water System. A central high-purity water system would provide water to the laboratory spaces. The delivery system for the high-purity water would be a dead-end system, which would provide water to point-of-use polishers as required by the laboratory program. Each polisher would provide filtration for bacteriological elements. BSL-3 areas would be provided with backflow protection consisting of in-line sanitary ball checks. The makeup water would be stored in a polypropylene distribution tank with a conical bottom that would be sized for the anticipated 8-hour usage. Concentrated filtrate from the high-purity water system would be discharged to the Argonne laboratory sewer.

Carbon Dioxide $\left(\mathrm{CO}_{2}\right)$ System. $\mathrm{CO}_{2}$ would be provided as needed for the vivarium. A semiautomatic switchover manifold that would allow for an uninterrupted supply of gas would serve each system.

Solid Waste Disposal. Solid wastes would be disposed of by commercial waste disposal organizations contracted by the University. Wastes would be disposed of off site at appropriately permitted facilities. 
Animal Tissue Disposal System. An animal tissue digester would be used for carcass disposal. The digester would use a sodium hydroxide solution and heat treatment, the combination of which would digest the tissue into a liquid waste and destroy microorganisms. After chemical attenuation to decrease the $\mathrm{pH}$ of the waste, it would be discharged to the Argonne sanitary wastewater treatment system.

\subsubsection{HTRL Construction}

The construction of the HTRL would take up to 16 months. Site clearing would be expected to begin in 2005. Up to 100 construction workers would be needed during this period. Construction would be expected to cost about $\$ 32$ million.

\subsubsection{HTRL Operations}

HTRL operations are expected to continue for the 25 years of the current University lease from DOE. The fate of the HTRL after the 25-year lease period has ended has not been determined.

\section{Personnel}

Prior to entry of the HTRL, employees and visitors would be admitted to the Argonne site in accordance with DOE security policies. Entry and exit specifically to the HTRL would be through the front lobby of the building for all employees and visitors. Employees and visitors would be admitted to the HTRL in accordance with security policies established by the University.

It is anticipated that the HTRL would employ up to 13 administrative personnel. Administrative personnel would be permitted in the BSL- 1 areas of the HTRL, including the offices, voice/data room, electrical room, janitor closet, cylinder storage, solvent storage, loading dock, and dumpster area. Administrative personnel would use the bathroom facilities, conference rooms, and break room in the BSL-1 areas.

Research laboratory personnel (RP-2) wearing appropriate personal protective equipment (PPE) would work in the BSL-2 laboratories. There are 30 wet laboratory bench workstations in the HTRL that allow up to 30 full-time equivalents (FTEs) to work in this environment. Work in the BSL-2 laboratories may include work with Escherichia coli, and attenuated bacterial and viral pathogens under BSL-2 conditions (e.g., Bacillus anthracis strain STERNE, Yersinia pestis strain KIM D27, and Francisella tularensis strain LVS) in common laboratory rooms, tissue culture rooms, and incubator rooms. RP-2 would also use the imaging facilities of the HTRL, the dark room, as well as the radioisotope room and freezer farm of the HTRL, all under BSL-2 conditions. When not working in BSL-2 areas, these personnel would leave their PPE in their laboratories and would work or be present in the offices, break rooms, conference rooms, and bathroom facilities of the HTRL. 
Appropriate personnel would work in BSL-3 areas, after donning appropriate PPE. These areas would include laboratories, and shared decontamination, autoclave, and pass-through rooms. There would be up to 20 laboratory bench workstations, each equipped with a BSC in each of the BSL-3 laboratories, permitting simultaneous work on up to four different agents.

During the first 5 years of HTRL operations, up to 11 animal research center personnel, including a veterinarian, animal care technicians, and cage wash technicians, would be appointed.

\section{Animal Research Areas}

Animals arriving at the facility would be delivered by truck from the vendor in cardboard or plastic animal shipping containers. The shipping containers would be taken off the delivery truck at the loading dock of the animal facility. Each container would be inspected as it is removed from the truck to ensure that no breach has occurred to the outside of the container. If a breach is detected, the shipping container would be evaluated to determine if the health of the animals was compromised and whether the container can enter the animal facility. The shipping container would then be placed in an environmentally controlled room on the loading dock, and the outside of the container would be sprayed with a disinfectant. From the loading dock room, the shipping containers would be transferred into the animal facility and into the designated animal room(s). The shipping containers would be opened in a BSC, and the animals would be placed into facility cages. The cages would then be placed into a cage rack equipped with HEPA filters to ensure filtration of the air to and from the room. The used shipping containers would be placed in the trash and autoclaved out of the containment laboratory.

Scientists that work in the BSL-3 animal research areas would wear appropriate PPE, including protective overcoats, respiratory protective equipment, top gloves, and shoe covers. For manipulations of the animals, one cage at a time would be placed in a BSC where all procedures involving live microbial agents would be performed. Following the procedures, animals would be returned to the closed system cage, and the cage would be closed and returned to a HEPA-filtered, exhaust system cage rack. For manipulations involving aerosol exposure of animals to agents, one cage at a time would be placed in the BSC. Animals would be removed from their cages, placed in containers, and placed in a glove box in the aerosol procedure room. After infection, the animals would be returned to their cages in the animal research area, and observed for signs of acute disease. Animals for post-mortem analysis would be placed into a clean sterile plastic container, sealed, and labeled; placed into a second container, sealed, and labeled; and then transported to BSL-3 microbiology laboratories. Animals destined for disposal may be placed into waste bags, sealed, disinfected, and autoclaved. Decontaminated carcasses may be shipped off site for disposal, or alternatively, would be processed on site in an alkaline tissue digester for removal. Maintenance of the tissue digester would be handled by a licensed contractor. 


\section{Environmental Health and Safety}

Summary. Although the HTRL would be located at Argonne, it would be owned and operated by the University, not DOE. The University provides a complete safety program through the University's Office of Safety, Environmental Affairs and Radiation Safety (OSEAR). The University's OSEAR would be responsible for Employee Health and Safety services, including radiation safety, at the HTRL located at Argonne.

The OSEAR would supply one full-time employee to be stationed at the HTRL. This employee would hold the title of Biological Safety Officer (BSO) and by education would be an Industrial Hygienist who has received additional training in the field of biological safety. The BSO would also be the authorized shipper of infectious materials and would have been trained in accordance with regulations promulgated by the Department of Transportation. The BSO would be responsible for all aspects of the safety program as noted below under the section titled Services. The University's OSEAR has a total of 11 professional staff who would support the BSO as assigned.

The BSO would report directly to the Director for the OSEAR, who also serves as the Responsible Official (RO) for the University, to include the HTRL. The BSO would be designated as an Alternate Responsible Official (ARO).

Services. The OSEAR is responsible for the development and coordination of the University's safety and environmental compliance programs, including radiation safety. These programs include, but are not limited to, the following:

- Industrial hygiene;

- Fire safety;

- Laboratory safety;

- Hazardous materials and waste management;

- Agent management;

- Safety training;

- Ergonomics;

- Emergency preparedness;

- Accident review;

- Environmental compliance; 
- Hazard communication;

- PPE;

- Building inspections;

- Laboratory inspections;

- Biological safety;

- Radiation safety; and

- Food service inspections.

The purpose of these programs is to alleviate or reduce the severity of exposure to conditions or actions that can cause personal injury or put the University out of compliance with applicable regulations. This goal is accomplished by the identification, analysis, and development of corrective action plans to alleviate or reduce the severity of risk to students, faculty, and staff from injurious conditions or actions. All buildings and laboratories comprising the University are inspected annually to identify and locate infractions of fire, laboratory, biological safety, radiation, or general safety concerns.

Regulatory Emphasis. The University's OSEAR is charged with the responsibility of ensuring compliance with various municipal, state, and federal regulations and codes that pertain to safety and the environment.

As it pertains to the HTRL, the following entities would regulate safety and the environment: OSHA, the U.S. Environmental Protection Agency (EPA), the Illinois Environmental Protection Agency (IEPA), U.S. Nuclear Regulatory Commission, Illinois Emergency Management Agency, CDC, and the USDA.

In addition to the external oversight, the University's Institutional Biological Safety Committee (IBC) must approve any research involving the use of agents.

Safety Training. All employees would attend mandatory safety training classes as determined by their job classification. The need to attend safety training is primarily based on the hazards or risks that an individual would be exposed to in the performance of their job duties.

In addition to the general safety training, staff who have access to agents would also be required to receive training in biosecurity, emergency response, agent material awareness, and facility decontamination.

Nonrestricted investigative personnel would complete all Laboratory training requirements necessary in order to be given general access to the facility. These training 
requirements would be determined by the Principal Investigator (PI) and would be based on the research to be preformed.

Training of laboratory personnel on specific scientific protocols involving research at the BSL-2/BSL-3 level would be facilitated by the PI. Participation in this training would be documented and maintained by the PI.

Nonrestricted personnel would complete all general safety and agent-specific safety and security training prior to being given access rights to the BSL-3 or toxin areas. These training requirements include the following:

1. Bloodborne Pathogens (annual);

2. Chemical Hygiene Plan (includes Hazard Communication and PPE);

3. Respirators (annual);

4. Fire Safety and Evacuation (annual);

5. Agent Safety and Emergency Response (annual); and

6. Agent Security and Inventory Control (annual).

The training would be provided by the RO or ARO. The RO would maintain records of initial and recurrent training required.

All training provided by the OSEAR and the PI would be lecture based, and hands-on drills would be required to display adequate knowledge and skill, such as PPE donning and doffing, respirator fit testing, spill procedures, and scientific manipulations.

All employees attending training would be required to demonstrate adequate comprehension of the material as demonstrated by successful completion of a multiple choice exam. Employees not demonstrating adequate comprehension would be retrained and retake the exam. If after two attempts the employee is unable to successfully demonstrate comprehension of the material, the individual would not be assigned to that task.

The passing criterion for the learning measurement exercise is $85 \%$.

To determine retention of the materials covered during training, during inspections a representative from the OSEAR would obtain an employee roster for the area being inspected and would test employee safety knowledge at random. The OSEAR representative would also review the department's employee roster against OSEAR's training database to ensure that employees have been trained. In situations where employees have not been trained, the department would be cited for the violation and given 90 days to correct the deficiency. 


\section{Class Frequency}

Initial Training. All safety training required by a specific job classification would be considered initial training and would be completed:

- Prior to an employee first beginning his or her assignment;

- When an employee is given a new assignment for which training has not previously been provided;

- Whenever new hazards are introduced into the workplace by new substances, processes, or equipment; and

- Whenever a supervisor is made aware of a new or previously unrecognized hazard.

Refresher Training. The following safety training classes have annual refresher requirements: Bloodborne Pathogens, Fire Safety and Evacuation, Hearing Conservation, and Respiratory Protection.

\section{Competency Assessment}

All employees attending training would be required to demonstrate adequate knowledge retention as demonstrated by successful completion of a multiple-choice exam. Employees not demonstrating adequate knowledge retention would be retrained and would retake the exam until adequate retention has been demonstrated. The passing criterion for the learning measurement exercise would be $85 \%$. If after two attempts the employee is unable to successfully demonstrate the required knowledge, he or she would not be assigned to that task.

In addition, hands on drills, on a spot basis, would be required to display adequate knowledge, such as PPE donning and doffing, respirator fit testing, spill procedures, etc.

During inspections, a representative from the OSEAR would obtain an employee roster for the area being inspected and would have the right to interview employees to determine the adequacy of safety knowledge.

Enforcement. The Director of the OSEAR is responsible to ensure that the University complies with all rules and regulations relative to safety, environmental management, hazardous material management, and radiation safety, for all properties owned and operated by the University. This responsibility encompasses inspections performed internally and by external agencies. 
These inspecting agencies include, but are not limited to, the following:

- Occupational Safety and Health Administration (OSHA);

- Centers for Disease Control and Prevention (CDC);

- U.S. Environmental Protection Agency (EPA);

- Illinois Environmental Protection Agency (IEPA);

- State of Illinois — Fire Marshall; and

- Fire Insurance Representatives.

Outside regulatory agencies and insurance representatives requesting to inspect University properties and/or review components of the safety program in order to determine compliance with environmental management, hazardous material management, and radiation safety, would be directed to Safety and Environmental Affairs.

A representative from Safety and Environmental Affairs would accompany the representative from the outside agency on all inspections conducted and facilitate the necessary corrective action plan.

The appropriate administrative department and the Office of Legal Counsel would be advised of the inspection and copied on all inspection-related materials. Agency requests for inspection-related materials would be directed to the Director of the OSEAR, who would then clear with the University's Office of Legal Counsel.

\section{Frequency of Facility Reviews}

Initial Review. All facilities would be reviewed annually. Safety concerns identified during the initial review would be corrected within 90 days, unless a shorter period of time is allowed because of the severity of concerns or a longer period of time is necessary because of operational considerations. Conditions that could take 90 days to correct would typically require design and development, and capital funding. Conditions that pose an imminent hazard to life would be stopped immediately by the OSEAR representative. Longer periods of time would be agreed upon by the OSEAR representative.

Follow-up Review. Follow-up reviews would be based on risk that is determined by the number and severity of deficiencies. Twenty-five percent of re-inspections scheduled each month would be re-evaluated 90 days after the initial review. Facilities selected for re-inspection would be based on those facilities with the highest number of concerns noted during the initial inspection in each given month. All facilities with serious concerns would be reviewed in 
accordance with the time frame identified in the inspection report. All concerns would be tracked until corrective action plans have been completed.

Imminent Hazards. Any work practices (e.g., handling or storage of materials) or facility deficiencies (e.g., emergency eyewash not operating properly) posing an imminent hazard to faculty, staff, students and visitors identified during the facility reviews would be stopped and corrected immediately. The BSO representing the OSEAR would have the authority to stop any activity that in his or her mind posed an imminent hazard. The representative from the OSEAR discovering any imminent hazard would immediately notify the PI who would be responsible for appropriate follow-up corrective action. All imminent hazards would also be noted in the inspection report.

\section{Progressive Resolution Process}

Departments and/or laboratories failing to correct concerns identified on any inspection report would be subject to the progressive resolution process. Each identified concern would be corrected prior to the corrective action date. For concerns not corrected, the following actions would take place:

- Stage One of Noncompliance: A letter identifying the concerns not corrected would be sent to the Chair of the department with a copy sent to the Dean;

- Stage Two of Noncompliance: A letter identifying the concerns not corrected would be sent to the Dean of the department with a copy sent to the Provost and Vice President for Administration/Chief Financial Officer; and

- $\quad$ Stage Three of Noncompliance: A letter identifying the concerns not corrected would be sent to the Provost and Vice President for Administration/Chief Financial Officer.

Hazardous Waste Management. All hazardous waste would be managed in accordance with federal, state, and local regulations.

Disposal of these materials into sinks, drains, commodes, or other sewage disposal channels would be STRICTLY PROHIBITED.

A contracted service would be responsible for the disposal of chemical and radioactive waste. Biohazardous materials would be rendered innocuous by chemical or steam inactivation.

The hazardous material waste streams would be defined as chemical, radioactive, animal, and agents. 
Research, animal care, and maintenance activities at the HTRL would generate various waste streams. These streams would include solid, radioactive, hazardous, potentially infectious medical, and recyclable wastes. Potentially infectious medical waste (PIMW) would be routinely generated within the HTRL from research and animal care operations primarily as discarded research materials (e.g. plastic containers, pipette tips), discarded animal bedding/feed, and animal carcasses. Storage and decontamination of this PIMW would be completed in accordance with applicable OSHA and IEPA regulations. The majority of this PIMW would be decontaminated by steam autoclaving within the HTRL, thereby allowing disposal as nonhazardous solid waste. A small volume of PIMW (e.g., sharps) would be shipped off site for treatment and disposal by a licensed contractor.

General refuse (nonhazardous solid waste) would be discarded in dumpsters staged at the HTRL. Wastes placed in dumpsters would be collected by a commercial waste hauler for disposal in an IEPA-permitted sanitary landfill. It is estimated that 2,100 $\mathrm{yd}^{3}\left(1,606 \mathrm{~m}^{3}\right)$ of refuse would be generated annually at the HTRL. Recyclable material (e.g., paper, cans, and glass) would be discarded into separate containers staged at the HTRL. Recyclable material would be removed by a commercial hauler for processing at an off-site facility. It is estimated that a total of $66 \mathrm{yd}^{3}\left(50 \mathrm{~m}^{3}\right)$ of recyclable material would be generated at the HTRL annually.

Hazardous waste generated within the HTRL would be collected in specific containers, documented, packaged, and initially accumulated at or near the point of generation. It is anticipated that the volume of hazardous waste routinely stored within the HTRL at any one time would not exceed 55 gal (208 L) of hazardous waste or 1 quart (1 L) of acutely hazardous waste. The total annual volume of hazardous waste generated at the HTRL is estimated to be 250 gal (946 L). At limited times due to maintenance activities, more than 55 gal (208 L) of nonhazardous special waste (e.g., used glycol solutions and used oil) may be generated at the HTRL. Hazardous waste would be shipped off site to properly RCRA-permitted treatment, storage, and disposal facilities.

The volume of radioactive waste generated at the HTRL is anticipated to be less than $8 \mathrm{ft}^{3} / \mathrm{yr}\left(0.3 \mathrm{yd}^{3} / \mathrm{yr}\right)$. Waste would contain short-lived radioisotopes (e.g., tritium, phosphorus-32) used in biomedical research and would be considered low-level radioactive waste (LLW). Radioactive waste would be collected in specific containers, documented and packaged in accordance with the applicable regulations promulgated by the Illinois Emergency Management Agency Division of Nuclear Safety. All LLW would be delivered by licensed carriers to properly permitted commercial treatment or disposal facilities.

Hazardous Materials Management. A current chemical inventory would be maintained for each location that stores hazardous materials at the University and off-site locations under the University's jurisdiction.

Submission Requirements. All locations that store chemicals or other hazardous materials would maintain a current inventory. A hazardous material is defined as any material 
listed by the federal or state Environmental Protection Agency or any material that exhibits one or a combination of the following characteristics: flammable, corrosive, toxic and/or reactive.

Any additions, deletions, or other changes would be marked directly on the form(s), and the form would be returned to OSEAR by the required submission date. If the inventory has not changed, this would be noted on the form. All data would be tracked and updated upon receipt.

Agent Inventory. Each PI would maintain a detailed inventory of agent stocks (both working and culture collections) under his or her control. This inventory would be maintained electronically in a standard database format on a secure computer or computer system. The inventory would be reviewed and updated at least monthly.

The Animal Resource Center (ARC) maintains an inventory of all animals brought into the ABSL-3; this inventory includes health checks. The PI maintains an inventory of animals infected with an agent.

Experimental samples and stock aliquots used for working stocks or experimental purposes would be tracked by laboratory records (e.g., lab notebooks and electronic databases) or a daily inventory log. The quantity of toxins used and date(s) of use would also be recorded. Any electronic systems would be secure. The location of material use would be included. At the conclusion of each experiment, the disposition of the infectious material, including the means of disposal, would be verified by the signature of the PI, or his or her designee. Materials retained after the conclusion of experiments would be entered into the investigator's inventory for tracking purposes.

Each time a material is added or depleted, the RO or ARO would notify the Chief of Argonne's Fire Department and the DOE. A hard copy of the inventory would be placed inside the Fire Department Information Center, just inside the main secured entry to the building. For security reasons, this is the only instance in which a hard copy of the agent inventory would be allowed. Only the Argonne Fire Department or the RO and ARO would have access to the Fire Department Information Center.

Material Audits. Monthly material audits would be completed by the RO or ARO. The RO would immediately notify the PI, Biological Sciences Division (BSD), the DuPage County Sheriff's Office, and DOE of any discrepancy in the inventory. While the discrepancy was being investigated, the RO would stop all work inside the agent laboratory. When work stoppage occurs, the RO would inform the individuals previously mentioned. The RO would ensure that all work with the agent was secured before stopping work. Discrepancies or deficiencies would be resolved, and corrective actions taken prior to resumption of any research operations.

Storage of Agents. Access to the agent would be under lock and key, with only the PI having access to the key, which must be signed out. And access to the BSL-3 laboratory would be restricted to those who have satisfied the requirements of the University's security risk 
assessment and training. The agents would be used as (1) infectious material for BSL-3 animal research at the HTRL, and (2) infectious material for storage or shipping. Infectious material for shipping would be shipped in accordance with International Air Transport Association regulations; that is, placed into a clean sterile container, appropriately labeled, and sealed; placed into a second clean, sterile container, and again appropriately labeled, sealed, and decontaminated. Shipment of this material would require the approval of the University's RO, or when the RO is not available, the ARO.

Environmental Sampling. To verify the adequacy of standard operating procedures, which are intended to control contamination of the facilities, environmental sampling would be performed. It should be noted that environmental sampling is not required, and that there are no known models one can use to perform such sampling. Prior to the introduction of an agent into the BSL-3 laboratory, the BSO, with assistance from the CDC, would attempt to develop a sampling model.

In those situations where a model is available, the following procedures would be utilized when performing indoor environmental sampling for agents.

\section{Type of Sampling}

Surface Sampling with Wipes or Swabs. Surface samples would be collected by wiping or swabbing a moistened, absorptive medium across a nonporous surface. The absorptive media, wetting agent, and bags used to transport samples would be selected with input from the laboratory personnel who would be analyzing the samples so that collection procedures would be compatible with the laboratory's analytical procedures.

Air Samples. Air sampling would be conducted in limited situations where a clear need exists to characterize the air concentration of spores found inside the facility but outside traditional forms of containment, for example, storage facility or BSC. Air sampling would also be used to evaluate activities that may result in re-aerosolization of settled spores.

\section{Sample Analysis}

Analysis would be conducted within the University BSL-3 facilities quarterly. In addition, quality assurance/quality control (QA/QC) samples would be sent to an external laboratory accredited by the CDC. QA/QC sampling would be conducted semiannually. 


\section{Sample Interpretation}

If a positive result was found inside or outside the BSL-3/ABSL-3 facility, the OSEAR would oversee a multidisciplinary team, including the RO, ARO, BSO, representatives from the BSD, ARC, IBC, PI, and other laboratory personnel to interpret analytical results. Inclusion of field investigators and laboratory personnel in the interpretation process would provide the best insight into sample collection and recovery.

Biosecurity Plan/Access Control System for Select Agents. A security risk assessment would be completed for all personnel provided unescorted access to agents or toxins. The employees of firms hired to provide staffing, such as the case of the ARC, would also be required to receive security risk assessments. The security risk assessment would be completed as specified in 7 CFR Part 331, 9 CFR Part 121, and/or 42 CFR Part 73, and those required by DOE.

No individual whose access was denied or revoked as a result of the security risk assessment would be given access, including while under escort, to agents or toxins. Other individuals (e.g., repair vendors) may be provided access to agent/toxin areas if an approved individual accompanies them in full accordance with this section. Access rights to agent and toxin areas would be given and maintained in strict accordance with this policy.

Completion of Safety and Security Training Requirements. Nonrestricted personnel would complete all general safety and agent-specific safety and security training prior to being given access rights to the agent or toxin areas. These training requirements include the following:

1. Bloodborne pathogens (annual);

2. Chemical Hygiene Plan (includes hazard communication and PPE);

3. Respirators (annual);

4. Fire safety and evacuation (annual);

5. Select agent safety and emergency response (annual); and

6. Select agent security and inventory control (annual).

Assigning Access Rights, PIN Numbers, and Biometric Readers. Once an individual has successfully completed the requirements of the security risk assessment and training, the individual would be provided with PIN numbers and verification of biometric indicator. 
Monitoring and Maintaining Access Rights to Select Agent or Toxin Areas. On a daily basis, the entry and exit records for nonescorted, nonrestricted personnel from each agent or toxin area would be reviewed, and all entries/exits would be verified as authorized. Any irregularities would be reported immediately to the RO or ARO, who would then initiate further investigation.

The PI or supervisor for all employees given access rights to agent or toxin areas would notify the RO immediately if the access needs, employment status, or security status of an individual changes such that access rights need to be removed. The RO would terminate the access rights if nonrestricted personnel do not complete annual safety or security training.

Access to Select Agent or Toxin Areas by Restricted Personnel. If restricted personnel (e.g., repair vendors) must enter an agent or toxin area, the RO or ARO would be notified of the date, time, and reason for entry and the restricted personnel would be accompanied by a dedicated escort for the duration of his or her work in the area. The escort must be nonrestricted personnel with appropriate access rights. The RO or ARO may deny access of the restricted personnel to the facility if there is knowledge that the person has previously been denied access to agents.

Security Systems. To determine what security systems were needed, a security risk assessment of the HTRL and Argonne was performed. In addition to security guards, CCTV, controlled access to the building, and restricted access to the BSL-3 and ABSL-3, cyber security, inventory control, and exterior lighting would be utilized. The "two-person" rule, meaning anyone performing manipulations with the agent will need to be in the company of another authorized individual, would also be utilized.

Emergency Response Plan. A specific emergency and off-normal condition response plan would be developed for each agent or toxin area, as defined in 7 CFR Part 331, 9 CFR Part 121, and/or 42 CFR Part 73, located at the HTRL. This plan would comply with the requirements of the aforementioned regulations. The Plan must also comply with University safety policies and must integrate with the Emergency Response Plan in place at Argonne.

The HTRL would have its own hazardous material first response team. These individuals would be required to work closely with Argonne's Fire Department when responding to hazardous material spills inside the facility. The HTRL first responders must be trained according to 29 CFR 1910.120 OSHA Hazardous Waste Operations and Emergency Response. In addition to this training, the emergency response personnel would also receive training on the specific agents used in the BSL-2 and BSL-3 laboratories.

Planning and Coordination with External Responders. The RO should coordinate and conduct emergency and off-normal condition planning sessions between internal organizations and appropriate external responders. These responders would include the Argonne Fire 
Department, DOE Protection Services, the Illinois Department of Public Health, and others as appropriate.

Decontamination. Various chemical agents would be used to decontaminate space associated with the BSL-2/BSL-3 laboratory. A bleach or Clidox solution would be used for surface decontamination or general cleaning of the laboratory. This would include daily cleaning of the BSC, other equipment, and mopping of floors. Complete decontamination of the facility may be warranted in response to an off-normal condition (e.g., spill of the agent). In these situations, vaporous hydrogen peroxide, or other approved materials, would be used.

Disinfectants approved for surface disinfecting, as recommended by the CDC, EPA, and World Health Organization, would be available in the agent laboratory and in the room directly adjacent. Disinfecting solutions would also be part of spill carts that would be stored away from the agent laboratory.

The decision to fumigate an area or pieces of equipment as part of emergency response would be made by the University's RO or ARO (Incident Commander), after consultation with the BSO.

Internal HTRL emergency responders who decontaminate the agent laboratories as part of an emergency response operation would be trained according to 29 CFR 1910.120, OSHA Hazardous Waste Operations and Emergency Response. In addition to this training, the emergency response personnel would also receive training on the specific agents.

Occupational Health and Medicine Review. All nonrestricted personnel would have a preexposure surveillance exam within the University of Chicago Occupational Medicine Clinic (UCOM). The exam includes the following procedures:

1. Development of medical history;

2. Physical exam;

3. Pulmonary function test;

4. Complete blood count;

5. Baseline blood serum draw;

6. Health screens required by other regulations (e.g., tuberculosis [TB] screen, hepatitis B virus [HBV], and vaccination/declination); and

7. Other procedures based on agent of concern, protocol requirements, and professional judgment of the Medical Director of the UCOM. 
Any serum sample taken would be tested and evaluated and the results noted in the employee's file. Baseline serum samples would be collected and stored for all BSL-3 laboratory personnel.

The UCOM would offer a vaccine for agents, for which one exists, and it would be made available to all personnel with nonrestricted status. The risks of exposure to the agent and the risks and benefits of a vaccine, if available, would be thoroughly explained to each individual to allow for an informed decision. Initial training would be provided by the RO or ARO and would be scheduled by calling 773-702-9999. Upon arrival at the UCOM, the employee would receive additional information and training regarding the risks and benefits of the vaccine from the Medical Director. The employee would then choose to accept or decline the vaccine, and complete and sign an acceptance or declination statement. The acceptance or declination statement would be included with the employee's medical record documenting the offer and decision of the immunization.

Upon completion of medical tests and administration of immunization, the Medical Director would determine if the employee is medically competent to be given access to BSL-3 or toxin areas. The Medical Director would complete Section 3 of the Request for Access to BSL-3 or Toxins Areas Form indicating whether the individual has been given medical clearance to enter BSL-3 or Toxin Areas.

Work-Related Injuries or Illness - Emergency Medical Treatment and First Aid. In the case of a non-life-threatening injury (e.g., autoinjection, laceration, and animal bite), personnel would exit the BSL-3 laboratory under normal procedures. The individual would call 911 and an ambulance would be dispatched to the HTRL by the Argonne Fire Department, and the individual would be transported to the appropriate emergency room. Each employee working within a BSL-3 would be provided with a medical card that summarizes the material he or she works with and resources to obtain information pertaining to diagnoses and treatment. In addition to the medical card, once outside the BSL-3, the injured employee could then obtain the detailed medical plan. This plan gives the healthcare provider the details needed to begin diagnosis and treatment. The individual would inform the clinical staff of the nature of the injury and the agent in use.

In the case of a medical emergency with a victim suspected to be contaminated with an agent or toxin, the Argonne Fire Department would be notified by calling 911. The Argonne Fire Department would then assist with preparing the individual for transport to the emergency care facility. The injured employee's supervisor would be responsible for ensuring that the medical plan is provided to the healthcare provider.

To assist the healthcare provider with the diagnoses and treatment of the injured, the medical plan would include the names and contact methods for the University's Infectious Disease Department.

The UCOM would provide medical follow-up of the victim. 
Personal Protective and Emergency Equipment. PPE, including, but not limited to, scrubs, Tyvex suits, aprons, gloves, head covers, booties, and clogs, as well as respirators (N95s and powered air purifying respirators) needed for entry into the agent laboratory would be maintained by laboratory personnel. PPE used by the University's Safety Office for emergency response would be maintained by that office.

Disinfecting solutions (e.g., bleach and Clidox) and items (e.g., plastic sheeting, tape, and spill pads) would be ready for use inside and outside the agent laboratory on designated emergency spill carts. External responders would provide their own PPE and emergency equipment.

Spills. If a small spill occurs that is contained within the BSC, or outside the BSC, but still within the BSL-3, the working surface would immediately be saturated with an appropriate disinfectant. The duration of exposure to the disinfectant on the contaminated surface would be no less than 10 minutes. If emergency assistance is needed, the Argonne Fire Department would be called by dialing 911 .

\subsection{NO ACTION}

Under the no action alternative, the University would not construct the HTRL. The impacts of no action would be those of normal Argonne operations. These impacts are discussed as part of the affected environment (Chapter 4). No action would not change the existing impacts of Argonne normal operations in any impact area, including geology and soils, surface and groundwater, human health, socioeconomics, air quality, noise, waste management, land use, visual setting, aquatic or terrestrial biota, wetlands, floodplains, threatened and endangered species, cultural resources, transportation, utilities and services, or environmental justice.

The only activities occurring at the proposed HTRL site would be vegetation management, including mowing and removal of undesirable species and parking for Argonne and DOE employees. 


\section{AFFECTED ENVIRONMENT}

This Chapter describes conditions at the Argonne site now, before construction of the proposed HTRL, to provide a basis for the analysis in Chapter 5, Environmental Consequences. Because the HTRL would be located at Argonne, most of the sections in Chapter 4 describe current conditions at the Argonne site. Section 4.4.2, however, describes the University's health and safety program because the HTRL would be owned and operated by the University rather than DOE.

\subsection{GEOLOGY}

\subsubsection{Stratigraphy}

The geology of the area around Argonne National Laboratory consists of about $100 \mathrm{ft}$ (30 m) of glacial drift on nearly horizontal bedrock consisting of Niagran and Alexandrian dolomite approximately $200 \mathrm{ft}$ (60 m) thick with an irregular, eroded upper surface (Golchert and Kolzow 2004).

\subsubsection{Seismic Activity}

No tectonic features within $62 \mathrm{mi}(135 \mathrm{~km})$ are known to be seismically active. The few recent minor earthquakes that have occurred in northern Illinois are presumed to be caused by isostatic adjustments of the earth's crust in response to glacial loading and unloading. The nearest areas of seismic activity are located in the St. Louis area (New Madrid Fault zone) and along the southern Illinois-Indiana border (Wabash Valley Fault zone), each about $200 \mathrm{mi}$ (322 km) away from Argonne. Although high-intensity earthquakes have occurred along the New Madrid Fault Zone, their relationship to plate motions remains speculative at this time. According to estimates, ground motions induced by near and distant seismic sources in northern Illinois are expected to be minimal. Peak accelerations of $10 \%$ of gravity (the approximate threshold of major damage) may occur once in approximately 600 years $(-250$ to +450 error range) (Golchert et al. 2001; Golchert and Kolzow 2004). In 1988, the Uniform Building Code Zone $\mathrm{O}$ (the least earthquake hazard) was determined for the project area (Leyendecker et al. 1995).

\subsection{SOILS}

The soils at Argonne were derived from glacial drift over the past 12,000 years and are primarily of the Morley series, with a slope ranging from 2 to 20\%. The surface layer is a dark grayish-brown silt loam; the subsoil is a brown silty clay; and the underlying material is a silty clay loam glacial drift. Morley soils have a relatively low organic content in the surface layer, moderately slow subsoil permeability, and a large water capacity. The remaining soils along 
creeks, intermittent streams, bottomlands, and a few small upland areas are of the Sawmill, Ashkum, Peotone, and Beecher series, which are generally poorly drained. They have a black to dark gray or brown silty clay loam surface layer, large amount of organic matter, and large water capacity (Golchert and Kolzow 2004).

\subsection{WATER RESOURCES}

\subsubsection{Surface Water}

The Argonne site lies above the bluffs bordering the Des Plaines River valley, which was formed by glacial meltwater draining the area that is now Lake Michigan about 11,000 to 14,000 years ago. This valley contains the Des Plaines River, the Chicago Sanitary and Ship Canal, and the Illinois and Michigan Canal. The HTRL site is drained by surface flow to Freund Brook, a tributary of Sawmill Creek (average flow of approximately 7.5 million gal/d [28 million L/d]), which drains into the Des Plaines River.

Wastewater generated at Argonne is treated in two independent treatment systems, the sanitary system and the laboratory system. The sanitary wastewater collection and treatment system collects wastewater from sanitation facilities, the cafeteria, office buildings, and other portions of the site that do not contain radioactive or hazardous materials. This wastewater is treated in a biological wastewater treatment system consisting of primary clarifiers, trickling filters, secondary clarifiers, and slow sand filters. Wastewater generated during research-related activities is collected by the laboratory wastewater sewer system and treated at the laboratory wastewater treatment plant. Treatment at the laboratory wastewater treatment plant consists primarily of aeration, solids-contactor clarification, and $\mathrm{pH}$ adjustment. Additional steps can be added, including powdered-activated carbon addition for organic removal, alum addition, and polymer addition or adjustment, if analysis demonstrates that any of these are required. Discharges from the two treatment plants are combined before being discharged to Sawmill Creek.

The IEPA has issued a National Pollution Discharge Elimination System (NPDES) permit for the Argonne site. This permit requires water quality monitoring at 28 points of water discharges to local streams, including the wastewater treatment plant discharges. At the sanitary treatment plant, the NPDES permit contains limits on five-day biological oxygen demand (BOD5), total suspended solids (TSS), iron, lead, zinc, manganese, chromium, copper, oil and grease, and $\mathrm{pH}$. Parameters limited by the NPDES permit at the laboratory treatment plant discharge include chemical oxygen demand (COD), $\mathrm{BOD}_{5}$, TSS, mercury, and $\mathrm{pH}$. Parameters

limited at the combined discharge include ammonia nitrogen, chloride, sulfate, copper, dissolved iron, manganese, zinc, and total dissolved solids (TDS). 


\subsubsection{Groundwater}

The two principal water-producing aquifers in the vicinity of Argonne are located at depths of approximately $200 \mathrm{ft}(60 \mathrm{~m})$ and 500 to $1,500 \mathrm{ft}$ (150 to $450 \mathrm{~m})$ below the surface. In northeastern Illinois, the shallow groundwater is within glacial drift units of varying character and extent and within the underlying Silurian dolomite (Hughes et al. 1966). Until 1997, Argonne relied on well water for its needs. After 1997, it began to receive Lake Michigan water originating from the City of Chicago municipal water system. Argonne now receives all its potable water from this source; it is purchased through the DuPage County Water Commission. Surrounding communities obtain drinking water from the Lake Michigan supply and private wells.

\subsection{HUMAN HEALTH}

\subsubsection{Medical Facilities}

Major health centers within a 10-mi (16-km) radius of Argonne are located in the towns/ cities of Naperville, Hinsdale, LaGrange, Downers Grove, and Joliet. Table 4.1 lists the numbers of hospitals and doctors located in nearby communities. The City of Chicago has 44 hospitals, and other major medical centers are located in the western, northern, and southern suburbs.

TABLE 4.1 Hospitals, Doctors, and Emergency Services in the Vicinity of Argonne

\begin{tabular}{lccc}
\hline Community & $\begin{array}{c}\text { Number of } \\
\text { Hospitals }\end{array}$ & $\begin{array}{c}\text { Number of } \\
\text { Doctors in } \\
\text { Community }\end{array}$ & $\begin{array}{c}\text { Distance to } \\
\text { Emergency Medical } \\
\text { Treatment, } \\
\text { mi (km) }\end{array}$ \\
\hline Bolingbrook & 0 & 51 & 0 \\
Darien & 0 & 26 & $4(6)$ \\
Downers Grove & 1 & 600 & 0 \\
Hinsdale & 2 & 291 & 0 \\
Joliet & 2 & 270 & 0 \\
Lemont & 0 & 20 & $7(11)$ \\
Lockport & 0 & 7 & $4(6)$ \\
Naperville & 2 & 65 & 0 \\
Romeoville & 0 & 170 & $3(5)$ \\
Westmont & 0 & 6 & $3(5)$ \\
Willowbrook & 0 & 8 & $2(3)$ \\
Woodridge & 0 & 30 & 0 \\
\hline
\end{tabular}

Source: Illinois Department of Commerce and Economic Opportunity (2004). 


\subsubsection{Health and Safety}

The University provides a complete safety program through the OSEAR. One department cannot ensure the safety of all persons within an institution the size and complexity of the University. Therefore, safety is a responsibility shared by everyone.

The University's safety and environmental compliance programs are listed in Section 3.1.5. The purpose of these programs is to alleviate or reduce the severity of exposure to conditions or actions that can cause personal injury or put the University out of compliance with applicable regulations. This goal is accomplished by the identification, analysis, and development of corrective action plans to alleviate or reduce the severity of risk to students, faculty, and staff from injurious conditions or actions. All buildings and laboratories comprising the University are inspected annually to identify and locate infractions of fire, laboratory, biological safety, radiation, or general safety concerns.

To ensure compliance with the regulations and to perform the various operations required, full-time BSO would be assigned to the HTRL. The BSO would report to the University's Director of OSEAR.

The University's OSEAR is charged with the responsibility of ensuring compliance with various municipal, state, and federal regulations and codes that pertain to safety and the environment.

As it pertains to the HTRL, the following entities would regulate safety and the environment: OSHA, the EPA, the IEPA, the Illinois Emergency Management Agency, the CDC, and the USDA.

In addition to external oversight, the University's IBC must approve any research involving the use of agents, and the Institutional Animal Use and Care Committee must approve any research involving the use of agents or animals.

\subsection{SOCIOECONOMICS}

The Argonne site is located in southern DuPage County in the greater Chicago metropolitan region in an area of suburban development and county parks. The site is surrounded by a number of suburban communities. The nearest are Darien, Downers Grove, Willowbrook, and Woodridge in DuPage County; Lemont in Cook County; and Bolingbrook and Romeoville in Will County. The area also contains centers of manufacturing, utility, transportation, warehousing, and commercial development. The Waterfall Glen Forest Preserve of the Forest Preserve District of DuPage County surrounds the Argonne site.

Socioeconomic data for the HTRL are presented for a region of influence (ROI) comprising the three counties - Cook, DuPage, and Will. The ROI is based on the residential locations of Argonne full-time employees and captures the area in which HTRL workers are expected to spend their wages and salaries, and where a substantial portion of construction and 
operation procurement is expected to occur. Currently, approximately $85 \%$ of Argonne workers live in the three-county ROI (Stepuszek 2005).

In the following sections, two key measures of economic development for the ROI are described: employment and personal income. Measures of impacts on the local community (e.g., population, housing, public services, and education) are not included, since no in-migrant labor force is expected for either the construction phase or the operations phase of the project.

\subsubsection{Employment}

In 2001, total employment in the ROI stood at 3.1 million, and it is expected to reach 3.2 million by 2005 (Table 4.2). ROI employment grew at an annual average rate of $1.7 \%$ over the period 1992 to 2002. The economy of the ROI is dominated by service industries, with employment in these activities currently contributing more than $50 \%$ of all employment in the ROI. The wholesale and retail trade sector $(17 \%)$ and manufacturing sector $(12 \%)$ are also significant employers in the ROI. Employment at Argonne in November 2004 was 3,792 FTEs (Gartman 2004).

\subsubsection{Income}

According to the U.S. Department of Commerce (DOC), personal income in the ROI was $\$ 260$ billion in 2002, and it is expected to reach $\$ 275$ billion in 2005. Personal income grew at an annual average rate of growth of $2.0 \%$ over the period 1992 to 2002 (Table 4.3). ROI personal income per capita also rose over that period. It is expected to reach $\$ 39,900$ in 2005 , compared with \$33,391 in 1992.

TABLE 4.2 ROI Employment by Industry

\begin{tabular}{lrr}
\hline \multicolumn{1}{c}{ Sector } & \multicolumn{1}{c}{$\begin{array}{c}\text { \% of } \\
\text { ROI Total }\end{array}$} \\
\hline & 2002 & \\
Agriculture & & \\
Mining & 616 & 0.0 \\
Construction & 663 & 0.0 \\
Manufacturing & 140,672 & 4.5 \\
Transportation and public utilities & 360,599 & 11.6 \\
Trade & 156,995 & 5.0 \\
Finance, insurance, and real estate & 516,740 & 16.6 \\
Services & 298,806 & 9.6 \\
Total & $1,635,209$ & 52.6 \\
\hline
\end{tabular}

a Source: USDA (2004).

Source: U.S. Bureau of the Census (2004). 
TABLE 4.3 ROI Personal Income (2003 dollars)

\begin{tabular}{lrrrr}
\hline & & & $\begin{array}{c}\text { Average Annual } \\
\text { Growth Rate (\%), } \\
\text { 1990-2002 }\end{array}$ & $\begin{array}{r}\text { 2005 } \\
\text { (projected } \\
\text { by Argonne) }\end{array}$ \\
\hline Income & 1990 & 2002 & & \\
Total personal income (billions of \$) & 206 & 260 & 2.0 & 275 \\
Personal income per capita (\$) & 33,391 & 38,466 & 1.2 & 39,900 \\
\hline
\end{tabular}

Source: DOC (2004).

\subsection{CLIMATE AND METEOROLOGY}

The climate of the area is representative of the upper Mississippi Valley as moderated by Lake Michigan: continental, with relatively warm summers and cold winters (Golchert and Kolzow 2004). Without the protection of natural barriers such as mountain ranges, the area experiences the full sweep of winds from surrounding regions. The weather patterns in the area are partially modified by Lake Michigan (e.g., land/lake breeze and lake-effect precipitation), located about $24 \mathrm{mi}(39 \mathrm{~km})$ east of the Argonne site.

Wind data at the on-site meteorological station, which is located at the southwest corner of the Argonne site, have been measured at two levels: $10 \mathrm{~m}(33 \mathrm{ft})$ and $60 \mathrm{~m}(197 \mathrm{ft})$. The wind rose at the 10-m (33-ft) level for the 10-year period 1994 through 2003 is shown in Figure 4.1. No wind direction is predominant at the Argonne site. The wind direction usually varies from the southwest quadrant (south to west, inclusive), but it has a significant northeast component. During the 10-year period, the average wind speed measured at the 10-m (33-ft) level was about $3.2 \mathrm{~m} / \mathrm{s}(7.2 \mathrm{mph})$, while the fastest wind speed was about $14.5 \mathrm{~m} / \mathrm{s}$ (32.5 mph). Directional wind speeds of greater than $3.6 \mathrm{~m} / \mathrm{s}(8.1 \mathrm{mph})$ from the southwest quadrant are relatively slower than those from other directions. Winds from the southwest quadrant prevail throughout the year, except in spring, when they are dominantly from the northeast. Wind speeds in summer are slower than in other seasons.

The historical (1971-2000) annual average temperature at O’Hare International Airport is $9.4^{\circ} \mathrm{C}\left(49.0^{\circ} \mathrm{F}\right)$ (National Oceanic and Atmospheric Administration [NOAA] 2003). January is the coldest month, averaging $-5.6^{\circ} \mathrm{C}\left(22.0^{\circ} \mathrm{F}\right)$, and July is the warmest month, averaging $22.9^{\circ} \mathrm{C}$ $\left(73.3^{\circ} \mathrm{F}\right)$. The highest temperature was $40^{\circ} \mathrm{C}\left(104^{\circ} \mathrm{F}\right)$ in July 1995 , and the lowest was $-32.8^{\circ} \mathrm{C}$ $\left(-27^{\circ} \mathrm{F}\right)$ in January 1985.

The average annual precipitation is approximately 36.3 in. (92.1 cm) (NOAA 2003). Most of the precipitation falls in spring and summer and is sometimes associated with thunderstorm activity. Annually, the area experiences about 38 thunderstorms, which are occasionally accompanied by hail, damaging winds, or tornadoes. Annual average snowfall in the area is about $38.0 \mathrm{in}$. $(96.5 \mathrm{~cm})$. The greatest amount of snow reported in a single month was 35.3 in. $(89.7 \mathrm{~cm})$ in December 1978, and the greatest amount in a 24-hour period was 18.6 in. (47.2 cm), which fell in January 1999. 
Site : ANL-E, IL (10-m level)

Period : 1994-2003
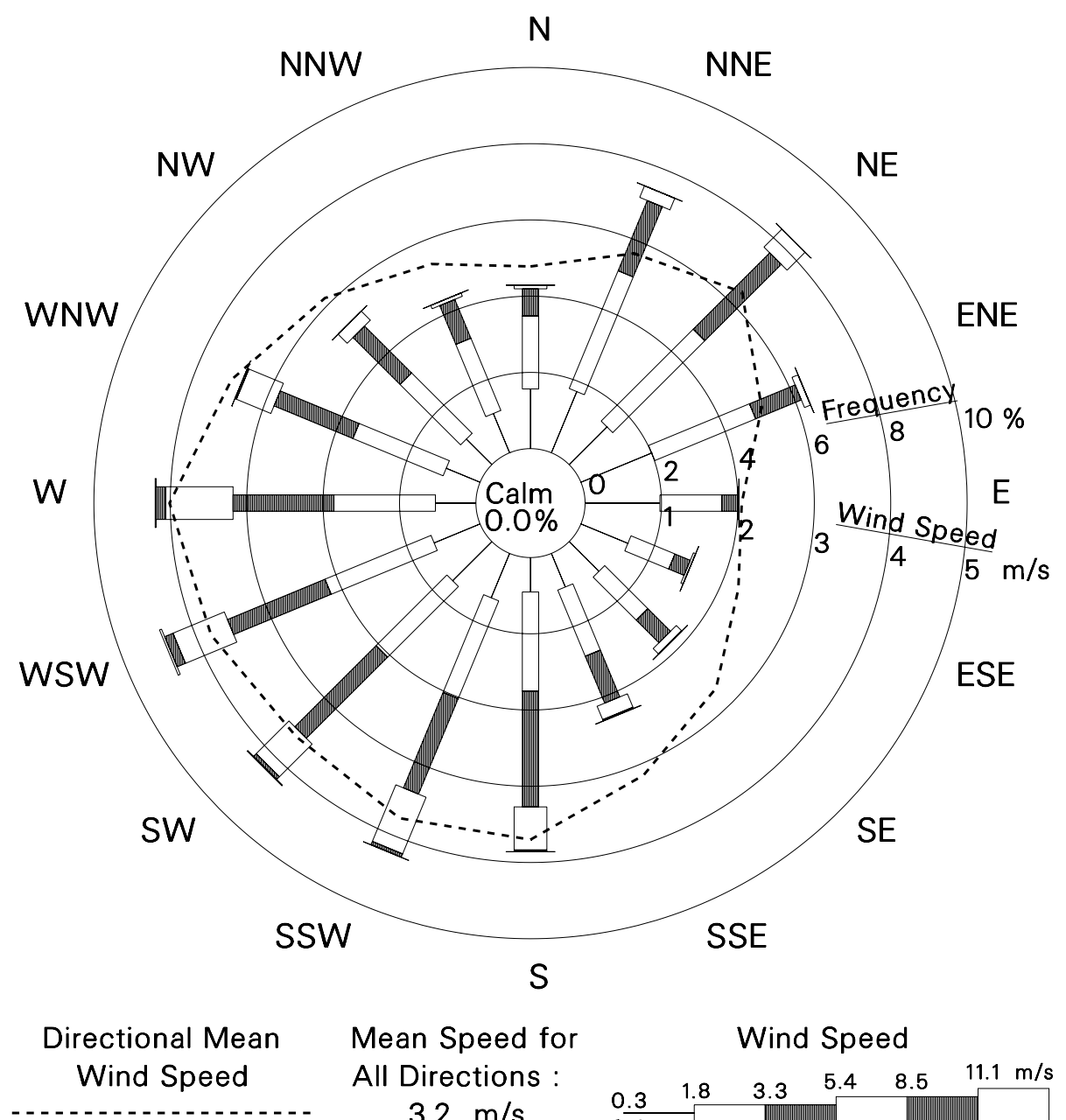

Mean Speed for

Wind Speed

All Directions :

$3.2 \mathrm{~m} / \mathrm{s}$

$7.2 \mathrm{mph}$

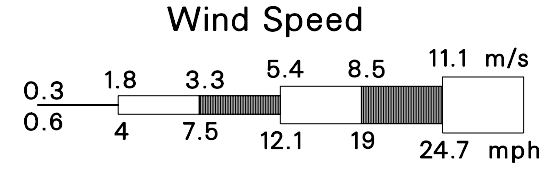

FIGURE 4.1 Wind Rose at the 10-m Level for the Argonne Meteorological Station from 1994 through 2003 (Source: ANL 2004)

The State of Illinois ranked seventh in tornado occurrences in the United States (NOAA 2005). Tornadoes occur relatively frequently in the area surrounding Argonne, although not as often as they do in tornado alley, which stretches from Texas to North Dakota and includes part of the Midwest. From 1950 to February 2004, 1,835 tornadoes were reported in Illinois, with a tornado event frequency of $6.1 \times 10^{-4}$ per year per square mile and an average of 34 tornadoes per year (National Climatic Data Center 2004). For the same period, 20 tornadoes were reported in DuPage County, with a tornado event frequency of $1.1 \times 10^{-3}$ per year per square mile. Over the 54-year period, most tornadoes that occurred in DuPage County were relatively weak (except for one F3 and one F4 on the Fujita tornado scale), with no fatalities. Fujita scale F3 and F4 are classified as severe and devastating tornadoes, with wind speeds of 71 to $92 \mathrm{~m} / \mathrm{s}$ (158 to $206 \mathrm{mph}$ ) and 93 to $116 \mathrm{~m} / \mathrm{s}$ (207 to $260 \mathrm{mph}$ ), respectively. Historically, 
the Argonne site has been struck by milder tornadoes, which have resulted in minor damage to buildings, trees, and power lines.

\subsection{AIR QUALITY}

\subsubsection{Existing Emissions}

The Argonne site contains several sources of criteria pollutants, volatile organic compounds (VOCs), and hazardous air pollutants (HAPs). Criteria pollutants are sulfur dioxide $\left(\mathrm{SO}_{2}\right)$, nitrogen dioxide $\left(\mathrm{NO}_{2}\right)$, $\mathrm{CO}$, ozone $\left(\mathrm{O}_{3}\right)$, particulate matter $\left(\mathrm{PM}_{10}\right.$ and $\mathrm{PM}_{2.5}$, particles with a mean aerodynamic diameter of $10 \mu \mathrm{m}$ and $2.5 \mu \mathrm{m}$, respectively), and lead $(\mathrm{Pb})$, as identified under Title I of the Clean Air Act (CAA). The EPA has set ambient air quality standards for these pollutants to protect human health and welfare. VOCs are a broad range of organic compounds that readily vaporize at ambient temperature and contribute to the formation of $\mathrm{O}_{3}$ in the atmosphere. HAPs are those pollutants not covered by ambient air quality standards but which may cause serious human health effects or adverse environmental effects. Currently, 188 air pollutants are regulated as hazardous under Title III of the CAA. Among the Argonne sources of air pollutants, steam plant and fuel-dispensing facilities are continuous and significant sources (Golchert and Kolzow 2004). The emergency generators at the Advanced Photon Source (APS) and the engine test facility are also significant sources but only when they are operational.

The Argonne site is classified as a major stationary source, for which actual or potential emissions are above the applicable source threshold (Golchert and Kolzow 2004). The IEPA issued the final Argonne Clean Air Act Permit Program (CAAPP) permit (also known as the Title V permit) in April 2001. All previous air operating permits (with the exception of the open burning permits) were incorporated into this sitewide, federally enforceable operating permit to cover emissions of all regulated pollutants from activities at the facility. Facilities like Argonne that are subject to Title V must characterize their emissions of all regulated air pollutants, not simply the pollutants that qualify the facilities as being major sources. Argonne must also evaluate emissions for criteria pollutants and VOCs, HAPs, and $\mathrm{O}_{3}$-depleting substances. The permit program requires that facilities pay annual fees on the basis of the total amount of regulated air pollutants (except $\mathrm{CO}$ ) that they are allowed to emit.

Pursuant to Title 35, Part 254 of the Illinois Administrative Code (35 IAC Part 254), an annual summary of emissions at the Argonne site should be submitted to the IEPA. The reported annual emissions from all categories of Argonne sources for 2003 were about 134.29 tons $(119.90 \mathrm{t})$ of nitrogen oxides $\left(\mathrm{NO}_{\mathrm{x}}\right)$; 99.50 tons $\left(88.8 \mathrm{t}\right.$ ) of $\mathrm{SO}_{2} ; 50.99$ tons (45.53 t) of $\mathrm{CO}$; 1.70 and 0.9963 tons $\left(1.52\right.$ and $0.89 \mathrm{t}$ ) of $\mathrm{PM}_{10}$ and $\mathrm{PM}_{2.5}$, respectively; 1.45 tons (1.30 t) of VOCs; and 0.0 tons of $\mathrm{Pb}$. Nitrogen oxide emissions are expressed in $\mathrm{NO}_{\mathrm{x}}$ (sum of nitric oxide [NO] and $\mathrm{NO}_{2}$ ), but the ambient air quality standards are expressed in $\mathrm{NO}_{2}$. Annual estimates of air pollutant emissions in 2003 from DuPage County and Argonne are listed in Table 4.4. The significance of Argonne emissions is expressed as a percentage of the total stationary point source emissions in DuPage County. As the table indicates, Argonne accounts for relatively large fractions of the $\mathrm{SO}_{2}, \mathrm{NO}_{\mathrm{x}}$, and $\mathrm{CO}$ emissions released from DuPage County, which come from 
Argonne's coal-fired steam plant. In addition, 6.29 tons (5.62 t) of HAPs and 0.1397 ton (0.12 t) of ammonia $\left(\mathrm{NH}_{3}\right)$ were reported to the IEPA for 2003.

\subsubsection{Ambient Air Quality}

The Illinois State Ambient Air Quality Standards (SAAQS) (IEPA 2003) for six criteria pollutants $-\mathrm{SO}_{2}, \mathrm{NO}_{2}, \mathrm{CO}, \mathrm{O}_{3}, \mathrm{PM}$ (both $\mathrm{PM}_{10}$ and $\mathrm{PM}_{2.5}$ ), and $\mathrm{Pb}-$ are identical to the National Ambient Air Quality Standards (NAAQS) set by the EPA, as shown in Table 4.5.

The Argonne site, situated at the southeast corner of DuPage County, is located in the Metropolitan Chicago Interstate Air Quality Control Region (AQCR 067), which covers northeastern Illinois and northwestern Indiana. DuPage County is currently an attainment area for all criteria pollutants except $\mathrm{O}_{3}$ and $\mathrm{PM}_{2.5}$ (40 CFR 81.314, and 40 CFR Part 81). An attainment area for a criteria pollutant is an AQCR (or portion thereof) in which the EPA has determined that ambient air concentrations do not exceed the pollutant's respective NAAQS. On April 15, 2004, the EPA designated DuPage County as a nonattainment area for 8-hour $\mathrm{O}_{3}$. On December 17, 2004, the EPA designated DuPage County as a nonattainment area for $\mathrm{PM}_{2.5}$.

As of December 2004, no on-site monitoring stations for criteria air pollutants exist at Argonne. Ambient air quality data in the general vicinity of the site (within $15 \mathrm{mi}$ [24 km]) for the 5-year period from 1999 through 2003 are also summarized in Table 4.5. The monitoring data indicate that the concentrations for all criteria pollutants around Argonne, except 8-hour $\mathrm{O}_{3}$

and annual $\mathrm{PM}_{2.5}$, are less than $92 \%$ of their respective NAAQS. Eight-hour $\mathrm{O}_{3}$ concentrations

TABLE 4.4 Emissions of Criteria Pollutants and Volatile Organic Compounds from DuPage County and Argonne Sources in 2002

\begin{tabular}{|c|c|c|c|}
\hline \multirow[b]{2}{*}{ Air Pollutant } & \multirow{2}{*}{$\begin{array}{c}\text { DuPage County } \\
\text { Emissions } \\
\text { (tons/yr) }^{\mathrm{a}, \mathrm{b}} \\
\end{array}$} & \multicolumn{2}{|c|}{ Argonne Emissions } \\
\hline & & $(\text { tons/yr) })^{\mathrm{b}, \mathrm{c}}$ & $\%$ of DuPage County \\
\hline $\mathrm{SO}_{2}$ & 335.5 & 99.50 & 29.7 \\
\hline $\mathrm{NO}_{\mathrm{x}}$ & 2,127.6 & 134.29 & 6.3 \\
\hline $\mathrm{CO}$ & $1,732.7$ & 50.99 & 2.9 \\
\hline VOCs & $2,020.4$ & 1.45 & 0.07 \\
\hline $\mathrm{PM}_{10}$ & 861.8 & 1.70 & 0.2 \\
\hline $\mathrm{PM}_{2.5}$ & $\mathrm{NA}^{\mathrm{d}}$ & 0.9963 & NA \\
\hline $\mathrm{Pb}$ & NA & 0 & NA \\
\hline \multicolumn{4}{|c|}{ a Source: IEPA (2004). } \\
\hline \multicolumn{4}{|c|}{ 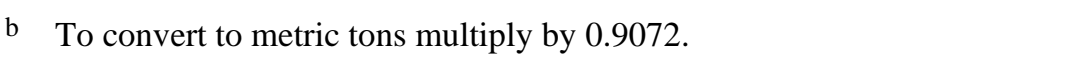 } \\
\hline \multicolumn{4}{|c|}{ c Source: Golchert and Kolzow (2004). } \\
\hline \multicolumn{4}{|c|}{ d $\quad$ NA = not available or not applicable. } \\
\hline
\end{tabular}


TABLE 4.5 National Ambient Air Quality Standards (NAAQS), Illinois State Ambient Air Quality Standards (SAAQS), Maximum Allowable Increments for Prevention of Significant Deterioration (PSD), and Highest Background Levels (1999-2003) Representative of Argonne National Laboratory

\begin{tabular}{|c|c|c|c|c|c|c|c|}
\hline \multirow[b]{2}{*}{ Pollutant } & \multirow[b]{2}{*}{$\begin{array}{c}\text { Averaging } \\
\text { Time }\end{array}$} & \multicolumn{2}{|c|}{ NAAQSa/Illinois SAAQS } & \multicolumn{2}{|c|}{$\begin{array}{c}\text { PSD Increment } \\
\left(\mu \mathrm{g} / \mathrm{m}^{3}\right)\end{array}$} & \multicolumn{2}{|c|}{ Highest Background Level } \\
\hline & & Standard Value & Standard Type ${ }^{\mathrm{b}}$ & Class I & Class II & Concentration (\%) & Location (Year) \\
\hline \multirow[t]{3}{*}{$\mathrm{SO}_{2}$} & 3 hours & $0.5 \mathrm{ppm}^{\mathrm{d}}\left(1,300 \mu \mathrm{g} / \mathrm{m}^{3}\right)$ & S & 25 & 512 & 0.168 ppm (34) & Lemont (1999) \\
\hline & 24 hours & $0.14 \mathrm{ppm}\left(365 \mu \mathrm{g} / \mathrm{m}^{3}\right)$ & $\mathrm{P}$ & 5 & 91 & 0.034 ppm (24) & Lemont (1999) \\
\hline & Annual & $0.030 \mathrm{ppm}\left(80 \mu \mathrm{g} / \mathrm{m}^{3}\right)$ & $\mathrm{P}$ & 2 & 20 & 0.006 ppm (20) & Lemont (2001) \\
\hline $\mathrm{NO}_{2}$ & Annual & $0.053 \mathrm{ppm}\left(100 \mu \mathrm{g} / \mathrm{m}^{3}\right)$ & $\mathrm{P}, \mathrm{S}$ & 2.5 & 25 & 0.028 ppm (53) & Cicero (2001) \\
\hline \multirow[t]{2}{*}{$\mathrm{CO}$} & 1 hour & 35 ppm (40 mg/m³) & $\mathrm{Pe}^{\mathrm{e}}$ & $-^{\mathrm{f}}$ & - & 6.8 ppm (19) & Maywood (1999) \\
\hline & 8 hours & 9 ppm $(10$ mg/m³) & $\mathrm{P}^{\mathrm{e}}$ & - & - & $5.1 \mathrm{ppm}(57)$ & Maywood (1999) \\
\hline \multirow{2}{*}{$\mathrm{O}_{3}$} & 1 hour & $0.12 \mathrm{ppm}\left(235 \mu \mathrm{g} / \mathrm{m}^{3}\right)$ & $\mathrm{P}, \mathrm{S}$ & - & - & 0.110 ppm (92) & Lemont (2002) \\
\hline & 8 hoursg & $0.08 \mathrm{ppm}\left(157 \mu \mathrm{g} / \mathrm{m}^{3}\right)$ & $\mathrm{P}, \mathrm{S}$ & - & - & $0.084 \mathrm{ppm}(101)^{\mathrm{h}}$ & Lemont (1999) \\
\hline \multirow[t]{2}{*}{$\mathrm{PM}_{10}$} & 24 hours & $150 \mu \mathrm{g} / \mathrm{m}^{3}$ & $\mathrm{P}, \mathrm{S}$ & 8 & 30 & $77 \mu \mathrm{g} / \mathrm{m}^{3}(51)^{\mathrm{i}}$ & Summit (2000) \\
\hline & Annual & $50 \mu \mathrm{g} / \mathrm{m}^{3}$ & $\mathrm{P}, \mathrm{S}$ & 4 & 17 & $34 \mu \mathrm{g} / \mathrm{m}^{3}(68)$ & Summit (1999) \\
\hline $\mathrm{PM}_{2.5^{\mathrm{g}}}^{\mathrm{g}}$ & 24 hours & $65 \mu \mathrm{g} / \mathrm{m}^{3}$ & $\mathrm{P}, \mathrm{S}$ & - & - & $37 \mu \mathrm{g} / \mathrm{m}^{3}(57)^{\mathrm{j}}$ & Naperville (2001) \\
\hline $\mathrm{Pb}$ & Calendar quarter & $1.5 \mu \mathrm{g} / \mathrm{m}^{3}$ & $\mathrm{P}, \mathrm{S}$ & - & - & $0.08 \mu \mathrm{g} / \mathrm{m}^{3}(5)$ & Summit (2003) \\
\hline
\end{tabular}

a 40 CFR Part 50 has detailed information on how attainment is determined and on the reference method for monitoring.

b $\quad \mathrm{P}=$ primary standards that set limits to protect public health; $\mathrm{S}=$ secondary standards that set limits to protect welfare.

c Values in parentheses are monitored concentrations as a percentage of NAAQS.

d $\quad$ ppm = part(s) per million.

e The State of Illinois has a secondary standard with the same value as the primary standard.

f A dash indicates that no standard exists.

$\mathrm{g}$ The State of Illinois has not adopted an 8-hour $\mathrm{O}_{3}$ standard or any $\mathrm{PM}_{2.5}$ standards at this time.

h The 4th highest.

i The 2nd highest.

j The 98th percentile.

Sources: 40 CFR Part 50; IEPA (2004); 40 CFR 52.21; EPA (2004). 
and annual $\mathrm{PM}_{2.5}$ concentrations, whose formation and transport is a regional issue, are a little over their standards in the Argonne area. In particular, at many monitoring stations in Illinois, the annual $\mathrm{PM}_{2.5}$ concentration either approaches or is over its standard.

Prevention of significant deterioration (PSD) regulations (40 CFR 52.21) limit the maximum allowable incremental increases in ambient concentrations of $\mathrm{SO}_{2}, \mathrm{NO}_{2}$, and $\mathrm{PM}_{10}$ above established baseline levels, as shown in Table 4.5. In 1975, the EPA developed a classification system as a part of the PSD program, which would allow some economic development in clean air areas (either attainment or unclassified areas) and still protect air quality from significant deterioration. Class I areas, including National Parks and Wilderness Areas, are specifically designated areas in which degradation of air quality is severely restricted under the Clean Air Act; Class II areas would allow moderate air quality deterioration. The PSD regulations, which are designed to protect ambient air quality in Class I and Class II attainment areas, apply to major new sources and major modifications to existing sources. No PSD Class I Area exists in the State of Illinois, and the nearest PSD Class I Area is located more than $311 \mathrm{mi}$ (500 km) away from the Argonne site.

\subsection{NOISE}

The Noise Control Act of 1972, with its subsequent amendments (Quiet Communities Act of 1978, 42 USC $\S \S 4901-4918$ ), delegates to the states the authority to regulate environmental noise and directs government agencies to comply with local community noise statues and regulations. The State of Illinois is one of the few states with quantitative noise-limit regulations (Illinois Noise Regulations, Title 35) for nonimpulsive sound (Table 4.6).

The EPA guideline recommends a day-night sound level $\left(\mathrm{L}_{\mathrm{dn}}\right.$ or $\left.\mathrm{DNL}\right)$ of $55 \mathrm{~dB}(\mathrm{~A})$, which is sufficient to protect the public from the effect of broadband environmental noise in typically quiet outdoor and residential areas (EPA 1974). $\mathrm{L}_{\mathrm{dn}}$ or DNL is the day-night A-weighted equivalent sound level, averaged over a 24-hour period, with a 10-dB penalty artificially added to the nighttime (10 p.m.-7 a.m.) sound level to account for noise-sensitive activities (e.g., sleep) during these hours. $\mathrm{dB}(\mathrm{A})$ is a unit of weighted sound-pressure level, measured by the use of the metering characteristics and the A-weighting specified in the American National Standard Specification for Sound Level Meters, ANSI S1.4-1983, and in Amendment S1.4A-1985 (Acoustical Society of America 1983, 1985). These levels are not regulatory goals, but they are "intentionally conservative to protect the most sensitive portion of the American population” with “an adequate margin of safety.” For protection against hearing loss in the general population from nonimpulsive noise, the EPA guidelines recommend an $\mathrm{L}_{\mathrm{eq}}$ of $70 \mathrm{~dB}(\mathrm{~A})$ or less over a 40 -year period. Leq is the equivalent steady sound level that, if continuous during a specific time period, would represent the same total acoustic energy as the actual time-varying sound. For example, $\mathrm{L}_{\mathrm{eq}}(1-\mathrm{h})$ is the 1-hour equivalent sound level.

The Argonne site is surrounded by forest preserve, and there are residential and commercial developments around the preserve. The major source of noise around the Argonne site is I-55, which runs southwest-northeast about $1,450 \mathrm{~m}$ (0.9 mi) north of the HTRL site. To 
TABLE 4.6 State of Illinois Sound Emission Standards ${ }^{a}$

\begin{tabular}{|c|c|c|c|c|c|c|c|c|c|}
\hline \multirow{4}{*}{$\begin{array}{c}\text { Octave- } \\
\text { Band Center } \\
\text { Frequency } \\
(\mathrm{Hz})\end{array}$} & \multicolumn{9}{|c|}{ Allowable Octave-Band Sound Pressure Levels (dB) of Sound Emitted to any Receiving: } \\
\hline & \multicolumn{6}{|c|}{ Class A Land from: } & & & \\
\hline & \multicolumn{3}{|c|}{ Daytime } & \multicolumn{3}{|c|}{ Nighttime } & \multicolumn{3}{|c|}{ Class B Land from: } \\
\hline & $\begin{array}{c}\text { Class C } \\
\text { Land }\end{array}$ & $\begin{array}{c}\text { Class B } \\
\text { Land }\end{array}$ & $\begin{array}{c}\text { Class A } \\
\text { Land }\end{array}$ & $\begin{array}{c}\text { Class C } \\
\text { Land }\end{array}$ & $\begin{array}{c}\text { Class B } \\
\text { Land }\end{array}$ & $\begin{array}{c}\text { Class A } \\
\text { Land }\end{array}$ & $\begin{array}{c}\text { Class C } \\
\text { Land }\end{array}$ & $\begin{array}{c}\text { Class B } \\
\text { Land }\end{array}$ & $\begin{array}{c}\text { Class A } \\
\text { Land }\end{array}$ \\
\hline 31.5 & 75 & 72 & 72 & 69 & 63 & 63 & 80 & 79 & 72 \\
\hline 63 & 74 & 71 & 71 & 67 & 61 & 61 & 79 & 78 & 71 \\
\hline 125 & 69 & 65 & 65 & 62 & 55 & 55 & 74 & 72 & 65 \\
\hline 250 & 64 & 57 & 57 & 54 & 47 & 47 & 69 & 64 & 57 \\
\hline 500 & 58 & 51 & 51 & 47 & 40 & 40 & 63 & 58 & 51 \\
\hline 1,000 & 52 & 45 & 45 & 41 & 35 & 35 & 57 & 52 & 45 \\
\hline 2,000 & 47 & 39 & 39 & 36 & 30 & 30 & 52 & 46 & 39 \\
\hline 4,000 & 43 & 34 & 34 & 32 & 25 & 25 & 48 & 41 & 34 \\
\hline 8,000 & 40 & 32 & 32 & 32 & 25 & 25 & 45 & 39 & 32 \\
\hline
\end{tabular}

a No person shall cause or allow the emission of sound that exceeds any allowable octave-band sound pressure level specified in the above table from any property-line-noise-source located on noise-emitting land to receiving land. Land is classified according to land use in terms of the Standard Land Use Coding Manual (SLUCM) codes. Class A land is the least noisy environment (e.g., residential areas), while Class $\mathrm{C}$ land is the most noisy environment (e.g., industrial areas).

Source: Illinois Pollution Control Board (2004).

the east and west lie the arterial roads (Cass Avenue and Lemont Road, respectively) that lead to the highway.

Currently, no major noise-producing sources exist on site, except for temporary truck traffic and heavy equipment operations (Hinterman 2004). No off-site sensitive noise receptors (e.g., hospital, schools) are located near the site. The closest sensitive receptor is the Argonne Child Development Center on the Argonne property, about $1.6 \mathrm{~km}(1.0 \mathrm{mi})$ east of the proposed HTRL site. The nearest residence is located about $970 \mathrm{~m}(0.6 \mathrm{mi})$ north-northwest of the proposed HTRL site.

Daytime ambient sound levels around the Argonne site were measured in September 2001 near Argonne's boundary and at the nearest residential area, which are $0.45 \mathrm{mi}$ $(720 \mathrm{~m})$ and $0.33 \mathrm{mi}(530 \mathrm{~m})$ from I-55, respectively (Hinterman 2001). Results showed that noise levels are relatively high due to heavy traffic from I-55, averaging $55 \mathrm{~dB}(\mathrm{~A})$ near the Argonne boundary and $60 \mathrm{~dB}(\mathrm{~A})$ at the nearby residential area. Considering the distance to I-55, the daytime noise level at the proposed HTRL site would be about $50 \mathrm{dBA}$. Nighttime ambient noise levels would typically be about $10 \mathrm{~dB}(\mathrm{~A})$ lower than daytime levels because there is less traffic then. 


\subsection{WASTE MANAGEMENT}

The only Argonne waste management facilities related to HTRL operations are wastewater facilities. A discussion of the University's solid waste management, including hazardous waste, is presented in Section 3. Sanitary wastewater and laboratory wastewater are collected, treated, and discharged separately by the Argonne sanitary wastewater treatment plant and the Argonne laboratory wastewater treatment plant. These treatment plants discharge to Sawmill Creek near the southeastern Argonne boundary at Outfall 001. The volume of wastewater discharged from these plants in 2002 averaged 0.29 million gal/d $(1.11 \mathrm{million} \mathrm{L/d})$ for the sanitary wastewater and 0.51 million gal/d (1.95 million L/d) for the laboratory process wastewater. As described in Section 4.3.1 (Surface Water), the IEPA regulates the water quality of the discharges from the wastewater treatment plants.

\subsection{LAND USE}

The HTRL site is in a campus-like setting, where buildings and facilities are interspersed with woodlands, grassland, wetlands, and streams. Argonne is surrounded by the Waterfall Glen Forest Preserve of the DuPage County Forest Preserve District. This forest preserve contains trails for hiking, biking, horse riding, cross-country navigation sports, and cross-country skiing. Argonne maintains Argonne Park, a picnic and recreational area east of the Argonne site that also contains the Argonne Child Development Center, a day-care center for the children of DOE, the University, and Argonne employees.

\subsection{VISUAL ENVIRONMENT}

The visual environment of the HTRL site is a mixture of parking lots, grassy areas, large oak trees, second-growth woods, and a utility corridor with aboveground steam pipes. From Outer Circle Drive, the HTRL site appears as a grassy area beyond several parking lots. From 94th Street to the north, the site is obscured by woods. From Railroad Drive, the site appears as a grassy area beyond a fringe of woods. The site is visible from Eastwood Drive to a point on the site beyond the aboveground steam pipes running at the edge of the road. From the HTRL site, one can see the parking lots near Building 202, Building 202 itself, Building 201, and the steam pipes along Outer Circle Drive.

\subsection{TERRESTRIAL BIOTA}

The 1,500-acre (608-ha) Argonne site includes approximately 850 acres (344 ha) of developed areas (including facilities, roadways, parking lots, lawns) and 650 acres (264 ha) of relatively undisturbed woodlands, prairies, old fields, and wetlands. The site is surrounded by the Waterfall Glen Forest Preserve, which contains habitat types similar to the undeveloped habitats present on Argonne. The 2,240-acre (907-ha) preserve is managed by the Forest Preserve District of DuPage County. 
Habitats on the Argonne site include deciduous forest, coniferous forest, woodland, savanna, old field, prairie, wetland (marsh and forested wetland), and open water. Large areas of mowed lawn are present in developed areas of the site. Mowed lawn, woodland, savanna, and old field are the most common habitat types. The dominant species of woodland and savanna communities are white oak, bur oak, red oak, and black oak. The woodlands and savannas represent remnant native natural communities. Coniferous forest, scattered throughout the site, consists of stands of jack pine, white pine, and red pine that were planted in the 1950s. Old field habitats are dominated by non-native grasses and forbs, including many invasive species, with infrequent occurrences of native prairie grass and forb species. Mowed lawns occur in the facility areas, Argonne Park area, and roadsides. Under Executive Order (E.O.) 13148, "Greening the Government through Leadership in Environmental Management," issued April 21, 2000, federal agencies are required to avoid or minimize adverse impacts of proposed actions on existing communities of native plants and natural habitats.

The many habitats at Argonne support a high diversity of wildlife species. Common mammal species include striped skunk, coyote, raccoon, opossum, woodchuck, eastern chipmunk, fox squirrel, muskrat, deer mouse, short-tailed shrew, and white-tailed deer. European fallow deer also occur on the site. American toad, western chorus frog, and green frog are common amphibians, while brown snake and eastern garter snake are common reptiles. Common bird species include Canada goose, mallard, mourning dove, blue jay, northern cardinal, American crow, American robin, European starling, common grackle, common yellowthroat, and song sparrow.

Terrestrial habitats in the vicinity of the proposed HTRL building site include remnant communities of native plant species as well as plant communities that have developed as a result of human disturbance. The northern portion of the site supports a high-quality native deciduous woodland, consisting of bur oak, white oak, red oak, and black oak. Several large bur oaks exceed 39 in. $(100 \mathrm{~cm})$ in diameter. Many oaks in this woodland are estimated to be more than 200 years old, indicating a remnant natural woodland community predating European settlement of the region. The understory includes wild black cherry, common buckthorn (a non-native invasive species), slippery elm, and shagbark hickory, as well as smaller individuals of the canopy oak species. Non-native bush honeysuckle is a shrub species occurring in much of the woodland. Herbaceous species include many common native woodland species, such as white trout lily, spring beauty, wild geranium, and toothwort, as well as species found in high-quality woodlands - green dragon, wood anemone, and rue anemone.

The central portion of the HTRL site consists of two communities that have developed following disturbance. They are made up of species that do not together form native community types. An old field community occupies the western portion of this area; it is composed of a mosaic of woody and herbaceous species frequently found in disturbed areas. Woody species include multiflora rose (non-native), bush honeysuckle (non-native), gray dogwood, blackberry, poison ivy, honey locust saplings, and mature trees of downy hawthorn. Herbaceous species include non-natives - crown vetch, garlic mustard, tall fescue, and orchard grass - as well as natives - goldenrod, agrimony, ironweed, and wild bergamot. A large bur oak is located in the western part of this community. The eastern portion of this area supports a dense community of trees and shrubs. The dominant trees are wild black cherry and downy hawthorn; both are native 
species. Common buckthorn, bush honeysuckle, multiflora rose, oriental bittersweet, and orchard grass are frequent non-native species. Blackberry, poison ivy, and woodland knotweed are frequently occurring native species.

The southern portion of the HTRL site has been mowed occasionally and supports predominantly non-native herbaceous species. Crown vetch, Canada thistle, field bindweed, and smooth brome are the dominant species in this area.

\subsection{WETLANDS, FLOODPLAINS, AND AQUATIC BIOTA}

A survey of wetlands on the Argonne site was conducted in 1993 (Van Lonkhuyzen and LaGory 1994). Thirty-five jurisdictional wetlands, totaling 44.6 acres (18.1 ha), were identified and delineated. Wetland types on the Argonne site include floodplain or riparian wetlands, forested wetlands, and marshes. Some wetlands have been formed as a result of human or beaver activities. Several high-quality, relatively undisturbed wetlands occur on the Argonne site; however, a number of wetlands are relatively disturbed and generally support degraded plant communities that contain invasive species and have low species diversity. Invasive plant species, such as common reed and reed canary grass, are especially prevalent in disturbed wetlands and form dense colonies in several areas. Disturbance, pollution, alteration of natural hydrologic regimes, and increased sedimentation generally favor the colonization and spread of invasive species. Impacts to wetlands are regulated under Section 404 of the Clean Water Act (CWA). In addition, E.O. 11990, "Protection of Wetlands," issued May 24, 1977, requires federal agencies to minimize the destruction, loss, or degradation of wetlands and to preserve and enhance the natural and beneficial values of wetlands. NIH complies with this E.O. through its policies and procedures. DOE implementation of this E.O. is included in 10 CFR Part 1022.

Within the Argonne site, 100-year floodplains are located along Sawmill Creek, Freund Brook, Wards Creek, and a small unnamed creek running through Argonne Park and the eastern portion of the Argonne site (Federal Emergency Management Agency [FEMA] 1982; ANL 1998). No 100-year floodplains are located in or adjacent to the proposed HTRL site. The 100-year floodplain of North Freund Brook is located south of Eastwood Drive, approximately $150 \mathrm{ft}$ (46 m) south of the HTRL project site.

Aquatic habitats on the Argonne site include streams (primarily Sawmill Creek and the north and south branches of Freund Brook), ditches, and ponds. Fish species occurring on the Argonne site include goldfish, creek chub, golden shiner, stoneroller, black bullhead, bluegill, green sunfish, orange-spotted sunfish, largemouth bass, and black crappie. Aquatic invertebrates include larvae of numerous insect species, such as blackflies, midges, mosquitoes, caddisflies, and dragonflies, as well as crayfish.

A small stream extends along the northern margin of the HTRL site and drains toward the east, entering a culvert under Outer Circle Drive. The stream is located in a broad swale within the deciduous woodland. The stream margin and adjacent swale areas support a wetland community. False nettle and swamp buttercup, both native species, are the dominant herbaceous species, while garlic mustard, a non-native species, occurs frequently. 
Much of the northern portion of the HTRL site lies within the watershed of Wetland 101 (Van Lonkhuyzen and LaGory 1994), which is located $240 \mathrm{ft}$ (73 m) east of Outer Circle Road. This wetland receives surface water flows from the stream along the northern margin of the HTRL site. Wetland 101 is a high-quality forested wetland, approximately 0.3 acre (0.1 ha) in size, and is inundated throughout the early part of the growing season. Water sources for this wetland are shallow groundwater flows (which result in a seasonally high water table) as well as surface flows. Surface water levels in the wetland recede gradually during late spring and early summer. Surface water is generally absent by late summer. The dominant canopy species are red ash, cottonwood, American elm, and box elder. False nettle, white grass, clearweed, and smartweed are the dominant herbaceous species. All of the dominant species in Wetland 101 are native species.

The southern portion of the HTRL site lies within the watershed of the North Branch of Freund Brook, which is located about $45 \mathrm{ft}(14 \mathrm{~m})$ south of Eastwood drive. This stream flows to the east and, after joining the South Branch of Freund Brook at Lower Freund Pond, is a tributary of Sawmill Creek.

Wetland 205 lies approximately $400 \mathrm{ft}(120 \mathrm{~m})$ north of the HTRL site. The primary water source for this 0.4 -acre (0.2-ha) wetland is storm sewer drainage. It also receives surface runoff from the immediately surrounding area. The HTRL site lies outside the watershed of Wetland 205.

\subsection{THREATENED AND ENDANGERED SPECIES}

No federal listed threatened or endangered species are known to occur on the Argonne site (Tuggle 1996), and no critical habitat of federal listed species is located on the Argonne site. Several listed species have been reported from the nearby Waterfall Glen Forest Preserve. The Hine's emerald dragonfly (Somatochlora hineana), federal listed and state listed as endangered, occurs in wetlands associated with calcarious seeps, from the dolomite aquifer, along the Des Plaines River floodplain, about $1 \mathrm{mi}(1.6 \mathrm{~km})$ south of Argonne. Suitable habitat for the dragonfly does not occur on the Argonne site (DOE 1990). The leafy prairie clover (Dalea foliosa), also federal listed and state listed as endangered, is associated with dolomite prairie remnants in the Des Plaines River valley. Two populations of this species have been planted in Waterfall Glen Forest Preserve. Dolomite prairie habitat does not occur on the Argonne site. The Indiana bat (Myotis sodalis), federal listed and state listed as endangered, may occur in the Argonne region, as indicated by an unconfirmed capture in Waterfall Glen Forest Preserve (DOE 1990). The Indiana bat may use trees with exfoliating bark as summer roosting sites, particularly trees in forested areas near open water. A planted population of the lakeside daisy (Hymenoxys herbacea), federal listed as threatened and state listed as endangered, is also located in the Waterfall Glen Forest Preserve. The bald eagle (Haliaeetus leucocephalus), federal listed

and state listed as threatened, piping plover (Charadrius melodus), federal listed and state listed as endangered, and least tern (Sterna antillarum), federal listed and state listed as endangered, could occur in the Argonne area as extremely rare nonbreeders during migration or in winter. 
Several species listed by the State of Illinois occur in DuPage County. The black-crowned night heron (Nycticorax nycticorax), listed as endangered, and Kirtland's snake (Clonophis kirtlandii), listed as threatened, have been observed on the Argonne site. The black-crowned night heron has been observed at many open water areas at Argonne. Kirtland's snake has been found in the southwestern portion of the Argonne site. No other state listed species are known to occur at Argonne, although the osprey (Pandion haliaetus), listed as endangered, shadbush (Amelanchier interior), listed as threatened, slender sandwort (Arenaria patula), listed as threatened, Tuckerman's sedge (Carex tuckermanii), listed as endangered, white lady's slipper (Cypripedium candidum), listed as threatened, glade quillwort (Isoetes butleri), listed as endangered, and marsh speedwell (Veronica scutellata), listed as threatened, occur in the vicinity of Argonne. In addition, the Blanding's turtle (Emydoidea blandingii), state listed as threatened, also occurs in DuPage County.

No federal listed or state listed species are known to occur on or near the proposed HTRL site. Habitats in the central and southern portions of the site are predominantly disturbed and generally would not provide suitable habitat for listed species. Although wetlands (such as marshy meadows, woodland ponds, and open swamp lands) are the preferred habitat for Kirtland's snake, this species may occasionally be found in other areas. The presence of this species on the HTRL site would be unlikely because of the availability of preferred habitat elsewhere in the vicinity.

\subsection{CULTURAL RESOURCES}

Cultural resources include archaeological sites and historic structures and features that are protected under the National Historic Preservation Act of 1966, as amended. Cultural resources also include traditional cultural properties that are important to a community's practices and beliefs and are necessary to maintain the community's cultural identity. Cultural resources that meet the eligibility criteria for listing on the National Register of Historic Places (NRHP) are considered "significant" resources and must be taken into consideration during the planning of federal projects. Federal agencies are also required to consider the effects of their actions on sites, areas, and other resources (e.g., plants) that are of religious significance to Native Americans as established under the American Indian Religious Freedom Act. Native American graves and burial grounds are protected by the Native American Graves Protection and Repatriation Act.

\subsubsection{Prehistoric Context}

Argonne is located in DuPage County on the bluffs overlooking the Des Plaines River. Prehistoric occupation of DuPage County covers every known archaeological phase for eastern North America. This includes the Paleoindian Period (10,000 to 8,000 B.C.), Archaic Period (8,000 to 1,500 B.C.), Woodland Period (1,500 B.C. to A.D. 1,000), Mississippian Period (A.D. 1,000 to A.D. 1,600), and Contact or Historic Period (1,600 to present) (Curtis and Berlin 1980). Each time period is indicative of a social and/or technological advance or change. 


\subsubsection{Ethnohistoric Context}

In 1804, the land around Argonne was claimed by the Potawatami, Ottawa, and Chippewa Tribes from the Sauk and Fox. The Potawatami, Ottawa, and Chippewa lands south from a line drawn straight west from Lake Michigan were ceded to the United States by treaty in 1816. This treaty also ceded land along the Illinois and Des Plaines Rivers (Alvord 1922, page 449). The remainder of these Tribes lands in northern Illinois were ceded to the Americans in 1836 (Tanner 1987, page 159).

\subsubsection{Historic Context}

Northeast Illinois was first visited by Europeans in the 1670s. Settlement in the Chicago area was sparse until the U.S. government approved construction of the Illinois and Michigan Canal, which connected Lake Michigan with the Mississippi. Construction on the canal began in 1836 and was completed in 1848. Argonne lies within the corridor for the Illinois and Michigan Canal.

In 1834, the community of Cass was founded as a stagecoach stop along the ChicagoJoliet Road on what would become the Argonne site. The canal and later the railroads gave the farmers here access to markets. This situation persisted into the 1940s.

\subsubsection{Argonne National Laboratory}

Argonne has its foundations in the Metallurgical Laboratory (Met Lab) at the University of Chicago where, in 1942, the first controlled nuclear chain reaction was achieved. At the close of World War II, Congress passed the Atomic Energy Act of 1946, which created the national laboratory system. Argonne was the first national laboratory formed under this act.

Argonne is located $27 \mathrm{mi}(43 \mathrm{~km})$ southwest of Chicago, Illinois. In 1947, Argonne was selected as the primary reactor center for the Atomic Energy Commission. The mission of the laboratory changed with the formation of DOE in 1980. By the 1990s, reactor work had all but ceased; environmental, nuclear waste cleanup and processing, and high-energy physics projects became the major funding sources.

\section{Known Archaeological Resources}

The entire Argonne facility has been surveyed for archaeological resources. The surveys have identified 46 archaeological sites. The sites discovered consist of prehistoric sites ranging in age from the Archaic Period (8,000-1,500 B.C.) to potentially the Mississippian Period (A.D. 1000-1600) and Historic Era farmsteads. Four of the archaeological sites identified at Argonne are eligible for listing on the NRHP, 21 sites are considered ineligible, and 21 sites have yet to be evaluated. 
Site 11-Du-210 (ANL 40) was previously identified during a survey for the Building 201 parking lot located to the west of the HTRL project area (Curtis et al. 1989). The site was located on the east side of the parking lot, and its eastern boundary extended into the project area. The site was described as a lithic scatter that included a Raddatz point, tool fragments, utilized scrapers, and flakes. Raddatz points have been dated to the middle Archaic period (6,000-3,000 years before present). Phase II investigations failed to identify any subsurface features. For a site to be determined eligible for listing on the NRHP, subsurface remains generally need to be present. It is the subsurface remains that would be protected. Therefore, the site was determined to be ineligible for listing on the NRHP. All evidence of the site appears to have been obliterated by the construction of the Building 201 parking lot.

\section{Known Traditional Properties}

No known traditional cultural properties have been identified within Argonne to date.

\section{Known Historic Structures}

Argonne was established in 1946 as the first national laboratory. A sitewide historic building inventory was developed for Argonne (Wescott and O’Rourke 2001). The survey identified seven individual buildings and two historic districts, the Main Campus and Freund Lodge, that are potentially eligible for listing on the NRHP. Three facilities — the Alpha Gamma Hot Cell Facility in Building 212, the Atomic Energy Commission regional bomb shelter, and the M Wing Caves in Building 200 - are also potentially eligible for listing on the NRHP because of their engineering value.

Building 202 (biological sciences) and Building 201 (DOE and Argonne administration) are located adjacent to the location proposed for the HTRL. Building 202 is considered eligible for listing on the NRHP as a contributing part of the Main Campus Historic District. It was built in 1952 as part of the original suite of buildings constructed at Argonne. Building 201, built in 1982, is currently not considered eligible for listing on the NRHP. However, the building was designed by the famous architect Helmut Jahn and has the potential to be historically significant in 2032 when it reaches 50 years of age.

\subsection{TRANSPORTATION}

The Argonne area is served by air, rail, and highway transportation systems. In addition, bulk materials are shipped near the Argonne site along the Ship and Sanitary Canal between the Illinois River and Lake Michigan. Entrances to the Argonne site are at the North Gate on Northgate Road, which connects to Cass Avenue, East Gate on Cass Avenue (only during the morning and evening commute) and the West Gate on Westgate Road, which connects to Lemont Road. Both entrances are controlled by security guards and locking gates. Currently, approximately $85 \%$ of Argonne workers commute to work from Cook, DuPage, and Will Counties (Stepuszek 2005). 
Minor traffic congestion occurs at the intersection of Westgate Road and Lemont Road and at the North Gate during the morning commute. Deliveries to Argonne enter the site by a delivery gate from Cass Avenue. Deliveries for the HTRL would be directed to the HTRL without passing through Argonne Shipping and Receiving. I-55 is within a mile of both Northgate and Westgate Roads. The Argonne site is serviced by a network of paved, two-lane roads. Outer Circle Drive is the major transportation loop in the northern part of the Argonne site. Both Westgate and Northgate Roads connect with Outer Circle Drive. The HTRL site is near the intersection of Eastwood Drive and Outer Circle Drive.

\subsection{UTILITIES AND SERVICES}

Electrical service to Argonne is provided by Exelon, formerly known as Commonwealth Edison. Argonne is a member of the ComEd (Exelon) energy cooperative, which has a voluntary agreement to curtail energy use during periods of peak energy demand. Argonne also has an on-site central heating plant, which is a boiler facility for producing heat and steam for the site. Argonne operates two water treatment plants: the sanitary waste treatment system and the laboratory waste treatment system. These discharge to Sawmill Creek at the southeastern Argonne boundary.

Utility services are located near the HTRL site along Eastwood Drive and along Outer Circle Drive. Redundant sources of power, steam, and water are available to the HTRL site.

\subsection{ENVIRONMENTAL JUSTICE}

On February 11, 1994, the President of the United States issued E.O. 12898, "Federal Actions to Address Environmental Justice in Minority and Low-Income Populations.” This E.O. mandates that federal agencies incorporate environmental justice considerations as part of their missions. It directs federal agencies to address, as appropriate, disproportionately high and adverse human health or environmental effects of their actions, programs, or policies on minority and low-income populations. The Order's accompanying cover memo specifically mentions NEPA, providing the opportunity to incorporate environmental justice as part of the NEPA process.

Approximately 8.7 million people live within census tracts located within a 50-mi (80-km) radius of Argonne, and approximately 184,000 people live within census tracts located within a 5-mi (8-km) radius of Argonne (Table 4.7). A 50-mi (80-km) radius area would include the potential extent of all possible adverse health and environmental effects, particularly those related to the dispersion and deposition of airborne material associated with accidental releases from the HTRL. Fifty-one percent of the $50-\mathrm{mi}(80-\mathrm{km})$ population and $24 \%$ of the $5-\mathrm{mi}(8-\mathrm{km})$ population are composed of minorities, as compared with the averages of $32.2 \%$ for Illinois, 14.2\% for Indiana, and 30.9\% for the nation (Figure 4.2). Ten and seven-tenths percent of the $50-\mathrm{mi}(80-\mathrm{km})$ population and $3.5 \%$ of the 5 -mi $(8-\mathrm{km})$ population are low-income, as compared with the Illinois average of $10.7 \%$, Indiana average of $9.5 \%$, and national average of $12.4 \%$ (Figure 4.3). The population located within a 5-mi $(8-\mathrm{km})$ radius of the proposed facility would 
not, therefore, be predominantly minority or low-income. Table 4.7 summarizes the distribution of minority and low-income populations for the area surrounding Argonne.

TABLE 4.7 Summary of the Distribution of Minority and LowIncome Populations Surrounding Argonne, 2000

\begin{tabular}{lrr}
\hline \multicolumn{1}{c}{ Population } & \multicolumn{1}{c}{$50 \mathrm{mi}$} \\
$(80 \mathrm{~km})$ & \multicolumn{1}{c}{$\begin{array}{c}5 \mathrm{mi} \\
(8 \mathrm{~km})\end{array}$} \\
\hline Total population & $8,705,854$ & 183,870 \\
& & \\
Minority population & $4,446,325$ & 44,830 \\
$\quad$ Native Americans or Alaska Natives & 23,026 & 259 \\
$\quad$ African Americans & $1,686,284$ & 10,427 \\
$\quad$ Hispanic origin & $1,462,388$ & 12,277 \\
$\quad$ Asians or Pacific Islanders and other race categories & $1,080,629$ & 18,898 \\
& & \\
Minority populations (\% of total) & $51 \%$ & $24 \%$ \\
Low-income population & 929,011 & 6,460 \\
& & \\
Low-income population (\% of total) & $10.7 \%$ & $3.5 \%$ \\
\hline
\end{tabular}




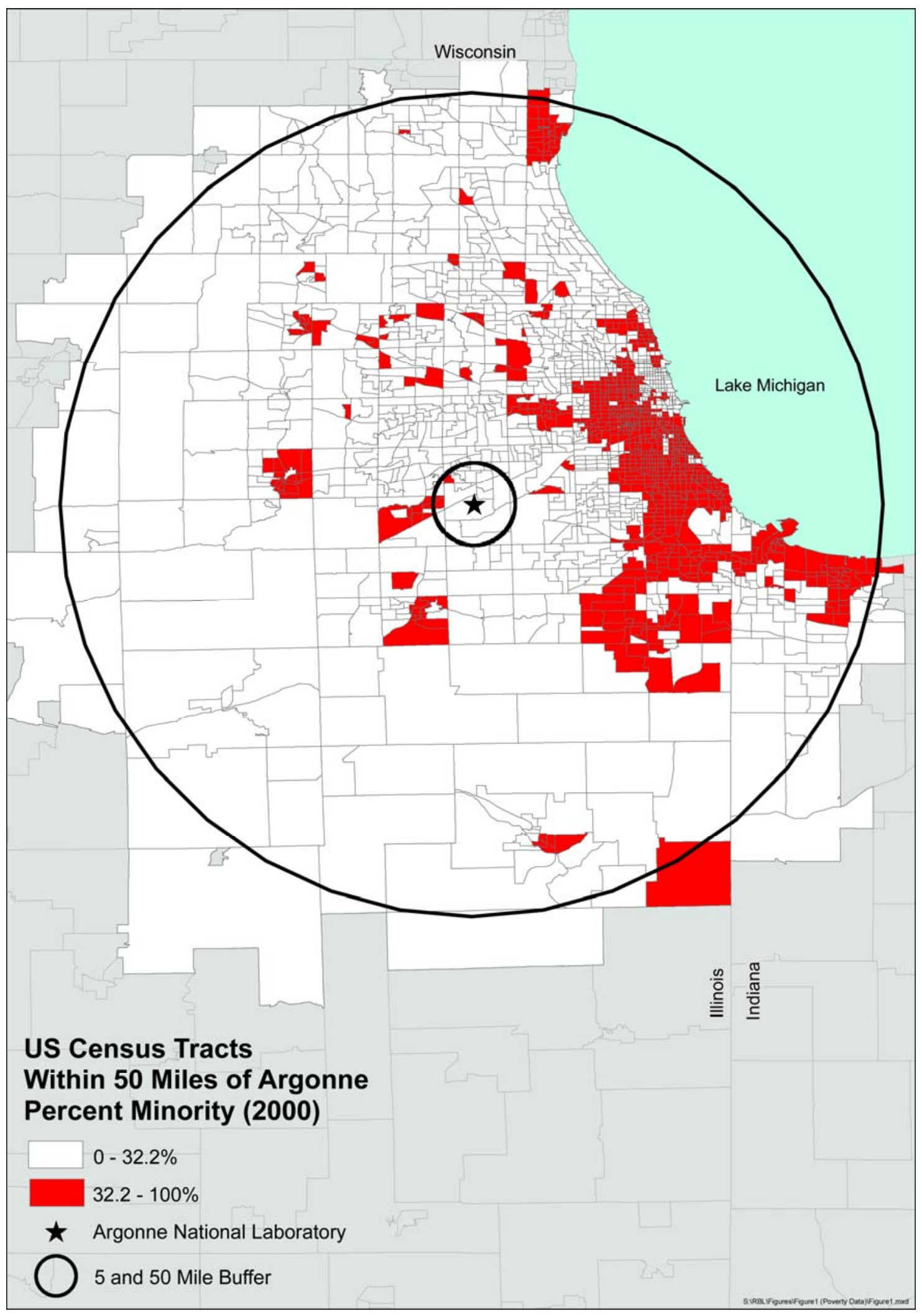

FIGURE 4.2 Minority Composition of Populations within 5 and $50 \mathrm{mi}$ (8 and $80 \mathrm{~km}$ ) of Argonne, Based on 2000 U.S. Census Data 


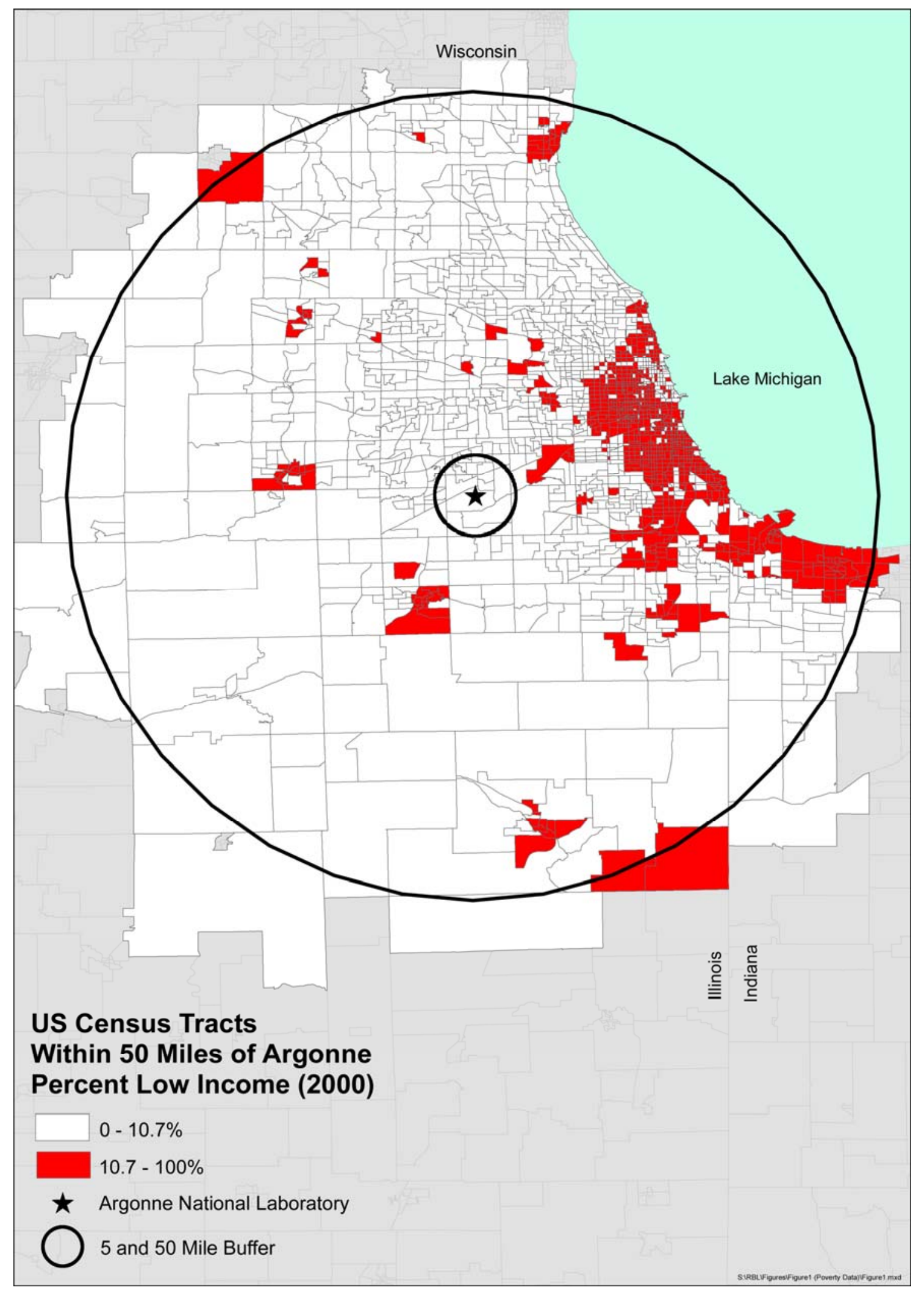

FIGURE 4.3 Low-Income Composition of Populations within 5 and 50 mi (8 and 80 km) of Argonne, Based on 2000 U.S. Census Data 


\section{ENVIRONMENTAL CONSEQUENCES}

\subsection{CONSTRUCTION AND ROUTINE OPERATIONS}

\subsubsection{Human Health}

The potential environmental consequences on human health and safety from construction and operation of the HTRL under the proposed action alternative are evaluated in this section. Two types of occupational impacts from routine operations are addressed: the industrial (physical hazard) risk and the potential risk to workers from exposure to chemical and biological agents. Impacts to human health and safety as a result of potential accidental releases are discussed in Section 5.2.

Operations, maintenance, and construction workers at any facility are subject to risks of injuries and fatalities from physical hazards. While such occupational hazards can be minimized when workers adhere to safety standards and use appropriate protective equipment, fatalities and injuries from on-the-job accidents can still occur. The use of best management practices (BMPs) to comply with OSHA regulations (e.g., 29 CFR Part 1926, "Safety and Health Regulations for Construction”) should reduce future fatality and injury incidence rates.

\section{Physical Hazards during Construction}

The U.S. Bureau of Labor Statistics (BLS) maintains statistics on the annual number of injuries and fatalities by industry type (National Safety Council [NSC] 2003). The incidence rates for the construction industry are 12.6 fatalities per 100,000 full-time workers and 4.0 losttime injuries per 100 full-time workers (defined as total lost workday cases).

Human health effects during site preparation and construction for the proposed BSL-3 laboratory would be the same as for any small single-story construction project at Argonne. The effects would be very localized and would affect only site workers or visitors to the site. There would be no public human health effects. Routine construction activities have the potential for exposing workers or site visitors to a number of common hazards including, for example:

- $\quad$ Biological hazards (e.g., poison ivy and insect stings);

- Electrical hazards (temporary electrical drops, excavations in areas with underground utilities, heavy-equipment lifting with nearby overhead utilities);

- Fire and explosion hazards (portable gasoline containers for generators and other gasoline-powered equipment, fuel transfers for on-site heavy equipment operation); 
- Physical hazards (slips/trips/falls, walking-working surfaces, powered handtool operation, pinch-points, hoisting, motor-vehicle operation, excavations, ladders, noise, heat stress, cold stress, sunburn, dust, and particulates).

These hazards would be reduced or eliminated by compliance with federal OSHA regulations (29 CFR 1910.12, 29 CFR 1926, 29 CFR 1990) and NFPA codes (NFPA 1997, 1998, 2000). University site inspectors and OSHA inspectors would verify that construction contractors are adhering to applicable health and safety standards by performing unannounced site visits. Adherence to the rules and regulations and completion of appropriate hazards training are expected to prevent any major adverse effects on construction workers.

Argonne workers would not be directly involved in the construction of the HTRL; Argonne worker involvement would be limited to utility hookups. Argonne workers are currently involved in similar activities on site. Because of the expected limited involvement of Argonne workers in the construction of the new building, only minor effects to these workers are anticipated.

The proposed action is expected to have no substantial effect on the health of any non-Argonne construction workers under normal operation conditions. Construction activities would take 12 months to complete, requiring an average of 100 FTEs per year. Construction workers would be actively involved in potentially hazardous activities such as heavy equipment operations, soil excavations, and the handling and assembly of various building materials. Appropriate personal protection measures would be a routine part of the construction activities (such as gloves, hard hats, steel-toed boots, eye shields, and ear plugs or covers). Therefore, no fatalities would be expected and only a small number of minor worker injuries might occur during construction of the HTRL.

\section{Physical Hazards during Operations}

The BLS maintains statistics on the annual number of injuries and fatalities by industry type (NSC 2003). It is assumed that, in general, the types of activities required of employees would be similar to those required of workers in the overall services industry (which includes research, development, and services).

The following incidence rates apply to the services industry: 1.3 fatalities per 100,000 full-time workers and 2.2 lost-time injuries per 100 full-time workers (defined as total lost workday cases). This is a conservative estimate when compared with the actual lost work time rate at the University, which is 0.72 (Beaudoin 2004). It is assumed that the HTRL would operate for 25 years, requiring an average of 30 FTEs per year. With compliance with OSHA regulations, state regulations, and University policies, on-the-job fatalities and injuries would be avoided. 


\section{Exposure to Hazardous, Toxic, and Infectious Materials and Agents}

Exposure to hazardous and toxic materials could potentially occur during the construction of the HTRL. However, it is expected that chemical exposures during construction would be routine and minimal and mitigated by using PPE and/or engineering controls to comply with OSHA permissible exposure limits (PELs) applicable to construction activities (U.S. Department of Labor [DOL] 1997).

It is expected that there would be no adverse health effects to noninvolved workers or the general public from chemical exposures during routine operations of the HTRL. Impacts to involved workers are not expected because of the preventive procedures that would be implemented. The workplace would be monitored to ensure that any airborne chemical concentrations are within applicable health standards that are protective of human health and safety. If planned work activities were likely to expose involved workers to chemicals, workers would be provided with appropriate protective equipment, as necessary.

HTRL operations would involve the use of infectious materials and agents capable of causing human disease and the use of laboratory animals that might be infected with biological agents that could be transmitted to humans. The inherent risks of these activities to laboratory (involved) workers, noninvolved workers, and the public would be mitigated by following the extensive engineering and work practice controls described in the BMBL (CDC and NIH 1999) and numerous other federal, state, and local regulations. Employing these and other guidelines, standards, practices, and procedures, together with the use of BSL-3 safety equipment and facility safety barriers, should result in a low potential risk of illness to laboratory workers from operations involving agents.

The BMBL describes combinations of standard and special microbiological practices, safety equipment, and facilities (including BSL-3) recommended for work with a variety of agents in various laboratory settings (CDC and NIH 1999). The recommendations are intended to provide guidance or a code of practice and to serve as a reference for constructing new laboratory facilities. However, the application of these recommendations to HTRL operations should also be based on a risk assessment of the special agents utilized and activities conducted. The risk assessment approach could be a job safety analysis or critical control point hazard analysis that would focus on developed standard practices for handling all agents, not just a specific agent (Sewell 1995). CDC/NIH guidance on the standard and special safety practices, equipment, and facilities that specifically apply to a BSL-3 laboratory is provided in Appendix A.

Impacts to involved workers from exposure to biological agents during routine operations are expected to be very low to nonexistent because of the engineering controls and work practices that would be used to contain and isolate agents, as discussed above. The effectiveness of these mitigation measures is demonstrated by the limited number of documented cases of laboratory-acquired illnesses (LAIs) during the past 10 years in biomedical laboratories throughout the United States (U.S. Army Medical Research and Materiel Command [USAMRMC] 2003; CDC and NIH 1999; Sewell 1995). In addition, regular medical monitoring 
would be provided for employees who worked with agents. Individuals in positions that required them to work with agents would also be able to volunteer to be given vaccines, if available.

Impacts to noninvolved workers or the general public from exposure to biological agents during routine laboratory operations are also not expected to occur. The risk of exposure to agents would be mitigated by adherence to BMBL requirements for engineering controls and work practices for biological containment (CDC and NIH 1999), as discussed above. There have been no instances of infection or disease resulting from the conduct of these types of activities in communities adjacent to facilities like the HTRL (NIH and U.S. Army Garrison 2003).

\subsubsection{Socioeconomics}

The socioeconomic impacts of constructing and operating the HTRL at Argonne were assessed for the three-county ROI. Impacts were measured in terms of employment and income. Impacts on population, housing, public services, and education were not assessed, since no in-migrant labor force is expected for either the construction phase or the operations phase of the project.

To calculate impacts, preliminary project construction and cost data were used (Hamm 2003, 2004). These data covered material and labor costs for project construction and operations and were used to calculate the direct economic impacts of the project. IMPLAN economic data (MIG, Inc. 2004) were then used to calculate the indirect impacts associated with project wage and salary and material procurement spending. IMPLAN is an input-output-based modeling tool that estimates employment and income multipliers for those sectors in the ROI in which HTRL labor and material expenditures would occur. The potential socioeconomic impacts from constructing and operating the HTRL at Argonne would be relatively small (Table 5.1).

\section{Construction}

Construction activities would create direct employment of approximately 100 jobs in the construction year and an additional 130 indirect jobs in the ROI. Construction activities would increase the annual average employment growth rate by less than 0.001 of a percentage point over the duration of construction. Facility employment and related wages and salaries would also produce about $\$ 10$ million of income in the year of construction.

\section{Operations}

Operational activities would create about 30 direct jobs annually and an additional 160 indirect jobs in the ROI. Facility employment and related wages and salaries would also produce about \$6 million in income during each year of operations. 
TABLE 5.1 Socioeconomic Impacts of the HTRL ${ }^{a}$

\begin{tabular}{lcc}
\hline \multicolumn{1}{c}{ Parameter } & Construction & Operations \\
\hline $\begin{array}{l}\text { Employment (number of jobs) } \\
\quad \text { Direct }\end{array}$ & & \\
$\quad$ Indirect & 100 & 30 \\
$\quad$ Total & 130 & 160 \\
& 220 & 190 \\
Income (millions of 2004 \$) & & \\
$\quad$ Direct & 4.4 & \\
$\quad$ Indirect & 5.4 & 4.4 \\
$\quad$ Total & 9.8 & 5.5 \\
\hline
\end{tabular}

a Impacts are shown for the peak year of construction (2005) and for the first year of operations (2006).

\section{Property Values}

In general, facilities that might be viewed as potentially hazardous by the public can sometimes affect property values in two ways (Clark et al. 1997). First, property values can be reduced if the facility is thought to pose a potential health risk. This could be based on individual perceptions of risk associated with the facility or on community-level perceptions that the presence of such a facility may adversely affect local economic development prospects. Even though a potential buyer may not personally fear a potentially hazardous facility, that buyer may still offer less for a property near the facility if he or she fears that the facility will reduce the rate of appreciation of housing in the area. Second, workers at the facility may believe that the facility has a positive influence on the value of nearby property because of their desire for accessibility to the workplace; workers may offer more for property close to the facility to minimize commuting times. Workers directly associated with the facility are likely to have much less fear of the technology and operations at the facility than the population as a whole. The importance of this influence on property values varies with the size of the workforce involved.

While the impact of BSL-3 research laboratories on local property values has not been studied in depth, the Rocky Mountain Laboratories Final EIS (NIH 2004b) assessed the impact of BSL-4 research laboratories, which conduct research on extremely hazardous biological agents, on local property markets. To evaluate potential impacts to property values, the value trends for residential property adjacent to BSL-4 laboratories were evaluated. The information suggests that construction and operation of BSL-4 laboratories in residential areas do not result in lower property values. The value of residential property adjacent to the CDC BSL-4 laboratory in Atlanta, Georgia, has increased over its operational history. The surrounding upscale residential area has townhouses valued between $\$ 300,000$ and $\$ 500,000$, and homes selling for more than $\$ 700,000$. Property values in the area surrounding a BSL-4 facility in Galveston, Texas, have not declined. In Winnipeg, Manitoba, property values have remained consistent with the surrounding mixed-use area despite the development of a BSL-4 laboratory. Property values in the area of a proposed BSL-4 facility in Hamilton, Montana, were stable and \$20,000 to 
$\$ 30,000$ higher than in other sections of the city. Houses did not remain on the market longer than normal following discussion of the proposed laboratory at a public meeting.

The HTRL would be small facility with a small workforce. The HTRL site is more than a half-mile from the nearest residence. The effect of the HTRL on the diverse and growing economy of DuPage County would be minor. Considering these factors and the results of the studies discussed above, it is unlikely that either environmental impacts or perceived impacts would have a measurable impact on local property values.

\subsubsection{Air Quality, Climate, and Meteorology}

\section{Construction}

HTRL construction activities would occur in a number of phases, including site preparation (clearing and grading), foundation treatment, building erection, electrical/mechanical installation, road construction, and landscaping. Potential sources of air emissions during construction activities would include fugitive dust and engine exhaust from heavy equipment and vehicular traffic, such as commuter/visitor vehicles, hauling trucks, supply trucks, and water trucks. Air pollutants from these sources would include criteria pollutants $\left(\mathrm{SO}_{2}, \mathrm{NO}_{\mathrm{x}}, \mathrm{CO}, \mathrm{PM}_{10}\right.$, and $\mathrm{PM}_{2.5}$ ) and VOCs. In general, the primary source of air emissions during construction would be fugitive dust from soil disturbed by heavy equipment and heavy-duty trucks traveling on disturbed areas and unpaved roads. Fugitive dust emissions would be higher in the earlier phases of construction and would tend to decrease in the later phases. It is expected that exhaust emissions would be relatively small when compared with fugitive dust emissions and also that their potential impacts would be smaller because of their elevated, buoyant release (as opposed to near-ground-level fugitive dust emissions).

Background concentration levels for $\mathrm{PM}_{10}$ and $\mathrm{PM}_{2.5}$ at Argonne (except for annual $\mathrm{PM}_{2.5}$ ) would be well below the NAAQS/SAAQS. PM emissions from construction activities would increase PM ambient concentrations, but they would remain under the standard (except annual $\mathrm{PM}_{2.5}$ ) at the Argonne site boundary, which would be about 1,312 ft (400 m) from the HTRL facility. PM concentrations at the nearest residence would be much lower. Site emissions would contribute to some extent to the annual $\mathrm{PM}_{2.5}$ concentration being over the background level (it is already a little over the standard), as shown in Table 4.5. Accordingly, construction activities should be conducted so as to minimize potential impacts on ambient air quality. To do so, where appropriate, fugitive dust would be controlled by implementing established standard dust control practices during construction, primarily by watering unpaved roads, disturbed surfaces, and temporary stockpiles. The construction period would be 16 months. Considering the small size of the facility and relatively flat terrain, no heavy construction activities, such as cut-and-fill and borrow operations, are anticipated. In addition, construction activities would occur only during daytime hours, 7:30 am to 4:30 pm Monday through Friday, when air dispersion is most favorable. 
DuPage County, including the Argonne site, is currently in nonattainment for $\mathrm{O}_{3}$ and $\mathrm{PM}_{2.5}$ (40 CFR 81.314 and 40 CFR Part 81). Ozone is a secondary pollutant formed from complex photochemical reactions involving $\mathrm{O}_{3}$ precursors, including $\mathrm{NO}_{\mathrm{x}}$ and $\mathrm{VOCs}_{3} \mathrm{O}_{3}$ precursor and $\mathrm{PM}_{2.5}$ emissions associated with construction of the proposed facility, primarily from engine exhaust of heavy equipment, would be negligible, because the small size of the facility and the flat terrain would minimize heavy-equipment activities. Accordingly, the cumulative impacts from potential pollutant releases from HTRL site construction on ambient $\mathrm{O}_{3}$ and $\mathrm{PM}_{2.5}$ concentrations would not be of concern. In summary, the potential impacts of construction activities on ambient air quality would be minor and temporary in nature.

\section{Operations}

There would be a few emission sources associated with operating the HTRL facility. A boiler would not be needed because the building would be provided with steam and condensate service from the Argonne central distribution system. The primary emission source for criteria pollutants and VOCs would be an emergency-power diesel generator. This generator might require IEPA permitting, and such permitting would be the responsibility of the University. The emergency generator would have to be tested monthly, but its emissions would not be continuous and would be limited only to times when it was operating. Another emission source would be vehicular traffic, including commuter, infrequent visitor, and material delivery traffic. However, the contribution of these activities would be small when compared with current Argonne activities. Exhaust air systems would be provided to serve laboratory general exhaust systems, fume hoods, BSCs, the radioisotope hood, vivarium, cage washing, etc. Exhaust air from BSL-3 laboratory spaces and ABSL-3 vivarium BSL-3 spaces would be HEPA filtered. Accordingly, emissions of criteria pollutants and VOCs from the exhaust air systems would be negligible.

Emissions from operations at the HTRL would be insignificant, and its contribution to ambient air quality would thus be minuscule. Even continuous operation (e.g., for 1 day) of the emergency-power diesel generator is not expected to cause emissions to exceed the NAAQS/ SAAQS at the Argonne boundary. $\mathrm{O}_{3}$ precursor and $\mathrm{PM}_{2.5}$ emissions from the proposed facility operations due to infrequent emergency generator operations and vehicular traffic would be negligible. Accordingly, the cumulative impacts of potential releases from HTRL site operations on ambient $\mathrm{O}_{3}$ and $\mathrm{PM}_{2.5}$ concentrations would not be of concern. In summary, it is expected that potential impacts from the proposed facility operations on ambient air quality would be negligible.

There would be no impact to climate and meteorology from either the construction or operation of the HTRL. 


\subsubsection{Noise}

\section{Construction}

In general, the dominant noise source from most construction equipment is the diesel engine (especially without sufficient muffling), which is continuously operating around a fixed location or with limited movement. In a few cases, noise generated by pile driving or pavement breaking dominates. In addition, vehicular traffic around a construction site and on nearby roads generates intermittent noise. However, the contribution to noise from these intermittent sources is limited to the immediate vicinity of the traffic route and is minor when compared with the contribution from continuous noise sources, such as bulldozers, during construction.

At the HTRL, the noise levels would be continuous and highest during the early phase of construction, when heavy equipment would be used for site preparation (clearing and grading). This early phase of construction would account for only about 1 month of the entire construction period of 16 months. After this phase, heavy equipment noise would become more sporadic and brief in duration. Simple noise propagation modeling indicates that the noise level from the HTRL site at the nearest residence would be below the EPA guideline of $55 \mathrm{~dB}(\mathrm{~A})$ as DNL for residential zones, which was established to protect against outdoor activity interference and annoyance (EPA 1974). This noise level from the HTRL site would be lost because it would be masked by the relatively high background noise level from highway traffic on I-55. And a tall, dense growth of trees between the proposed HTRL site and the nearest receptor would further attenuate noise propagation. Accordingly, noise from the HTRL site would be barely or not discernable at the nearest residence, depending on such factors as background noise levels, meteorological conditions, forest and ground conditions by season, and the hearing sensitivity of a listener.

Most construction activities would occur during the day, when noise is tolerated better than at night, because of the masking effects of background noise. Nighttime noise levels would drop to the background levels of a suburban environment because construction activities would cease at night. Noise emitted from construction activities is expected to be temporary and local in nature. This type of construction noise is specifically exempted from compliance with Illinois noise pollution control regulations (Illinois Pollution Control Board 2004, Section 901.107, "Exemptions"). No unusual or significant noise impact is expected from the HTRL construction activities.

\section{Operations}

Operation of the HTRL facility would generate some noise, caused by the emergency generator, cooling tower, site traffic, etc. However, many noise sources would be inside the buildings. All air handlers and fans would be located in an enclosed penthouse. The chilled water system, including the centrifugal chiller and cooling tower, would be placed within the building. The emergency-power diesel generator would be outdoors in a heated, sound-attenuated, weatherproof enclosure. Commuting traffic of about 50 staff members and infrequent visitors 
and material delivery traffic would be negligible compared with traffic related to current Argonne activities. Another noise source is the Argonne paging system, which provides public address announcements of short duration (e.g., early warning of impending storms).

There would be no major outdoor noise sources associated with HTRL operations. Intermittent traffic noise would be the major noise source associated with HTRL operations. In terms of noise, the HTRL facility is considered similar to any other office building. Noise levels associated with operating the HTRL facility would be very low at the nearest residence and would not be distinguishable from the relatively higher background noise level due to highway traffic on I-55. In conclusion, noise levels generated by facility operations would be well below the EPA guideline limit of $55 \mathrm{dBA}$ as DNL for residential areas, and the potential impacts of any noise that would result from HTRL operations is considered insignificant.

\subsubsection{Water Quality}

\section{Construction}

Soil at the HTRL site would not erode much during construction because of the level site topography and required procedures that would be implemented according to a site-specific sedimentation and erosion control plan and a site-specific storm water pollution prevention plan (SWPPP). These plans would be developed prior to construction. Together these plans would include (but not be limited to) provisions for silt fencing, compaction, contouring, and/or retention basins to limit erosion, sediment-containing runoff, and sedimentation from the surrounding water bodies. The site-specific SWPPP would be a stand-alone document during the construction phase, and its provisions would be incorporated into the Argonne sitewide SWPPP when the HTRL was operational.

Before the HTRL would be built, the University would prepare an application for a State General Storm Water Permit for Construction Activities. This permit would require the two plans mentioned above. An application to modify the Argonne NPDES permit to allow HTRL discharges to the Argonne wastewater treatment plants would also be prepared prior to construction.

As part of the construction project, landscaping and revegetation of disturbed soils would be conducted according to the provisions of the Argonne Plant Facilities and Services (PFS) Division Specification 2936, “Grass Establishment,” and the Argonne sitewide SWPPP.

\section{Operations}

After construction of the HTRL, landscaping and revegetation of disturbed soils would retard runoff and control erosion. Impacts to surface waters from sedimentation would be very low. Management of storm water during operations would be coordinated with the requirements of the Argonne SWPPP. 
Wastewater generated inside the HTRL during operations would include sanitary wastewater, wastewater generated from animal tissue digesters and cage washers, and laboratory wastewater. HTRL sanitary wastewater would be treated in the Argonne sanitary wastewater system. Because the 50 employees and visiting scientists who would occupy the HTRL would be small in number compared with the approximately 4,000 employees and visiting scientists at Argonne facilities, the HTRL sanitary wastewater would cause only a minor increase in the amount of sanitary wastewater.

Wastewater from the animal digester would have high concentrations of TDS, TSS, and organic matter, which contribute to $\mathrm{BOD}_{5}$. This waste stream would be routed to the Argonne sanitary wastewater system because the Argonne laboratory wastewater treatment plant does not have the capability to remove $\mathrm{BOD}_{5}$. Discharges from the animal digester would be limited to one batch of about $180 \mathrm{gal} / \mathrm{d}(600 \mathrm{~L} / \mathrm{d})$ in order to avoid exceeding the $\mathrm{BOD}_{5}$ limit at the Argonne sanitary wastewater treatment plant. This limit would also ensure that the HTRL would not cause violations of the TDS or TSS limits. A maximum of 25 batches of cage washing discharge could be released per day. Each batch would be about 375 gal $(1,420 \mathrm{~L})$ and would have much lower concentrations of $\mathrm{BOD}_{5}$, TDS, and TSS than the digester discharge. The Argonne sanitary wastewater treatment plant would easily be able to accommodate the addition of 1 batch of digester discharge and 25 batches of cage washing discharge per day.

In the digester, animal carcasses would be digested with hydroxides ( $\mathrm{pH}$ of 10 ), then neutralized with acids ( $\mathrm{pH}$ of 4.0). With a digester output of $180 \mathrm{gal} / \mathrm{d}(600 \mathrm{~L} / \mathrm{d})$ ), the $\mathrm{pH}$ of the sanitary wastewater treatment plant would be maintained at 7.2 to 7.23 , well within the $\mathrm{pH}$ limits of the treatment plant permit, which are 6 to 9.

Laboratory wastewater from the HTRL would be routed to the Argonne laboratory wastewater treatment plant for treatment and discharge. Discharges from the HTRL would include wastewater from laboratory sinks and drains.

\subsubsection{Solid Waste Management}

\section{Construction}

Solid wastes, including hazardous wastes, from construction would be collected by the University and transported and disposed of off site according to the disposal contracts between the University and commercial waste management organizations. These wastes would be disposed of at licensed disposal facilities. Construction of the HTRL would not impact waste management activities at Argonne. 


\section{Operations}

Solid wastes from operations (see Section 3.1.5) would be collected by the University and transported and disposed of off site according to the disposal contracts between the University and commercial waste management organizations. These wastes would be disposed of at properly licensed disposal facilities. Operations of the HTRL would not impact waste management activities at Argonne.

\subsubsection{Land Use}

HTRL construction and operations would be consistent with the Argonne mission of research and development. The HTRL would be located adjacent to other laboratory and office facilities.

\subsubsection{Visual Environment}

The HTRL would be visible from nearby office buildings. Its exterior design (Figure 3.2) is a blend of the older look of the brick buildings in the nearby Historic District (Building 202, for example) and the more modern look of the DOE and Argonne administration building (Building 201).

\subsubsection{Cultural Resources}

Although construction of the HTRL facility has the potential to impact cultural resources, results of the analysis conducted for this EA indicate that no adverse impacts are likely. Impacts to archaeological sites are generally caused by ground-disturbing activities, such as ground clearing for construction. The location chosen for construction of the HTRL, which is east of Building 202, is currently undeveloped. To minimize the potential for impacts, a systematic archaeological survey of the land necessary for construction based on HTRL design studies compiled in August 2003 was conducted (O’Rourke 2003). No new archaeological sites were identified, and no evidence of Site 11-Du-210 was discovered. Therefore, no impacts to archaeological sites are expected from construction of the HTRL. However, if buried archaeological material was discovered, work would cease immediately, and the Illinois State Historic Preservation Office would be contacted for further instructions. No impacts to archaeological sites are expected during operation of the HTRL facility.

Construction of the HTRL is not expected to impact historically significant structures. The nearest historically significant structure is Building 202, which is part of the Main Campus Historic District. The district includes Buildings 200, 202, 203, 205, 208, and 211. The significance of the Historic District is partially defined by the visual continuity of and landscaping between the buildings as viewed from Inner Circle Drive. Therefore, the district could be impacted by obstacles or obstructions to the view. The proposed HTRL would be located east of the district, in an area where the visual integrity of the district is already 
compromised by Building 201. The current HTRL design incorporates red brick and large glass panels to tie the building architecture into that of Buildings 201 and 202. The addition of the $1 \frac{1}{2}$-story structure would represent an insignificant change in the overall appearance of the Historic District.

\subsubsection{Soils and Geology}

Construction of the HTRL building and related facility components would disturb soils in the project area. Construction of the HTRL, walkways, loading areas, utility connections, and roadways, beginning as early as 2005, would disturb approximately 4 acres (2 ha) of land. Although no prior construction has occurred on the proposed site, soils over most of this area have been disturbed by previous agricultural activities. Soil on the HTRL site is identified as Morley silt loam with 2 to 5\% slopes (USDA 1979), a commonly occurring soil on the Argonne site. This is a gently sloping, well-drained upland soil. None of this area is classified as wetland or as a solid waste management unit (SWMU) as defined by the RCRA. A SWMU unit is any structure, or site that has been used for the treatment, storage, or disposal of solid waste at any time. These units include storage tanks, dumpsters, waste piles, drain fields, waste treatment units, and surface impoundments.

During construction of the HTRL facility, Argonne-approved construction practices, such as use of sediment fences, compaction, contouring, and sediment retention basins, would limit potential erosion and runoff. After construction of the facility, covering exposed soils and immediate revegetation of disturbed areas would retard runoff and control erosion. No adverse impacts to soils on the HTRL site are expected.

Storm water runoff from a portion of the HTRL site would be directed to Freund Brook, south of Eastwood Drive. Storm water would enter Freund Brook through existing drainage swales. Soil erosion near Freund Brook would be controlled by BMPs, for example, soil-retention fencing, site grading and revegetation, or other soil cover.

Construction and operation of the HTRL building and related facility components would not impact the geology around Argonne, including the stratigraphy and seismic activity.

\subsubsection{Terrestrial Biota}

Construction of the HTRL facility, including the access road, walkways, and other support areas, would require the disturbance of approximately 4 acres ( 2 ha) of land. The total area disturbed would also include utility lines and areas used temporarily for construction-related activities and grading. Existing vegetation within the disturbed area would be eliminated during land clearing. Deposition of fugitive dust during the construction period could adversely affect vegetation; however, the use of BMPs to control dust production would minimize impacts. Disturbed areas would be replanted with native species as soon as possible to comply with E.O. 13148, "Greening the Government through Leadership in Environmental Management," issued April 21, 2000, and to help minimize impacts to vegetation. The use of native plant 
species for landscaping of the HTRL site would avoid the introduction of non-native species into nearby natural areas.

E.O. 13148 requires federal agencies to avoid or minimize adverse impacts of proposed actions on existing communities of native plants and natural habitats. The NIH has procedures and policies in place to comply. Where adverse impacts are unavoidable, compensatory mitigation is required. Under the proposed action, direct impacts to the deciduous woodland in the northern portion of the proposed site are not expected. The layout of the facility was designed to avoid encroachment on the woodland. However, many trees just beyond the south margin of the woodland would be removed. Four large trees at least $24 \mathrm{in} .(61 \mathrm{~cm})$ in diameter, including two oak trees exceeding 40 in. $(100 \mathrm{~cm})$ in diameter, would be removed. Removal of trees along the south margin could result in indirect disturbance to interior woodland areas, by changing light and moisture conditions and introducing nonwoodland species, including potentially invasive ones. Large trees remaining along the margin of the construction area might decline as a result of the stress induced by altered conditions. The disturbance of surface soils near trees could also adversely affect trees along the margin. Root disturbance, soil compaction, topsoil loss, reduced soil moisture or aeration, or altered drainage patterns might contribute to tree losses in addition to the losses that occurred when trees were removed during land clearing. Many of these effects could be minimized by fencing and avoiding the area within the drip lines of trees near the construction area and by planting the disturbed area with native plants to replace the lost vegetation.

In the central and southern portion of the proposed site, portions of the old field community, dense stands of trees and shrubs, and managed grassland would be eliminated during facility construction. These areas were previously disturbed and represent associations of native and non-native species that became established after prior impacts to vegetation. These communities do not represent undisturbed native habitats. Similar plant associations make up a large portion of the vegetation on the Argonne site.

During land clearing, wildlife on the proposed site would be destroyed or displaced to adjacent available areas with suitable habitat, with subsequent increase in population densities. Wildlife in the vicinity of the construction site would be disturbed by land clearing, noise, and human presence. Construction of the HTRL adjacent to the woodland could limit the suitability of this habitat for some wildlife species. Loss of large, mature trees would constitute a small loss of habitat for the wildlife species that depend on them, including several species of neotropical migratory birds. However, additional large trees of the same species occur in other portions of the Argonne area and nearby forest preserves. Although construction would result in the loss of old field, thicket, or managed grassland habitat on the proposed site, it is expected that the wildlife species that use these areas would use other areas of similar habitat, which are abundant in the vicinity.

\subsubsection{Wetlands and Aquatic Biota}

Impacts to wetlands are regulated under Section 404 of the CWA. In addition, E.O. 11990, "Protection of Wetlands," requires federal agencies to minimize the destruction, 
loss, or degradation of wetlands and to preserve and enhance the natural and beneficial value of wetlands. NIH complies with this E.O. through its policies and procedures. DOE implementation of this E.O. is included in 10 CFR Part 1022.

Approximately half of the proposed HTRL construction site lies within the watershed of Wetland 101, which is located east of Outer Circle Road. Construction of the facility and support areas could increase sedimentation in Wetland 101. It is expected that implementation of approved Argonne practices for storm water and erosion control during construction (see Section 5.1.5) would prevent or minimize impacts to water quality. During construction, surface runoff from all disturbed areas would be prevented from flowing into the Wetland 101 watershed. Therefore, it is expected that wetlands and aquatic biota would not be adversely impacted.

Alteration of soils and vegetation and the construction of impervious surfaces within the watershed of Wetland 101 could result in indirect impacts to the wetland. Potential impacts to Wetland 101 could include (1) a decrease in the quantity of surface or groundwater inflow to the wetland and (2) increased variability in the flow and surface elevation of water.

During HTRL facility operations, management of storm water would involve redirecting it from some land areas within the Wetland 101 watershed to Freund Brook, south of Eastwood Drive, which is outside the Wetland 101 watershed. A depletion of inflow to the wetland, both as surface flow and shallow groundwater flow, could cause a reduction in the wetland surface area, depth of the water, and frequency and duration of inundation. The HTRL facility would occupy approximately 0.62 acre ( 0.25 ha) of the Wetland 101 watershed, representing $2 \%$ of the entire Wetland 101 watershed. A portion of the roof drains would retain water within the Wetland 101 watershed. It is not expected that the removal of storm water from the remaining portion of the watershed occupied by the facility would result in measurable changes to Wetland 101.

Because developed land surfaces generally have a lower degree of infiltration of precipitation, the presence of the facility within the watershed could result in an increase in surface runoff of precipitation. Increases in impervious surfaces (e.g., roofs, roadways, walkways, and parking areas) within the watershed would result in the largest increases in runoff. Increased surface runoff could cause a greater variability in inflow and more rapid changes in the water surface elevation within wetlands after storms, as well as more rapid reductions in water levels during periods of low precipitation. Increased fluctuations could impact wetland biotic communities, as species less tolerant of disturbance would be replaced by more tolerant species. Biodiversity might subsequently be reduced. Although surface runoff from some of the impervious surfaces of the HTRL facility would be directed out of the Wetland 101 watershed, some of the roof drains would retain storm water within the Wetland 101 watershed. Remaining areas of the facility, such as landscaped and other revegetated areas, would likely have a higher degree of surface runoff than undisturbed areas. However, by using deep-rooted native vegetation to replant disturbed areas and by implementing an approved storm water management plan, it is expected that the small change in storm water runoff would not adversely affect Wetland 101. Effects on wetlands downstream of Freund Brook would be negligible, because of the stream's large watershed and the numerous storm water discharges from other Argonne facilities. 
The salt used to deice walkways, parking areas, and roadways, which might be found in snowmelt and storm water runoff, could adversely affect wetland biota. Organic compounds, such as petroleum products and coolants, metals, and other contaminants, might also be found in runoff from parking areas and roadways. In addition, the elevated temperatures of runoff from impervious surfaces could adversely affect wetland biota. Because storm water from roadways of the HTRL facility would be directed to Freund Brook, the water quality in Wetland 101 would not be adversely affected. Roadway contaminants from the facility would enter Freund Brook. However, because of the stream's large watershed and the numerous storm water discharges from other Argonne facilities, effects on the downstream wetlands would be negligible.

Because the HTRL site is located entirely outside of the watershed of Wetland 205, there would be no impacts to the hydrology or water quality of that wetland. No surface runoff from the HTRL site would enter Wetland 205 during construction or operation of the HTRL.

\subsubsection{Threatened and Endangered Species}

It is expected that the construction and operation of the HTRL would not adversely affect threatened or endangered species. No federal listed or state listed species are known to occur on or near the proposed site. Implementation of the proposed action would not affect the wetlands near the Des Plaines River that support the Hine's emerald dragonfly or the dolomite aquifer that supplies water to those wetlands. The HTRL would be located more than $1.5 \mathrm{mi}(2.4 \mathrm{~km})$ from the Des Plaines River. Wastewater from the HTRL would be treated at the Argonne wastewater treatment plants and discharged to Sawmill Creek. Storm water would be directed to Freund Brook, a tributary of Sawmill Creek. Neither construction nor operation of the HTRL facility would involve pumping water from the dolomite aquifer. Because there is very little connection between the glacial till aquifer and the dolomite aquifer that feeds the dragonfly habitat, there would be no impacts on the dolomite aquifer from construction or operation of the HTRL facility. The U.S. Fish and Wildlife Service has concurred (see Section 6) that, therefore, no impacts to the Hine's emerald dragonfly would occur. The occurrence of Kirtland's snake, state listed as threatened, on the HTRL site would be unlikely because its preferred habitat is available elsewhere in the vicinity.

\subsubsection{Transportation}

Approximately 4,000 workers commute daily to Argonne. The addition of 150 workers (during HTRL construction) or 50 employees and visitors (during HTRL operations) would have little impact on road congestion or congestion at the Argonne gates. Trucks carrying materials and wastes during construction would noticeably increase in truck traffic on the Argonne site and might cause short delays on Argonne roadways. Deliveries at the East Gate would be routed directly to the HTRL; a few deliveries per day would not result in a noticeable increase in truck traffic. 
The HTRL site is adjacent to a parking lot now used by Argonne and DOE employees at Buildings 201 and 202. HTRL construction and operations would increase use of this lot and might cause some current users to be displaced to other lots.

\subsubsection{Utilities and Services}

The HTRL facilities would use a variety of utilities and services provided by the Argonne infrastructure, including power, natural gas, water, and steam. The University of Chicago would purchase these services from Argonne or local utilities. The HTRL's requirements would be within the capacity of the utilities.

\subsubsection{Environmental Justice}

No disproportionately high and adverse human health or environmental impacts to minority and low-income populations are anticipated from construction and operation of the HTRL for two reasons. First, none of the impacts from construction or operations of the HTRL would have high or adverse health or environmental impacts. The impacts of the HTRL would be largely limited to within Argonne site boundaries. Second, the populations immediately

surrounding the Argonne site cannot be considered minority or low-income, on the basis of national and Illinois thresholds for minority and low-income populations (see Section 4.17). While the greater Chicagoland area within $50 \mathrm{mi}(80 \mathrm{~km})$ of Argonne is ethnically and racially diverse, containing sections with a high proportion of minority populations, these sections would not be adversely affected by HTRL operations.

\subsection{ACCIDENTS/ABNORMAL EVENTS}

Although the probability of an accident or abnormal event is low, the potential hazards associated with them are identified in this section. Potential accidents include fires, natural disasters, and an unintentional release of agent; potential abnormal events include security breaches, terrorist threats, release of an animal inside containment, and LAIs and their possible transmission to others. The mitigation of the possible consequences of these events is discussed in this section; the mitigation of the possible consequences of an atmospheric release is discussed in Appendix C.

\subsubsection{Impacts to Facility Workers}

Laboratory workers are exposed to a variety of potential occupational health risks that include infectious materials and cultures, radiation, toxic and flammable chemicals, and mechanical and electrical hazards (Sewell 1995). Occupational hazards under routine operating conditions are addressed in Section 5.1.1. Biological hazards to HTRL workers are considered to be the result of an abnormal event or accident. 
While the potential risk of infection to a laboratory worker by a pathogenic microorganism is real, the actual risk of an LAI is difficult to measure (Sewell 1995). This difficulty is due to the lack of a systematic reporting system that monitors the number of laboratory workers and infections associated with the workplace (Sewell 1995). A limited number of LAIs have been recorded in a wide variety of laboratories throughout the United States (Shane 2005; USAMRMC 2003; CDC and NIH 1999; Sewell 1995).

However, because of the extensive risk management practices that would be implemented to manage biological hazards in the HTRL workplace, impacts to the health and safety of laboratory workers would be minimized. Most risks from biological hazards would be reduced through the use of appropriate microbiological procedures and techniques, containment devices and facilities, protective barriers, and PPE, combined with worker safety training programs (Sewell 1995). Inherent risks to workers that would result from exposure to agents or infected laboratory animals associated with HTRL activities would be mitigated by adherence to the numerous guidelines and regulations for laboratory safety and health (e.g., CDC and NIH 1999). Specific engineering and work practice controls for containment would be required to minimize worker exposure. In particular, all the building construction activities, standard operating procedures, biocontainment equipment and monitoring systems, employee training programs, safety plans, and security procedures would be designed to reduce the potential for transmission of agents to workers. Consequently, an LAI could be considered a breach of the mitigation measures that would be in place. If there was an accidental exposure to an infectious material, immediate medical attention would be provided.

The federal agencies that regulate and/or develop guidelines on safety-related issues in microbiological laboratories include OSHA, the National Institute for Occupational Safety and Health, and the EPA. Other agencies and organizations, such as the CDC, NIH, and National Committee on Clinical Laboratory Standards, also set standards and develop applicable guidance (Sewell 1995). The BMBL guidelines for special safety practices, equipment, and facilities for each biosafety level are described in Appendix A. HTRL-specific safety plans and procedures for mitigating the potential risk of infection to laboratory workers would be developed before the HTRL began operations.

\subsubsection{Impacts to Noninvolved Workers and the Public}

Potential risks to public health and safety from biological hazards associated with the proposed HTRL that could result from abnormal events and accidents, such as LAIs, accidental releases, and external events, are extremely remote. However, impacts to noninvolved workers and the general public (both outside the building and off site) are not anticipated because of the extensive risk management practices that will be implemented to manage biological hazards at the HTRL. Risks to public health and safety resulting from the release of agents would be mitigated further by adherence to the guidelines and regulations for waste management, safety, health, and security. The decontamination of potentially infectious air emissions and liquid or solid waste, followed by environmentally safe disposal, would prevent or minimize the release of agents to the environment and possible public exposure. Potential hazards to noninvolved workers and the general public from abnormal events and accidents are discussed below. 


\section{Accidental Releases to the Surrounding Environment}

The accidental release of an agent to the environment (e.g., via air emissions from exhaust vents in biological containment facilities or an infected laboratory animal that escapes) is extremely remote. The risk of infection or disease for noninvolved Argonne workers or nearby residents would be lessened by adherence to BMBL standards for engineering controls and work practices for biological containment (CDC and NIH 1999). Although the probabilities of adverse impacts on human health and the environment occurring would be remote, given the planned operational and facility safeguards, the hazard of an atmospheric release is further evaluated and discussed in Appendix C. A quantitative risk assessment was made on the basis of a maximum credible event (MCE) scenario that used assumptions and site-specific information to conservatively model the release of a representative biological agent (C. burnetti) to the environment and any resulting impacts on human health. It is expected that the estimated concentration of organisms in the ambient air would not pose a risk to human health.

The likelihood of an animal escaping from the proposed HTRL is negligible because of the engineering and procedural controls in the laboratory. The laboratory is designed and will be built to provide containment of infectious materials, whether airborne or animal in origin. Standard operating procedures of the animal care staff and animal research staff, as well as the design of biocontainment cage racks to house the animals, would mitigate the risk of escape of infected animals from the animal holding and procedural rooms. For example, rodent cages that would be used in the laboratory are specially designed closed system cages that would be completely sealed when residing in cage racks. These cages would only be opened in a BSC, and only one cage at a time would be opened. Therefore, if an animal was to escape during a manipulation, the laboratory employee would be immediately aware of the incident and would not exit the laboratory until the animal was located and contained. The animal holding and procedural rooms would be constructed with concrete or similar material and sealed with epoxy. This would be applied to the floor, walls, and ceiling, and the door to the room would be equipped with a door sweep. These measures would prevent the animal from exiting the space. In addition, no animal room would open to a hallway with a door that leads directly to the outside. In summary, the HTRL would have multiple layers of containment in place that would prevent an infected animal from reaching the outside of the building. Thus, the risk of accidental exposure to noninvolved workers or the public resulting from the escape of an infected animal would be negligible.

\section{Laboratory-Acquired Infections}

Related to the issue of HTRL workers getting LAIs is the concern about the potential for HTRL workers to inadvertently transmit agents to other workers, family members, or the general public. While LAIs have been recorded to occur in a variety of laboratories throughout the United States, there have been no instances of infection or disease resulting from activities at BSL-3 facilities occurring in the communities adjacent to them (NIH and U.S. Army Garrison 2003). 
The same control measures used in a laboratory to protect employees from exposure to agents can also protect the public (e.g., the safe disposal of infectious wastes) (Sewell 1995). The HTRL safety program would therefore address the cultivation, storage, and disposal of biohazardous materials; facility operations; employee education; and medical surveillance of laboratory workers. Most occupational and public health risks from biological hazards would be reduced through the use of appropriate microbiological procedures and techniques, containment devices and facilities, and protective barriers (Sewell 1995). Strategies for managing and preventing LAIs and their transmission to others would be based on the containment of agents (by physically separating them from the laboratory workers and the environment), employee education on occupational risks, and an employee health program.

In addition to the safety mitigation strategies outlined above, adherence to biosafety guidelines mandated or recommended by various governmental and accrediting agencies would reduce the risk of occupational or public exposure to agents handled in the workplace. All rules and regulations promulgated by regulatory or accrediting entities would be enforced by the University. In summary, it is anticipated that no LAI-related impacts to public health and safety would result from the operation of the proposed HTRL.

\section{Shipment of Biological Material}

Accidents during the shipment of agents to or from the proposed HTRL could expose members of the public outside the facility to a risk of infection or disease. These risks would be mitigated by the regulations and guidelines for packaging and transporting agents, including those of the U.S. Department of Transportation, Federal Aviation Administration, and CDC. There have been no known instances of infection or disease resulting from accidents related to transportation during more than 60 years of shipping of infectious materials through postal services or regulated common carriers (USAMRMC 2003; NIH and U.S. Army Garrison 2003). It is expected that shipments of agents associated with the operation of the proposed HTRL would not have any impacts on public health and safety.

\section{External Events and Terrorist Threats}

No historical data indicate that terrorist attacks or security breaches would occur at the proposed HTRL. The effects of any such events that might occur in the future would be mitigated by design considerations, such as making the laboratory fire- and tornado-resistant. The probability of a tornadic wind higher than $104 \mathrm{mph}$ occurring on the Argonne site is approximately $2 \times 10^{-4}$, corresponding to a return period of about 5,000 years (Coats and Murray 1985). The building would be designed to withstand winds of up to $104 \mathrm{mph}$, in the upper range of an F1 tornado and would, therefore, be expected to withstand weaker tornadoes. A comprehensive security and emergency response plan would further enhance the mitigation for external event and terrorist threat hazards. Security provisions and fire safety systems would be specified in the security plan developed for the HTRL facility. 
For example, if there was a fire or an explosion at the HTRL, any experiment underway would be stopped immediately, and appropriate safety measures would be taken to assure that no infectious material was released while the fire was being contained. Fire alarms would utilize the Argonne standard system, consisting of smoke detectors, heat detectors, duct heat detectors, manual pull stations, and audio/visual signaling devices. If a fire was intense enough to cause structural damage to the BSCs and laboratory chambers, it is likely that the heat would destroy any pathogenic microorganisms as well. Therefore, a fire or an explosion is not a credible hazard with regard to the potential release of infectious biological materials.

The prevention of security breaches would be a high priority addressed by measures such as security access control, the Argonne emergency response system, and the uniformed protective force in Argonne's Office of Safeguards and Security. Security procedures would reflect the update to the BMBL (CDC and NIH 1999), which now includes guidance on security and emergency response procedures for laboratories working with agents (Richmond and NesbyO'Dell 2002). The CDC and NIH recommendations address physical security concerns as well as more recent information regarding personnel, risk assessments, and inventory controls. Appendix F of the updated BMBL (Richmond and Nesby-O’Dell 2002) addresses the following biosecurity policies and procedures:

- Risk and threat assessment;

- Facility security plans;

- Physical security;

- Data and electronic technology systems;

- Security policies for personnel;

- Policies regarding access to laboratory and animal areas;

- Specimen accountability;

- Receipt of agents into the laboratory;

- Transfer or shipping of agents from the laboratory;

- Emergency response plans; and

- Reporting of incidents, unintentional injuries, and security breaches.

The attacks on September 11, 2001, made it clear that the United States is vulnerable to significant acts of terrorism. Although the probability of such attacks occurring at the proposed HTRL is impossible to predict, protection against terrorism is being incorporated into the design and operation of the HTRL. 


\subsection{NO ACTION}

Under the no action alternative, the HTRL would not be constructed; thus, there would be no impacts.

\subsection{CUMULATIVE IMPACTS}

The President's CEQ has described cumulative impact as "the impact on the environment which results from the incremental impact of the action when added to other past, present, and reasonably foreseeable future actions regardless of what agency (Federal or non-Federal) or person undertakes such other actions. Cumulative impacts can result from individually minor but collectively significant actions taking place over a period of time" (40 CFR 1508.7). Certain impacts from constructing and operating the HTRL would be cumulative with (i.e., in addition to or in combination with) the impacts on ongoing Argonne operations. HTRL operations would cause emissions of air pollutants from emergency generators. These would make a negligible contribution to overall air pollutant emissions from Argonne operations. Wastewaters from HTRL operations would be routed to either the Argonne sanitary wastewater treatment plant or the Argonne laboratory wastewater treatment plant. The sanitary wastewater from human occupancy and animal digesters would increase total sanitary wastewater discharges by only about $1 \%$. With these additional discharges, the Argonne sanitary wastewater treatment plant could operate within currently permitted $\mathrm{pH}$ limits. The Argonne NPDES permit would be modified to reflect the addition of both the sanitary and laboratory wastewater from the HTRL.

Operation of the HTRL would require only about 50 more employees and visiting scientists in addition to the approximately 4,000 workers at the Argonne site. The increase in all worker-number-related impacts, including socioeconomic impacts, would therefore be negligible. All other impacts from HTRL construction and operation would represent a negligible addition to the impacts of ongoing Argonne operations. Therefore, no cumulative impacts have been identified as a result of constructing and operating this facility. 


\section{CONSULTATION LETTERS}

The following correspondence constitutes consultation with federal and state agencies. 


\section{United States Department of the Interior}

\author{
FISH AND WILDLIFE SERVICE \\ Chicago Ecological Services Field Office \\ 1250 South Grove Avenue, Suite 103 \\ Barrington, Illinois 60010 \\ Phone: (847) 381-2253 Fax: (847) 381-2285
}

ARGONNE SITE OFFICE

AUG 272004

RECEIVED

IN REPLY REFER TO:

FWS/AES-CIFO/4-2026

August 24, 2004

Mr. Robert C. Wunderlich

Department of Energy

Argonne Area Office

9800 South Cass Avenue

Argonne, Illinois 60439

Dear Mr. Wunderlich:

This responds to your letter dated August 5, 2004 requesting information on endangered or threatened species on or near the proposed construction site of a regional biocontainment laboratory at Argonne National Laboratory-East. The proposed project site is located at T37N, R11E, Section 9 at Argonne National Laboratory, DuPage County, Illinois as depicted on the map you enclosed.

The proposed site as depicted on your map is approximately 1 mile from a known habitat location for the federally endangered Hine's emerald dragonfly (Somatochlora hineana). The Hine's emerald dragonfly occupies marshes and sedge meadows fed by calcareous groundwater seepage and underlain by dolomite bedrock. In general, these areas are characterized by the presence of slowly flowing water and nearby or adjacent forest edges. Water quality and quantity is an important element of the Hine's emerald dragonfly habitat. Maintaining adequate water quality through surface and groundwater monitoring is essentiai since the species uses its aquatic habitat for breeding and spends the majority of its life cycle in an aquatic form. We request that studies be conducted in order to determine if the proposed project, could adversely affect the habitat of the Hine's emerald dragonfly. Studies should focus on determining if the proposed project is in the same aquifer as the aquifer that supplies groundwater to the Hine's emerald dragonfly site and if the project would affect water quality or quantity. Watershed-wide studies are currently underway coordinated by Corlands and the U.S. Army Corps of Engineers Chicago District. If the studies reveal that the project adversely affects water quality or quantity, consultation on this project should begin with the Service and the U.S. Army Corps of Engineers in accordance with section 7 of the Act.

Please note, this information is valid only for one year or until new information develops that indicates endangered or threatened species may or may not be affected. 
This letter only addresses federally listed species; the Illinois Department of Natural Resources should be contacted for information on State-listed species. Any impacts to wetlands or waters of the United States may require a permit from the U. S. Army Corps of Engineers. This letter does not preclude separate evaluation and comment by the U.S. Fish and Wildlife Service on wetland impacts proposed for section 404, Clean Water Act authorization.

If you have any questions, please contact Ms. Cathy Pollack at 847/381-2253, ext. 239 or Ms. Karla Kramer at 847/381-2253, ext. 230.

Sincerely,

$$
\text { golm D. Rogm }
$$

John D. Rogner

Field Supervisor 


\section{Department of Energy \\ Argonne Site Office \\ 9800 South Cass Avenue \\ Argonne, Illinois 60439}

AUG 052004

Ms. Anne E. Haaker

Deputy State Historic Preservation Officer

Illinois Historic Preservation Agency

Old State Capitol

Springfield, Illinois 62701

Dear Ms. Haaker:

The U.S. Department of Energy (DOE) is requesting your concurrence that construction and operation of a Regional Biocontainment Laboratory (RBL) at Argonne National Laboratory (ANL) would not affect structures or archaeological sites that are eligible for listing on the National Register of Historic Places (National Register).

DOE and the National Institutes of Health $(\mathrm{NIH})$ are jointly preparing an Environmental Assessment for a proposed RBL that would be constructed and operated by the University of Chicago on land at ANL-E leased to the University by DOE. The NIH has awarded a grant to the University to partially fund construction of the proposed RBL. The RBL would be an approximately 54,000 square foot building with 8,900 net square feet of Biosafety Level (BSL)-2 and -3 molecular laboratory space and 13,300 net square feet of BSL-2 and -3 animal research laboratories. The RBL would be operated by the University of Chicago to conduct BSL-2 and -3 research primarily sponsored by the $\mathrm{NIH}$. The University's operation of the RBL would be distinct from the University's operation of ANL under contract to DOE.

The area in which the RBL would be located has been surveyed for archaeological resources. None were identified (see enclosed survey report). The only existing structures that could be affected by the proposed construction and operation of the RBL are some steam lines that have been evaluated and determined not eligible for listing on the National Register. The proposed location of the RBL has been shifted since the archaeological survey has been completed. The new proposed location is shown as enclosure 2. This location is with the area surveyed.

Later this year we will provide for your review the draft Environmental Assessment.

Should you have any questions, please contact Donna Green at (630) 252-2264.

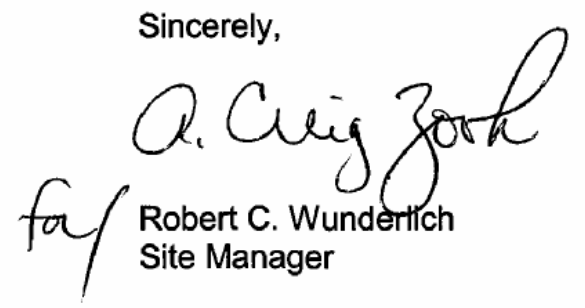

Enclosures:

As Stated 


\section{Department of Energy \\ Argonne Site Office \\ 9800 South Cass Avenue \\ Argonne, Illinois 60439}

AUG 052004

Mr. John Rogner, Field Supervisor

U.S. Fish and Wildlife Service

Chicago Illinois Field Office

1250 South Grove Avenue, Suite 103

Barrington, Illinois 60010

Dear Mr. Rogner:

\section{SUBJECT: PROPOSED CONSTRUCTION OF REGIONAL BIOCONTAINMENT LABORATORY AT ARGONNE NATIONAL LABORATORY-EAST (ANL-E)}

The U.S. Department of Energy (DOE) is requesting your concurrence that construction and operation of a Regional Biocontainment Laboratory (RBL) at ANL-E will not adversely affect Federally-listed threatened or endangered species.

DOE and the National Institutes of Health $(\mathrm{NIH})$ are jointly preparing an Environmental Assessment for a proposed RBL that would be constructed and operated by the University of Chicago on land at ANL-E leased to the University by DOE. The NIH has awarded a grant to the University to partially fund construction of the proposed RBL. The RBL would be an approximately 54,000 square foot building with 8,900 net square feet of Biosafety Level (BSL)-2 and -3 molecular laboratory space and 13,300 net square feet of BSL-2 and -3 animal research laboratories. The RBL would be operated by the University of Chicago to conduct BSL-2 and -3 research primarily sponsored by the NIH. The University's operation of the RBL would be distinct from the University's operation of ANL under contract to DOE.

The RBL would be constructed in a disturbed area on the edge of oak woodland (see enclosures 1 and 2 for a map showing the proposed project area and an ANL-E vegetation map). A few isolated oak trees would need to be removed. No Federally-listed threatened or endangered species have been identified on the ANL-E site.

Later this year we will provide for your review the draft Environmental Assessment.

If you or your staff would like more information about this proposal, please contact Donna Green at (630) $252-2264$.

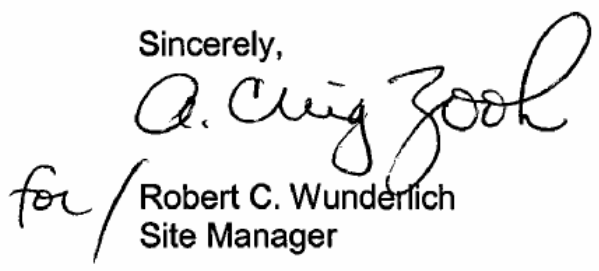

Enclosures:

As Stated

cc: V. Nottingham, NIH, w/encls. 


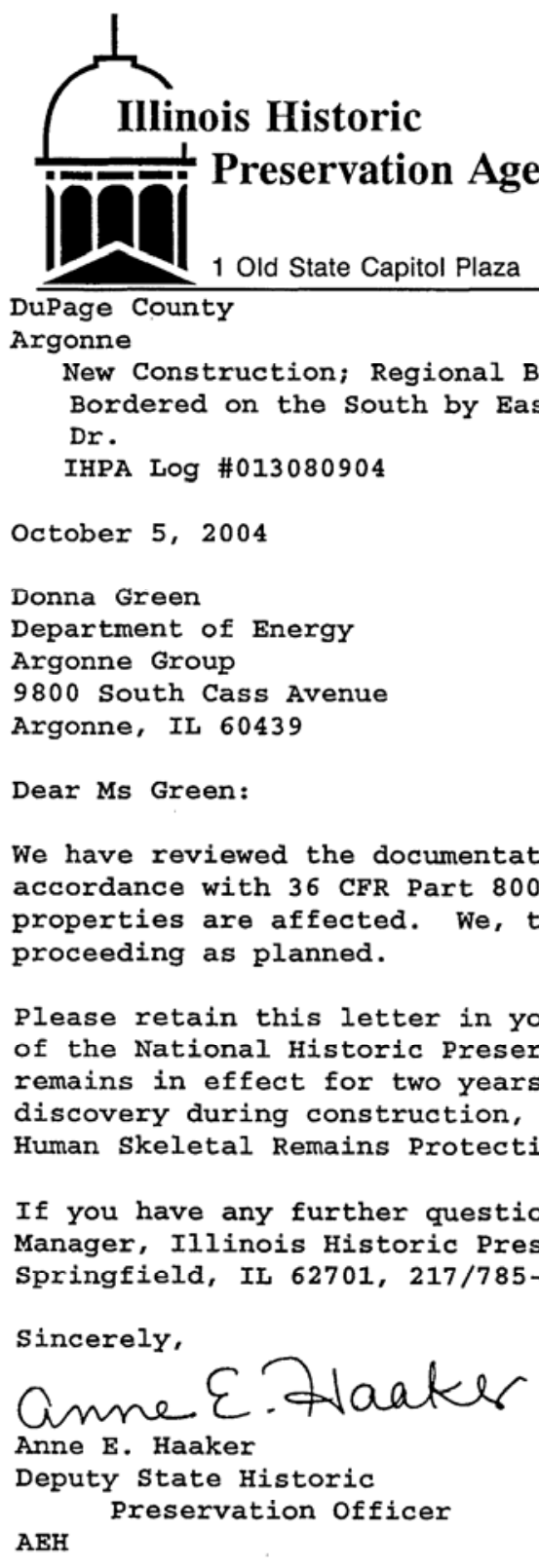
IHPA Log \#013080904

October 5, 2004

Department of Energy

S Avenue

IL 60439

Sincerely,

Anne E. Haaker

Deputy State Historic

$\mathrm{ABH}$

\begin{tabular}{|} 
ARGONNE SITE \\
OFFICE \\
OCT 132004 \\
RECEIVED
\end{tabular}

Springfield, Illinois 62701-1507 - Teletypewriter Only (217) $524-7128$

iocontainment Laboratory Bordered on the South by Eastwood Extention Rd. and on the East by Outer Circle
Dr.

We have reviewed the documentation submitted for the referenced project(s) in accordance with 36 CFR Part 800.4. Based upon the information provided, no historic properties are affected. We, therefore, have no objection to the undertaking

of the National Historic Preservation Act of 1966, as amended. This clearance It does not pertain to any discovery during construction, nor is it a clearance for purposes of the Illinois Protection Act (20 ILCS 3440).

Manager, Illinois Historic Preservation Agency, 1 Old State Capitol Plaza, 


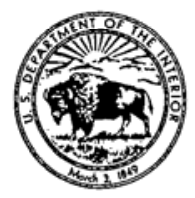

IN REPLY REFER TO:

FWS/AES-CIFO/(4-2026) / 5-1087

\section{United States Department of the Interior}

FISH AND WILDLIFE SERVICE

Chicago Ecological Services Field Office

1250 South Grove Avenue, Suite 103

Barrington, Illinois 60010

Phone: (847) 381-2253 Fax: (847) 381-2285

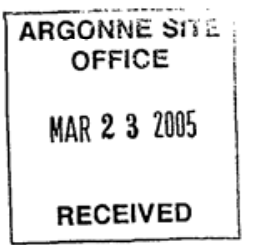

March 18, 2005

Mr. Robert C. Wunderlich

Department of Energy

Argonne Area Office

9800 South Cass Avenue

Argonne, Illinois 60439

Dear Mr. Wunderlich:

Thank you for your response dated February 28, 2005 in regards to a letter from us dated August 24, 2004 requesting searches for the habitat of the federally listed Hine's Emerald dragonfly (Somatochlora hineana) for the proposed construction of a regional biocontainment laboratory at Argonne National Laboratory-East. The proposed project site is located at T37N, R11E, Section 9 at Argonne National Laboratory, DuPage County, Illinois.

After reviewing additional detailed information submitted regarding the proposed project area, we concur with your conclusion for reasons given that suitable habitat does not exist at the site for the federally listed Hine's emerald dragonfly, and that the quantity and quality of groundwater responsible for the wetland seeps south of Argonne National Lab that support the Hine's emerald dragonfly would not be impacted by this project.

Based on the information provided in your submittal and a review of our records, we do not believe that any federally endangered or threatened species occur in the vicinity of the site. Based on the information provided, it does not appear that the project is likely to adversely affect any federally threatened or endangered species or adversely modify critical habitat of such species. This precludes the need for consultation on this project in accordance with section 7 of the Endangered Species Act of 1973, as amended. Should project modifications or new information indicate that endangered or threatened species may be affected, and the project is funded, authorized or carried out by a federal agency, then consultation with the Service should be initiated by the Army Corps of Engineers.

This letter only addresses federally listed species; the Illinois Department of Natural Resources should be contacted for information on State-listed species. Any impacts to wetlands or waters of the United States may require a permit from the U. S. Army Corps. of Engineers. This letter 
does not preclude separate evaluation and comment by the U.S. Fish and Wildlife Service on wetland impacts proposed for section 404, Clean Water Act authorization.

If you have any questions, please contact Ms. Cathy Pollack at 847/381-2253, ext. 239 or Ms. Karla Kramer at 847/381-2253, ext. 230.

Sincerely,

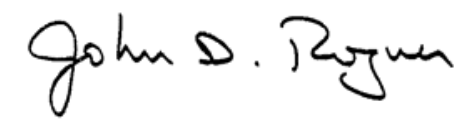

John D. Rogner

Field Supervisor

cc: Valerie Nottingham, National Institutes of Health 


\section{REFERENCES}

Acoustical Society of America, 1983, American National Standard Specification for Sound Level Meters, ANSI S1.4-1983, New York, N.Y., Feb.

Acoustical Society of America, 1985, American National Standard Specification for Sound Level Meters, ANSI S1.4A-1985, Amendment to ANSI S1.4-1983, New York, N.Y., June.

Alvord, C.W., 1922, The Illinois Country 1673-1818, A.C. McClurg \& Co., Chicago, Ill.

ANL (Argonne National Laboratory), 1998, Site Development Plan, Document JOSTD-106-GT007, Argonne, Ill.

ANL, 2004, ANL Hourly Met Data. Available at http://www.atmos.anl.gov/ANLMET. Accessed June 8.

Beaudoin, S., 2004, personal communication from Beaudoin (the University of Chicago, Chicago, Ill.) to J. Butler (Argonne National Laboratory, Argonne, Ill.), July 14.

CDC and NIH (Centers for Disease Control and Prevention and National Institutes of Health), 1999, Biosafety in Microbiological and Biomedical Laboratories, 4th ed., U.S. Department of Health and Human Services, Public Health Service, Washington, D.C., April.

Clark, D., et al., 1997, “Nuclear Power Plants and Residential Housing Prices,” Growth and Change 28:496-519.

Coats, D.W., and R.C. Murray, 1985, Natural Phenomena Hazards Modeling Project: Extreme Wind/Tornado Hazard Models for Department of Energy Sites, UCRL-53526, Rev. 1, Lawrence Livermore National Laboratory, Livermore, California.

Curtis, S.A., et al., 1989, Building 202 Parking Lot Survey Phase I and II Evaluation of Site ANL-40, Argonne National Laboratory, Argonne, Ill., July.

Curtis, S., and A. Berlin, 1980, A Study of the Cultural Resources at Argonne National Laboratory, Argonne National Laboratory, Argonne, Ill.

DOC (U.S. Department of Commerce), 2004, Regional Accounts Data - Local Area Personal Income, Bureau of Economic Analysis, Washington, D.C. Available at http://www.bea.doc.gov/ bea/regional/reis/.

DOE (U.S. Department of Energy), 1990, Environmental Assessment, Proposed 7-GeV Advanced Photon Source, DOE/EA-0389, Washington, D.C., Feb.

DOE, 1998, Worker Protection Management for DOE Federal and Contractor Employees, Office of Environment, Safety, and Health, Washington, D.C., March 27. 
DOL (U.S. Department of Labor), 1997, "Limits for Air Contaminants," Table Z-1 in "Occupational Health and Safety Standards, Toxic and Hazardous Substances," Code of Federal Regulations, Title 29, Part 1910, Section 1000.

EPA (U.S. Environmental Protection Agency), 1974, Information on Levels of Environmental Noise Requisite to Protect Public Health and Welfare with an Adequate Margin of Safety, EPA-550/9-74-004, Washington, D.C.

EPA, 2004, AirData: Monitor Summary Report. Available at http://www.epa.gov/air/data/ monsum.html. Accessed May 20, 2004.

FEMA (Federal Emergency Management Agency), 1982, Flood Insurance Rate Map, Community Panel Number 1701970065 B, DuPage County, Ill.

Gartman, D., 2004, intraoffice personal communication from Gartman to T. Allison (Argonne National Laboratory, Argonne, Ill.), Sept.

Golchert, N.W., et al., 2001, Argonne National Laboratory-East Site Environmental Report for Calendar Year 2000, ANL-01/2, Argonne National Laboratory, Argonne, Ill., Sept.

Golchert, N.W., and R.G. Kolzow, 2004, Argonne National Laboratory-East, Site Environmental Report for Calendar Year 2003, ANL-04/2, Argonne National Laboratory, Argonne, Ill., Aug. Available at http://www.anl.gov/Community_and_Environment/Environmental_Reports/2003. pdf. Accessed Nov. 4, 2004.

Hamm, J., 2003, “Detailed Cost Estimates," personal communication from Hamm (the University of Chicago, Chicago, Ill.) to T. Allison (Argonne National Laboratory, Argonne, Ill.), Feb.

Hamm, J., 2004, “RBL Business Plan Draft," personal communication from Hamm (the University of Chicago, Chicago, Ill.) to T. Allison (Argonne National Laboratory, Argonne, Ill.), April.

Hinterman, R., 2001, intraoffice personal communication from Hinterman to Y.-S. Chang (Argonne National Laboratory, Argonne, Ill.), Sept. 21.

Hinterman, R., 2004, intraoffice personal communication from Hinterman to Y.-S. Chang (Argonne National Laboratory, Argonne, Ill.), May 19.

Hughes, G.M., et al., 1966, Bedrock Aquifers of Northeastern Illinois: Illinois State Geological Survey, Circular 406, Champaign, Ill.

IEPA (Illinois Environmental Protection Agency), 2003, Illinois Annual Air Quality Report 2002, IEPA/BOA/03-015, Bureau of Air, Springfield, Ill., Sept. Available at http://www.epa. state.il.us/air/air-quality-report/2002/air-quality-report-2002.pdf. Accessed May 18, 2004. 
IEPA, 2004, Illinois Annual Air Quality Report 2003, IEPA/BOA/04-019, Bureau of Air, Springfield, Ill., Aug. Available at http:/www.epa.state.il.us/air/air-quality-report/2002/airquality-report-2003.pdf. Accessed Nov. 4, 2004.

Illinois Department of Commerce and Economic Opportunity, 2004, Community Profiles. Available at http://www.illinoisbiz.biz/com/index.html. Accessed Sept. 27, 2004.

Illinois Pollution Control Board, 2004, Title 35 of the Illinois Administrative Code, Subtitle H, “Noise.” Available at http://www.ipcb.state.il.us/SLR/IPCBandIEPAEnvironmentalRegulationsTitle35.asp. Accessed May 19, 2004.

Leyendecker, E.V., et al., 1995, USGS Spectral Response Maps and their Relationship with Seismic Design Forces in Building Codes, U.S. Geological Survey, Open File Report 95-596.

MIG, Inc. (Minnesota IMPLAN Group), 2004, 2001 IMPLAN Data, Version 0.2.15.2004, CD-ROM, Stillwater, Minn.

National Climatic Data Center, 2004, Storm Events. Available at http:/www4.ncdc.noaa.gov/ cgi-win/wwcgi.dll?wwEvent Storms. Accessed June 11, 2004.

NFPA (National Fire Protection Association), 1997, Standard for the Installation of Lightning Protection Systems, NFPA 780, 1997 ed., Washington, D.C.

NFPA, 1998, NFPA 70, National Electrical Code, 1999 ed., Aug. 6, Washington, D.C.

NFPA, 2000, Life Safety ${ }^{\circledR}$ Code, NFPA 101, 2000 ed., Washington, D.C.

NIH (National Institutes of Health), 2003, NIH Design Policy and Guidelines. Available at http://orf.od.nih.gov/policy/index.htm. Accessed Dec. 13, 2004.

NIH, 2004a, NIH Model Commissioning Guide. Available at http://facilities.nih.gov/eWeb/ research/farhad2/Commissioning/nih_cx_guide/Guide/hh_start.htm. Accessed Sept. 27, 2004.

NIH, 2004b, Final Environmental Impact Statement, Rocky Mountain Laboratories, Integrated Research Facility, Hamilton, Montana, April.

NIH and U.S. Army Garrison, 2003, Final Environmental Impact Statement, Construction and Operation of an Integrated Research Facility (IRF) by the National Institutes of Health (NIH) at Fort Detrick, Maryland, Bethesda, MD, and Fort Detrick, MD, Dec. 5.

NOAA (National Oceanic and Atmospheric Administration), 2003, Local Climatological Data: Annual Summary with Comparative Data for Chicago, O’Hare International Airport, National Climatic Data Center, Asheville, N.C.

NOAA, 2005, Storm Prediction Center, Historic Tornado Data Archive. Available at http://www.spc.noaa.gov/archive/tornadoes/index.html. 
NSC (National Safety Council), 2003, Injury Facts, 2003 Edition, Itasca, Ill.

O’Rourke, D.J., 2003, Results of the Phase I Archaeological Survey for the Regional Biocontainment Laboratory at Argonne National Laboratory-East, prepared by Argonne National Laboratory, Argonne, Ill., for U.S. Department of Energy.

Richmond, J.Y., and S.L. Nesby-O’Dell, 2002, “Appendix F - Laboratory Security and Emergency Response Guidance for Laboratories Working with Select Agents,” in Biosafety in Microbiological and Biomedical Laboratories, 4th ed., CDC and NIH, U.S. Department of Health and Human Services, Public Health Service, Washington, D.C., Dec. 6.

Sewell, D.L., 1995, “Laboratory-Associated Infections and Biosafety," Clin. Microbiol. Rev. 8(3):389-405.

Shane, S., 2005, “Exposure at Germ Lab Reignites a Public Health Debate,” The New York Times, Jan. 24.

Stepuszek, P.A., 2005, “County Report,” personal communication from Stepuszek (Manager, HR Records \& Information Center, Argonne, Ill.) to N. Akiyoshi (Argonne National Laboratory, Argonne, Ill.), April 28.

Tanner, H.H., 1987, Atlas of Great Lakes Indian History, University of Oklahoma Press, Norman, Okla.

Tuggle, B., 1996, letter from Tuggle (U.S. Fish and Wildlife Service, Chicago Field Office, Barrington, Ill.) to E. Dodd (Argonne National Laboratory, Argonne, Ill.), July 25.

USAMRMC (U.S. Army Medical Research and Materiel Command), 2003, Draft Programmatic Environmental Impact Statement; Chemical and Biological Defense Program, Fort Detrick, Frederick, Md., April.

U.S. Bureau of the Census, 2004, County Business Patterns, 2001, Washington, D.C. Available at http://www.census.gov/ftp/pub/epcd/cbp/view/cbpview.html.

USDA (U.S. Department of Agriculture), 1979, Soil Survey of DuPage and Part of Cook Counties, Illinois, Soil Conservation Service, in cooperation with the Illinois Agricultural Experiment Station, May.

USDA, 2004, Census of Agriculture - County Data 2002, National Agricultural Statistics Service, Washington, D.C. Available at http://www.nass.usda.gov/census/census97/volume1/ vol1pubs.htm.

Van Lonkhuyzen, R.A., and K.E. LaGory, 1994, Wetlands of Argonne National LaboratoryEast, DuPage County, Illinois, ANL/EAD/TM-12, Argonne National Laboratory, Argonne, Ill.

Wescott, K., and D. O’Rourke, 2001, Sitewide Historic Property Inventory, Argonne National Laboratory-East, DuPage County, Illinois, Argonne National Laboratory, Argonne, Ill. 


\section{LIST OF PREPARERS}

Name
Education/Expertise

Contribution

\section{The University of Chicago}

Steven Beaudoin

Director, Office of Safety and

Environmental Affairs, Office of Risk

Management, the University of

Chicago

\section{Argonne National Laboratory}

Timothy Allison

James Butler

Young-Soo Chang

Daniel O’Rourke

Elisabeth Stull

Robert Van Lonkhuyzen
M.S., Mineral and Energy Resource Economics; M.A., Geography; 16 years of experience in regional analysis and economic impact analysis

Ph.D., Environmental Health Sciences; 22 years of experience in health risk assessment and exposure analysis

Ph.D., Chemical Engineering; 22 years of experience in air quality impact analysis

M.S., Industrial Archaeology; 11 years of experience in cultural resource management; 6 years of experience in historical property issues

Ph.D., Ecology, 34 years of experience in ecological research and environmental assessment

B.A., Biology, 13 years of experience in ecological research and environmental assessment
Project coordination and management, proposed action

Socioeconomics, transportation, environmental justice

Human health

Air quality, noise

Cultural resources

Primary document author

Ecology, wildlife, wetlands, threatened and endangered species 


\section{APPENDIX A:}

\section{GUIDELINES FOR BIOSAFETY LEVEL 1 (BSL-1) THROUGH BSL-3}

This appendix provides the Centers for Disease Control and Prevention (CDC) guidelines for biosafety level 1 (BSL-1) through BSL-3 activities as found on the CDC Web site (http://www.cdc.gov/ od/ohs/biosfty/bmbl4/bmbl4s3.htm) accessed on June 10, 2004. The CDC regulates these activities according to the requirements found in the fourth edition of Biosafety in Microbiological and Biomedical Laboratories, published by the CDC and National Institutes of Health (NIH), U.S. Department of Health and Human Services, Public Health Service, Washington, D.C., in April 1999, as revised in 2002. There are also similar guidelines for animal biosafety levels (ABSLs) for working in animal facilities. All of the text that follows is a direct quote from the CDC Web site.

\section{Biosafety Level 1 (BSL-1)}

Biosafety Level 1 is suitable for work involving well-characterized agents not known to consistently cause disease in healthy adult humans, and of minimal potential hazard to laboratory personnel and the environment. The laboratory is not necessarily separated from the general traffic patterns in the building. Work is generally conducted on open bench tops using standard microbiological practices. Special containment equipment or facility design is neither required nor generally used. Laboratory personnel have specific training in the procedures conducted in the laboratory and are supervised by a scientist with general training in microbiology or a related science.

The following standard and special practices, safety equipment and facilities apply to agents assigned to Biosafety Level 1:

\section{A. Standard Microbiological Practices}

1. Access to the laboratory is limited or restricted at the discretion of the laboratory director when experiments or work with cultures and specimens are in progress.

2. Persons wash their hands after they handle viable materials, after removing gloves, and before leaving the laboratory.

3. Eating, drinking, smoking, handling contact lenses, applying cosmetics, and storing food for human use are not permitted in the work areas. Persons who wear contact lenses in laboratories should also wear goggles or a face shield. Food is stored outside the work area in cabinets or refrigerators designated and used for this purpose only.

4. Mouth pipetting is prohibited; mechanical pipetting devices are used. 
5. Policies for the safe handling of sharps are instituted.

6. All procedures are performed carefully to minimize the creation of splashes or aerosols.

7. Work surfaces are decontaminated at least once a day and after any spill of viable material.

8. All cultures, stocks, and other regulated wastes are decontaminated before disposal by an approved decontamination method such as autoclaving. Materials to be decontaminated outside of the immediate laboratory are to be placed in a durable, leakproof container and closed for transport from the laboratory. Materials to be decontaminated outside of the immediate laboratory are packaged in accordance with applicable local, state, and federal regulations before removal from the facility.

9. A biohazard sign can be posted at the entrance to the laboratory whenever infectious agents are present. The sign may include the name of the agent(s) in use and the name and phone number of the investigator.

10. An insect and rodent control program is in effect (see Appendix G).

B. Special Practices

None

C. Safety Equipment (Primary Barriers)

1. Special containment devices or equipment such as a biological safety cabinet are generally not required for manipulations of agents assigned to Biosafety Level 1.

2. It is recommended that laboratory coats, gowns, or uniforms be worn to prevent contamination or soiling of street clothes.

3. Gloves should be worn if the skin on the hands is broken or if a rash is present. Alternatives to powdered latex gloves should be available.

4. Protective eyewear should be worn for conduct of procedures in which splashes of microorganisms or other hazardous materials is anticipated.

D. Laboratory Facilities (Secondary Barriers)

1. Laboratories should have doors for access control.

2. Each laboratory contains a sink for handwashing. 
3. The laboratory is designed so that it can be easily cleaned. Carpets and rugs in laboratories are not appropriate.

4. Bench tops are impervious to water and are resistant to moderate heat and the organic solvents, acids, alkalis, and chemicals used to decontaminate the work surface and equipment.

5. Laboratory furniture is capable of supporting anticipated loading and uses. Spaces between benches, cabinets, and equipment are accessible for cleaning.

6. If the laboratory has windows that open to the exterior, they are fitted with fly screens.

\section{Biosafety Level 2 (BSL-2)}

Biosafety Level 2 is similar to Biosafety Level 1 and is suitable for work involving agents of moderate potential hazard to personnel and the environment. It differs from BSL-1 in that (1) laboratory personnel have specific training in handling pathogenic agents and are directed by competent scientists; (2) access to the laboratory is limited when work is being conducted; (3) extreme precautions are taken with contaminated sharp items; and (4) certain procedures in which infectious aerosols or splashes may be created are conducted in biological safety cabinets or other physical containment equipment.

The following standard and special practices, safety equipment, and facilities apply to agents assigned to Biosafety Level 2:

\section{A. Standard Microbiological Practices}

1. Access to the laboratory is limited or restricted at the discretion of the laboratory director when experiments are in progress.

2. Persons wash their hands after they handle viable materials, after removing gloves, and before leaving the laboratory.

3. Eating, drinking, smoking, handling contact lenses, and applying cosmetics are not permitted in the work areas. Food is stored outside the work area in cabinets or refrigerators designated for this purpose only.

4. Mouth pipetting is prohibited; mechanical pipetting devices are used.

5. Policies for the safe handling of sharps are instituted.

6. All procedures are performed carefully to minimize the creation of splashes or aerosols. 
7. Work surfaces are decontaminated on completion of work or at the end of the day and after any spill or splash of viable material with disinfectants that are effective against the agents of concern.

8. All cultures, stocks, and other regulated wastes are decontaminated before disposal by an approved decontamination method such as autoclaving. Materials to be decontaminated outside of the immediate laboratory are placed in a durable, leakproof container and closed for transport from the laboratory. Materials to be decontaminated off-site from the facility are packaged in accordance with applicable local, state, and federal regulations, before removal from the facility.

9. An insect and rodent control program is in effect (see Appendix G).

\section{B. Special Practices}

1. Access to the laboratory is limited or restricted by the laboratory director when work with infectious agents is in progress. In general, persons who are at increased risk of acquiring infection, or for whom infection may have serious consequences, are not allowed in the laboratory or animal rooms. For example, persons who are immunocompromised or immunosuppressed may be at increased risk of acquiring infections. The laboratory director has the final responsibility for assessing each circumstance and determining who may enter or work in the laboratory or animal room.

2. The laboratory director establishes policies and procedures whereby only persons who have been advised of the potential hazards and meet specific entry requirements (e.g., immunization) may enter the laboratory.

3. A biohazard sign must be posted on the entrance to the laboratory when etiologic agents are in use. Appropriate information to be posted includes the agent(s) in use, the biosafety level, the required immunizations, the investigator's name and telephone number, any personal protective equipment that must be worn in the laboratory, and any procedures required for exiting the laboratory.

4. Laboratory personnel receive appropriate immunizations or tests for the agents handled or potentially present in the laboratory (e.g., hepatitis B vaccine or TB skin testing).

5. When appropriate, considering the agent(s) handled, baseline serum samples for laboratory and other at-risk personnel are collected and stored. Additional serum specimens may be collected periodically, depending on the agents handled or the function of the facility. 
6. Biosafety procedures are incorporated into standard operating procedures or in a biosafety manual adopted or prepared specifically for the laboratory by the laboratory director. Personnel are advised of special hazards and are required to read and follow instructions on practices and procedures.

7. The laboratory director ensures that laboratory and support personnel receive appropriate training on the potential hazards associated with the work involved, the necessary precautions to prevent exposures, and the exposure evaluation procedures. Personnel receive annual updates or additional training as necessary for procedural or policy changes.

8. A high degree of precaution must always be taken with any contaminated sharp items, including needles and syringes, slides, pipettes, capillary tubes, and scalpels.

a. Needles and syringes or other sharp instruments should be restricted in the laboratory for use only when there is no alternative, such as parenteral injection, phlebotomy, or aspiration of fluids from laboratory animals and diaphragm bottles. Plasticware should be substituted for glassware whenever possible.

b. Only needle-locking syringes or disposable syringe-needle units (i.e., needle is integral to the syringe) are used for injection or aspiration of infectious materials. Used disposable needles must not be bent, sheared, broken, recapped, removed from disposable syringes, or otherwise manipulated by hand before disposal; rather, they must be carefully placed in conveniently located puncture-resistant containers used for sharps disposal. Non-disposable sharps must be placed in a hardwalled container for transport to a processing area for decontamination, preferably by autoclaving.

c. Syringes which re-sheathe the needle, needleless systems, and other safety devices are used when appropriate.

d. Broken glassware must not be handled directly by hand, but must be removed by mechanical means such as a brush and dustpan, tongs, or forceps. Containers of contaminated needles, sharp equipment, and broken glass are decontaminated before disposal, according to any local, state, or federal regulations.

9. Cultures, tissues, specimens of body fluids, or potentially infectious wastes are placed in a container with a cover that prevents leakage during collection, handling, processing, storage, transport, or shipping.

10. Laboratory equipment and work surfaces should be decontaminated with an effective disinfectant on a routine basis, after work with infectious materials 
is finished, and especially after overt spills, splashes, or other contamination by infectious materials. Contaminated equipment must be decontaminated according to any local, state, or federal regulations before it is sent for repair or maintenance or packaged for transport in accordance with applicable local, state, or federal regulations, before removal from the facility.

11. Spills and accidents that result in overt exposures to infectious materials are immediately reported to the laboratory director. Medical evaluation, surveillance, and treatment are provided as appropriate and written records are maintained.

12. Animals not involved in the work being performed are not permitted in the lab.

\section{Safety Equipment (Primary Barriers)}

1. Properly maintained biological safety cabinets, preferably Class II, or other appropriate personal protective equipment or physical containment devices are used whenever:

a. Procedures with a potential for creating infectious aerosols or splashes are conducted. These may include centrifuging, grinding, blending, vigorous shaking or mixing, sonic disruption, opening containers of infectious materials whose internal pressures may be different from ambient pressures, inoculating animals intranasally, and harvesting infected tissues from animals or embryonate eggs.

b. High concentrations or large volumes of infectious agents are used. Such materials may be centrifuged in the open laboratory if sealed rotor heads or centrifuge safety cups are used, and if these rotors or safety cups are opened only in a biological safety cabinet.

2. Face protection (goggles, mask, face shield or other splatter guard) is used for anticipated splashes or sprays of infectious or other hazardous materials to the face when the microorganisms must be manipulated outside the BSC [biological safety cabinet].

3. Protective laboratory coats, gowns, smocks, or uniforms designated for lab use are worn while in the laboratory. This protective clothing is removed and left in the laboratory before leaving for non-laboratory areas (e.g., cafeteria, library, administrative offices). All protective clothing is either disposed of in the laboratory or laundered by the institution; it should never be taken home by personnel.

4. Gloves are worn when hands may contact potentially infectious materials, contaminated surfaces or equipment. Wearing two pairs of gloves may be 
appropriate. Gloves are disposed of when overtly contaminated, and removed when work with infectious materials is completed or when the integrity of the glove is compromised. Disposable gloves are not washed, reused, or used for touching “clean” surfaces (keyboards, telephones, etc.), and they should not be worn outside the lab. Alternatives to powdered latex gloves should be available. Hands are washed following removal of gloves.

\section{Laboratory Facilities (Secondary Barriers)}

1. Provide lockable doors for facilities that house restricted agents (as defined in 42 CFR [Code of Federal Regulations] 72.6).

2. Consider locating new laboratories away from public areas.

3. Each laboratory contains a sink for handwashing.

4. The laboratory is designed so that it can be easily cleaned. Carpets and rugs in laboratories are inappropriate.

5. Bench tops are impervious to water and are resistant to moderate heat and the organic solvents, acids, alkalis, and chemicals used to decontaminate the work surfaces and equipment.

6. Laboratory furniture is capable of supporting anticipated loading and uses. Spaces between benches, cabinets, and equipment are accessible for cleaning. Chairs and other furniture used in laboratory work should be covered with a non-fabric material that can be easily decontaminated.

7. Install biological safety cabinets in such a manner that fluctuations of the room supply and exhaust air do not cause the biological safety cabinets to operate outside their parameters for containment. Locate biological safety cabinets away from doors, from windows that can be opened, from heavily traveled laboratory areas, and from other potentially disruptive equipment so as to maintain the biological safety cabinets' airflow parameters for containment.

8. An eyewash station is readily available.

9. Illumination is adequate for all activities, avoiding reflections and glare that could impede vision.

10. There are no specific ventilation requirements. However, planning of new facilities should consider mechanical ventilation systems that provide an inward flow of air without recirculation to spaces outside of the laboratory. If the laboratory has windows that open to the exterior, they are fitted with fly screens. 


\section{Biosafety Level 3 (BSL-3)}

Biosafety Level 3 is applicable to clinical, diagnostic, teaching, research, or production facilities in which work is done with indigenous or exotic agents which may cause serious or potentially lethal disease as a result of exposure by the inhalation route. Laboratory personnel have specific training in handling pathogenic and potentially lethal agents, and are supervised by competent scientists who are experienced in working with these agents.

All procedures involving the manipulation of infectious materials are conducted within biological safety cabinets or other physical containment devices, or by personnel wearing appropriate personal protective clothing and equipment. The laboratory has special engineering and design features.

It is recognized, however, that some existing facilities may not have all the facility features recommended for Biosafety Level 3 (i.e., double-door access zone and sealed penetrations). In this circumstance, an acceptable level of safety for the conduct of routine procedures, (e.g., diagnostic procedures involving the propagation of an agent for identification, typing, susceptibility testing, etc.), may be achieved in a Biosafety Level 2 facility, providing 1) the exhaust air from the laboratory room is discharged to the outdoors, 2) the ventilation to the laboratory is balanced to provide directional airflow into the room, 3) access to the laboratory is restricted when work is in progress, and 4) the recommended Standard Microbiological Practices, Special Practices, and Safety Equipment for Biosafety Level 3 are rigorously followed. The decision to implement this modification of Biosafety Level 3 recommendations should be made only by the laboratory director.

The following standard and special safety practices, equipment and facilities apply to agents assigned to Biosafety Level 3:

A. Standard Microbiological Practices

1. Access to the laboratory is limited or restricted at the discretion of the laboratory director when experiments are in progress.

2. Persons wash their hands after handling infectious materials, after removing gloves, and when they leave the laboratory.

3. Eating, drinking, smoking, handling contact lenses, and applying cosmetics are not permitted in the laboratory. Persons who wear contact lenses in laboratories should also wear goggles or a face shield. Food is stored outside the work area in cabinets or refrigerators designated for this purpose only.

4. Mouth pipetting is prohibited; mechanical pipetting devices are used.

5. Policies for the safe handling of sharps are instituted.

6. All procedures are performed carefully to minimize the creation of aerosols. 
7. Work surfaces are decontaminated at least once a day and after any spill of viable material.

8. All cultures, stocks, and other regulated wastes are decontaminated before disposal by an approved decontamination method, such as autoclaving. Materials to be decontaminated outside of the immediate laboratory are placed in a durable, leakproof container and closed for transport from the laboratory. Infectious waste from BSL-3 laboratories should be decontaminated before removal for off-site disposal.

9. An insect and rodent control program is in effect (see Appendix G).

\section{B. Special Practices}

1. Laboratory doors are kept closed when experiments are in progress.

2. The laboratory director controls access to the laboratory and restricts access to persons whose presence is required for program or support purposes. Persons who are at increased risk of acquiring infection or for whom infection may have serious consequences are not allowed in the laboratory or animal rooms. For example, persons who are immunocompromised or immunosuppressed may be at risk of acquiring infections. The director has the final responsibility for assessing each circumstance and determining who may enter or work in the laboratory. No minors should be allowed in the laboratory.

3. The laboratory director establishes policies and procedures whereby only persons who have been advised of the potential biohazard, who meet any specific entry requirements (e.g., immunization), and who comply with all entry and exit procedures, enter the laboratory or animal rooms.

4. When infectious materials or infected animals are present in the laboratory or containment module, a hazard warning sign, incorporating the universal biohazard symbol, is posted on all laboratory and animal room access doors. The hazard warning sign identifies the agent, lists the name and telephone number of the laboratory director or other responsible person(s), and indicates any special requirements for entering the laboratory, such as the need for immunizations, respirators, or other personal protective measures.

5. Laboratory personnel receive the appropriate immunizations or tests for the agents handled or potentially present in the laboratory (e.g., hepatitis B vaccine or TB skin testing), and periodic testing as recommended for the agent being handled.

6. Baseline serum samples are collected as appropriate and stored for all laboratory and other at-risk personnel. Additional serum specimens may be 
periodically collected, depending on the agents handled or the function of the laboratory.

7. A biosafety manual specific to the laboratory is prepared or adopted by the laboratory director and biosafety precautions are incorporated into standard operating procedures. Personnel are advised of special hazards and are required to read and follow instructions on practices and procedures.

8. Laboratory and support personnel receive appropriate training on the potential hazards associated with the work involved, the necessary precautions to prevent exposures, and the exposure evaluation procedures. Personnel receive annual updates or additional training as necessary for procedural changes.

9. The laboratory director is responsible for ensuring that, before working with organisms at Biosafety Level 3, all personnel demonstrate proficiency in standard microbiological practices and techniques, and in the practices and operations specific to the laboratory facility. This might include prior experience in handling human pathogens or cell cultures, or a specific training program provided by the laboratory director or other competent scientist proficient in safe microbiological practices and techniques.

10. A high degree of precaution must always be taken with any contaminated sharp items, including needles and syringes, slides, pipettes, capillary tubes, and scalpels.

a. Needles and syringes or other sharp instruments should be restricted in the laboratory for use only when there is no alternative, such as parenteral injection, phlebotomy, or aspiration of fluids from laboratory animals and diaphragm bottles. Plasticware should be substituted for glassware whenever possible.

b. Only needle-locking syringes or disposable syringe-needle units (i.e., needle is integral to the syringe) are used for injection or aspiration of infectious materials. Used disposable needles must not be bent, sheared, broken, recapped, removed from disposable syringes, or otherwise manipulated by hand before disposal; rather, they must be carefully placed in conveniently located puncture-resistant containers used for sharps disposal. Non-disposable sharps must be placed in a hard-walled container for transport to a processing area for decontamination, preferably by autoclaving.

c. Syringes which re-sheathe the needle, needleless systems, and other safe devices are used when appropriate. 
d. Broken glassware must not be handled directly by hand, but must be removed by mechanical means such as a brush and dustpan, tongs, or forceps. Containers of contaminated needles, sharp equipment, and broken glass should be decontaminated before disposal, and disposed of according to any local, state, or federal regulations.

11. All open manipulations involving infectious materials are conducted in biological safety cabinets or other physical containment devices within the containment module. No work in open vessels is conducted on the open bench. Clean-up is facilitated by using plastic-backed paper toweling on nonperforated work surfaces within biological safety cabinets.

12. Laboratory equipment and work surfaces should be decontaminated routinely with an effective disinfectant, after work with infectious materials is finished, and especially after overt spills, splashes, or other contamination with infectious materials.

a. Spills of infectious materials are decontaminated, contained and cleaned up by appropriate professional staff, or others properly trained and equipped to work with concentrated infectious material. Spill procedures are developed and posted.

b. Contaminated equipment must be decontaminated before removal from the facility for repair or maintenance or packaging for transport, in accordance with applicable local, state, or federal regulations.

13. Cultures, tissues, specimens of body fluids, or wastes are placed in a container that prevents leakage during collection, handling, processing, storage, transport, or shipping.

14. All potentially contaminated waste materials (e.g., gloves, lab coats, etc.) from laboratories are decontaminated before disposal or reuse.

15. Spills and accidents that result in overt or potential exposures to infectious materials are immediately reported to the laboratory director. Appropriate medical evaluation, surveillance, and treatment are provided and written records are maintained.

16. Animals and plants not related to the work being conducted are not permitted in the laboratory.

C. Safety Equipment (Primary Barriers)

1. Protective laboratory clothing such as solid-front or wrap-around gowns, scrub suits, or coveralls are worn by workers when in the laboratory. Protective clothing is not worn outside the laboratory. Reusable clothing is 
decontaminated before being laundered. Clothing is changed when overtly contaminated.

2. Gloves must be worn when handling infectious materials, infected animals, and when handling contaminated equipment.

3. Frequent changing of gloves accompanied by hand washing is recommended. Disposable gloves are not reused.

4. All manipulations of infectious materials, necropsy of infected animals, harvesting of tissues or fluids from infected animals or embryonate eggs, etc., are conducted in a Class II or Class III biological safety cabinet (see Appendix A).

5. When a procedure or process cannot be conducted within a biological safety cabinet, then appropriate combinations of personal protective equipment (e.g., respirators, face shields) and physical containment devices (e.g., centrifuge safety cups or sealed rotors) are used.

6. Respiratory and face protection are used when in rooms containing infected animals.

D. Laboratory Facilities (Secondary Barriers)

1. The laboratory is separated from areas that are open to unrestricted traffic flow within the building, and access to the laboratory is restricted. Passage through a series of two self-closing doors is the basic requirement for entry into the laboratory from access corridors. Doors are lockable (see Appendix F). A clothes change room may be included in the passageway.

2. Each laboratory room contains a sink for handwashing. The sink is handsfree or automatically operated and is located near the room exit door.

3. The interior surfaces of walls, floors, and ceilings of areas where BSL-3 agents are handled are constructed for easy cleaning and decontamination. Seams, if present, must be sealed. Walls, ceilings, and floors should be smooth, impermeable to liquids and resistant to the chemicals and disinfectants normally used in the laboratory. Floors should be monolithic and slip-resistant. Consideration should be given to the use of coved floor coverings. Penetrations in floors, walls, and ceiling surfaces are sealed or capable of being sealed to facilitate decontamination. Openings such as around ducts and the spaces between doors and frames are capable of being sealed to facilitate decontamination. 
4. Bench tops are impervious to water and are resistant to moderate heat and the organic solvents, acids, alkalis, and those chemicals used to decontaminate the work surfaces and equipment.

5. Laboratory furniture is capable of supporting anticipated loading and uses. Spaces between benches, cabinets, and equipment are accessible for cleaning. Chairs and other furniture used in laboratory work should be covered with a non-fabric material that can be easily decontaminated.

6. All windows in the laboratory are closed and sealed.

7. A method for decontaminating all laboratory wastes is available in the facility and utilized, preferably within the laboratory (i.e., autoclave, chemical disinfection, incineration, or other approved decontamination method). Consideration should be given to means of decontaminating equipment. If waste is transported out of the laboratory, it should be properly sealed and not transported in public corridors.

8. Biological safety cabinets are required and are located away from doors, from room supply louvers, and from heavily-traveled laboratory areas.

9. A ducted exhaust air ventilation system is provided. This system creates directional airflow which draws air into the laboratory from "clean" areas and toward "contaminated" areas. The exhaust air is not recirculated to any other area of the building. Filtration and other treatments of the exhaust air are not required, but may be considered based on site requirements, and specific agent manipulations and use conditions. The outside exhaust must be dispersed away from occupied areas and air intakes, or the exhaust must be HEPA-filtered. Laboratory personnel must verify that the direction of the airflow (into the laboratory) is proper. It is recommended that a visual monitoring device that indicates and confirms directional inward airflow be provided at the laboratory entry. Consideration should be given to installing an HVAC control system to prevent sustained positive pressurization of the laboratory. Audible alarms should be considered to notify personnel of HVAC system failure.

10. HEPA-filtered exhaust air from a Class II biological safety cabinet can be recirculated into the laboratory if the cabinet is tested and certified at least annually. When exhaust air from Class II safety cabinets is to be discharged to the outside through the building exhaust air system, the cabinets must be connected in a manner that avoids any interference with the air balance of the cabinets or the building exhaust system (e.g., an air gap between the cabinet exhaust and the exhaust duct). When Class III biological safety cabinets are used they should be directly connected to the exhaust system. If the Class III cabinets are connected to the supply system, it is done in a manner that prevents positive pressurization of the cabinets (see Appendix A). 
11. Continuous flow centrifuges or other equipment that may produce aerosols are contained in devices that exhaust air through HEPA filters before discharge into the laboratory. These HEPA systems are tested at least annually. Alternatively, the exhaust from such equipment may be vented to the outside if it is dispersed away from occupied areas and air intakes.

12. Vacuum lines are protected with liquid disinfectant traps and HEPA filters, or their equivalent. Filters must be replaced as needed. An alternative is to use portable vacuum pumps (also properly protected with traps and filters).

13. An eyewash station is readily available inside the laboratory.

14. Illumination is adequate for all activities, avoiding reflections and glare that could impede vision.

15. The Biosafety Level 3 facility design and operational procedures must be documented. The facility must be tested for verification that the design and operational parameters have been met prior to operation. Facilities should be re-verified, at least annually, against these procedures as modified by operational experience.

16. Additional environmental protection (e.g., personnel showers, HEPA filtration of exhaust air, containment of other piped services and the provision of effluent decontamination) should be considered if recommended by the agent summary statement, as determined by risk assessment, the site conditions, or other applicable federal, state, or local regulations. 


\section{APPENDIX B:}

\section{CENTERS FOR DISEASE CONTROL AND PREVENTION CATEGORY A, B, AND C PRIORITY PATHOGENS}

The Centers for Disease Control and Prevention (CDC) developed a categorized list of priority pathogens. Table B-1 presents the list. The categories are defined as follows.

Category A consists of high-priority biological agents, including pathogens that are rarely seen in the United States. High-priority agents include organisms that pose a risk to national security because they

- Can be easily disseminated or transmitted from person to person,

- Result in high mortality rates and have the potential for a major public health impact,

- Might cause public panic and social disruption, and

- $\quad$ Require special action for public health preparedness.

Category B consists of the second-highest-priority agents, including those that

- Are moderately easy to disseminate,

- Result in moderate morbidity rates and low mortality rates, and

- Require specific enhancements of the diagnostic capacity of the CDC and enhanced disease surveillance.

Category $\mathrm{C}$ consists of the third-highest-priority agents, including emerging pathogens that could be engineered for mass dissemination in the future because of

- Availability,

- $\quad$ Ease of production and dissemination, and

- $\quad$ Potential for high morbidity and mortality rates and a major health impact. 
TABLE B-1 NIAID Category A, B, and C Priority Pathogens

\begin{tabular}{|c|c|c|}
\hline Category A & Category B & $\begin{array}{l}\text { Category C (emerging infectious } \\
\text { disease threats such as Nipah virus } \\
\text { and additional hantaviruses) }\end{array}$ \\
\hline Bacillus anthracis (anthrax) & Burkholderia pseudomallei & NIAID priority areas: \\
\hline Clostridium botulinum & Coxiella burnetii (Q fever) & Tickborne hemorrhagic fever viruses \\
\hline Yersinia pestis & Brucella species (brucellosis) & Crimean-Congo hemorrhagic fever \\
\hline Variola major (smallpox) and & Burkholderia mallei (glanders) & virus \\
\hline other pox viruses & Ricin toxin (from Ricinus communis) & Tickborne encephalitis viruses \\
\hline Francisella tularensis (tularemia) & Epsilon toxin of Clostridium perfringens & Yellow fever \\
\hline Viral hemorrhagic fevers & Staphylococcus enterotoxin B & Multi-drug-resistant TB \\
\hline Arenaviruses & Typhus fever (Rickettsia prowazekii) & Influenza \\
\hline LCM, Junin virus, & Food and waterborne pathogens & Other rickettsias \\
\hline Machupo virus, & Bacteria & Rabies \\
\hline Guanarito virus & Diarrheagenic E. coli & \\
\hline Lassa fever & Pathogenic vibrios & \\
\hline Bunyaviruses & Shigella species & \\
\hline Hantaviruses & Salmonella & \\
\hline Rift Valley fever & Listeria monocytogenes & \\
\hline Flaviruses & Campylobacter jejuni & \\
\hline Dengue & Yersinia enterocolitica & \\
\hline Filoviruses & Viruses (caliciviruses, hepatitis A) & \\
\hline Ebola & Protozoa & \\
\hline \multirow[t]{15}{*}{ Marburg } & Cryptosporidium parvum & \\
\hline & Cyclospora cayatanensis & \\
\hline & Giardia lamblia & \\
\hline & Entamoeba histolytica & \\
\hline & Toxoplasma & \\
\hline & Microsporidia & \\
\hline & Additional viral encephalitides & \\
\hline & West Nile virus & \\
\hline & LaCrosse & \\
\hline & California encephalitis & \\
\hline & VEE & \\
\hline & EEE & \\
\hline & WEE & \\
\hline & Japanese encephalitis virus & \\
\hline & Kyasanur forest virus & \\
\hline
\end{tabular}




\section{APPENDIX C:}

\section{ATMOSPHERIC RELEASE OF BIOLOGICAL AGENTS}

\section{C.1 INTRODUCTION}

Even though the probability of a significant accident or the unintentional release of an agent is low, this appendix evaluates the potential hazard that could result from an accidental release to the ambient environment during operation of the proposed regional biocontainment laboratory, the Howard T. Ricketts Laboratory (HTRL). Specifically, it evaluates the effects that aerosol releases of harmful biological agents from the laboratory could have on the health of members of the public and noninvolved workers. A maximum credible event (MCE) scenario was used as the quantitative risk assessment method for analyzing a hypothetical biological release to the atmosphere. An MCE analysis is a realistic worst-case analysis that applies credible information about the effectiveness of existing safeguards, such as engineering controls, design features, and adherence to standard operating procedures by workers (U.S. Army Medical Research and Materiel Command [USAMRMC] 2003).

Much of the information utilized in this hazard analysis was obtained by the U.S. Army during its long-standing, leading role in the U.S. biological defense program. The Department of the Army (DA) serves as the executive agent of the Chemical and Biological Defense Program (CBDP), a research, development, testing, and evaluation program being conducted by the U.S. Department of Defense.

\section{C.2 KEY ASSUMPTIONS AND MODELS USED IN HAZARD ANALYSIS}

For purposes of this environmental assessment (EA), the evaluation of the releases is based on the U.S. Army's MCE analysis in the CBDP programmatic environmental impact statement (PEIS). This robust, programmatic analysis was developed so that it could be extended to all of the Army's activities at all its locations (USAMRMC 2003). The U.S. Army's analysis does not have a specific literature reference but was incorporated into the PEIS. The analysis for this EA was made using typical and worst-case meteorological conditions that were incorporated into the Gaussian puff dispersion model following hypothetical release of the organism into the surrounding community.

The Army developed a biosafety level 3 (BSL-3) scenario for a biological agent release. Coxiella burnetii (a National Institute of Allergy and Infectious Diseases [NIAID] Category B agent, Centers for Disease Control and Prevention [CDC] select agent, and Q-fever causative agent) was chosen as the microorganism to represent all types of BSL-1, BSL-2, and BSL-3 laboratory microorganisms. It was considered an appropriate (i.e., worst-case) choice for modeling in this release assessment for several reasons. First of all, it is highly infectious, very persistent, and resistant to environmental conditions. It also presents a potential human health hazard because it can survive being aerosolized and has a high survival rate in the environment. The study of many viruses also requires the use of BSL-3 laboratories; however, the viruses 
cannot survive long in the environment without a host, such as a human or an animal. Bacteria can represent a high risk to human health, and the study of many bacteria requires the use of BSL-3 or BSL-4 laboratories. The infective dose for this species of bacteria ranges from only 10 organisms to possibly as few as 1 (USAMRMC 2003). Note, however, that $C$. burnetii was selected for modeling on the basis of its physical and biological characteristics, not because there are any plans to use it in the proposed HTRL facility.

A simple Gaussian puff model was used in the analysis for this EA to estimate the quantity of human infective doses. Three meteorological conditions (unstable, neutral, and stable) were evaluated by using the puff formula for instantaneous release. Wind speeds typical of the respective stability classes were assumed. The effective stack height (physical stack height plus plume rise due to stack discharge momentum) was estimated by using the U.S. Environmental Protection Agency's (EPA's) SCREEN3 model. Maximum instantaneous and time-averaged ground-level concentrations were calculated.

\section{C.3 ASSUMPTIONS ABOUT INITIAL CONDITIONS AND ACCIDENT SCENARIO}

The following assumptions about the initial conditions and accident scenario for an MCE analysis were developed for the potential accidental release of a biological aerosol resulting from work in BSL-3 facilities (USAMRMC 2003) and evaluated on the basis of local conditions at the proposed HTRL. These assumptions were based on those used by the DA (USAMRMC 2003).

\section{C.3.1 Initial Model Assumptions}

- The BSL-3 laboratory will comply with Biosafety in Microbiological and Biomedical Laboratories (BMBL) guidelines (CDC and NIH 1999).

- A centrifuge, the key piece of equipment in this scenario, is in a room and not in a biological safety cabinet (all centrifuges must have sealed rotors or safety cups).

- $\quad$ The room is under negative pressure, and airflow is continuous.

- The room exhausts air via two filters in series, which are conservatively estimated to have a 95\% particulate removal efficiency as a worst-case scenario. Under normal operating conditions, the high-efficiency particulate air (HEPA) filters are $99.97 \%$ efficient at 0.3 mrem. A description of the HTRL exhaust system, including HEPA filters, can be found in Section 3.1.3. Air then exits through an air exhaust vent.

- The only microorganism handled in the laboratory is the Q-fever causative agent, C. burnetii. 
- A single worker processes $1 \mathrm{~L}$ of $C$. burnetii slurry to prepare an experimental vaccine.

\section{C.3.2 Accident Scenario}

- The worker places $165 \mathrm{~mL}$ of slurry into each of six 250-mL polypropylene centrifuge tubes. The worker fails to insert O-rings or tighten the screw-on centrifuge caps, which are designed to prevent leakage into the centrifuge compartment that houses the rotor.

- The $990 \mathrm{~mL}$ of slurry contains a total of $9.9 \times 10^{12}$ (9.9 trillion) human infective doses $\left(\mathrm{HID}_{50}\right)$ of the organism. (One HID 50 is the dose that infects $50 \%$ of exposed humans.)

- All six tubes spill slurry into the rotor cups, and some of this slurry leaks into the rotor compartment, which is not sealed against the release of organisms in a small-particle aerosol.

- Ten percent of the slurry spills. One percent of this spill leaks into the rotor compartment, where $0.1 \%$ of the leakage is aerosolized. Ninety percent of the aerosol settles as liquid droplets inside the chamber.

- Thus, $10 \%$ (spilled from tubes) $\times 1 \%$ (leaked from rotor cups) $\times 0.1 \%$ (aerosolized) $\times 10 \%$ (did not settle out) $=0.00001 \%$ of the original slurry placed in the centrifuge tubes for processing is released into the room.

- The most serious consequence of this laboratory accident would be the release of enough concentrated aerosol to pass through the air filter system, with the subsequent release of a significant number of infectious doses into the surrounding community.

- On the basis of the above assumptions, $9.9 \times 10^{5}(990,000) \mathrm{HID}_{50}$ $\left(0.00001 \% \times 9.9 \times 10^{12} \mathrm{HID}_{50}\right)$ would reach the filter.

- When it is further assumed that the air filter system is $95 \%$ efficient, approximately $5 \times 10^{4}(50,000) \mathrm{HID}_{50}\left(5 \%\right.$ not removed $\left.\times 9.9 \times 10^{12} \mathrm{HID}_{50}\right)$ would be released to the atmosphere from the exhaust vent. (Under perfect conditions, HEPA filters are $99 \%$ efficient for particle removal.)

\section{C.4 IMPACTS TO THE GENERAL PUBLIC AND NONINVOLVED WORKERS}

A simple Gaussian puff model was used to quantify risk for the MCE scenario. Accounting for the air handling unit's capacity and the building volume, the release would only last for several minutes. On the basis of the conservative assumption of an instantaneous release 
occurring, a maximum 10-min concentration is estimated at $1.3 \times 10^{-2}$ organisms $/ \mathrm{m}^{3}$. Assuming a typical breathing rate of $20 \mathrm{~m}^{3} / \mathrm{d}$, the maximum inhalation dose over the 10-min exposure duration is then estimated at $1.8 \times 10^{-3}$ organisms. There are no standards or guidelines for a minimum infective dose. However, because the total exposure of a person breathing ground-level air would be less than 1 HID $_{50}$ of $C$. Burnetti at all downwind distances under both typical and worst-case meteorological conditions, it is expected that this concentration of organisms would not pose a risk to human health (USAMRMC 2003).

\section{C.5 REFERENCES}

CDC and NIH (Centers for Disease Control and Prevention and National Institutes of Health), 1999, Biosafety in Microbiological and Biomedical Laboratories, 4th ed., U.S. Department of Health and Human Services, Public Health Service, Washington, D.C., April.

USAMRMC (U.S. Army Medical Research and Materiel Command), 2003, Draft Programmatic Environmental Impact Statement; Chemical and Biological Defense Program, Fort Detrick, Frederick, Md., April. 